UNIVERSIDADE DE SÃO PAULO

FLÁVIA RODRIGUES DE OLIVEIRA SILVA

DESENVOLVIMENTO DE UM BIOSSENSOR DE PERÓXIDO DE HIDROGÊNIO DE BAIXO CUSTO BASEADO NA EMISSÃO DO EURÓPIO III 
FLÁVIA RODRIGUES DE OLIVEIRA SILVA

\title{
DESENVOLVIMENTO DE UM BIOSSENSOR DE PERÓXIDO DE HIDROGÊNIO DE BAIXO CUSTO BASEADO NA EMISSÃO DO EURÓPIO III
}

\author{
Dissertação apresentada à Escola \\ Politécnica da Universidade de São \\ Paulo para obtenção do título de \\ Mestre em Engenharia
}


FLÁVIA RODRIGUES DE OLIVEIRA SILVA

\title{
DESENVOLVIMENTO DE UM BIOSSENSOR DE PERÓXIDO DE HIDROGÊNIO DE BAIXO CUSTO BASEADO NA EMISSÃO DO EURÓPIO III
}

\author{
Dissertação apresentada à Escola \\ Politécnica da Universidade de São \\ Paulo para obtenção do título de \\ Mestre em Engenharia \\ Área de Concentração: \\ Engenharia Elétrica
}

Orientadora: Profa. Doutora

Lilia Coronato Courrol 
Este exemplar foi revisado e alterado em relação à versão original, sob responsabilidade única do autor e com a anuência de seu orientador.

São Paulo, 31 de março de 2008.

Assinatura do autor

Assinatura do orientador

Silva, Flávia Rodrigues de Oliveira

Desenvolvimento de um biossensor de peróxido de hidrogênio de baixo custo baseado na emissão do európio III / F.R.O. Silva. -- ed.rev. -- São Paulo, 2008.

p. 106

Dissertação (Mestrado) - Escola Politécnica da Universidade de São Paulo. Departamento de Engenharia de Sistemas Eletrônicos.

1. Sensores biomédicos 2. Equipamentos de medidas elétricas 3. Compostos orgânicos 4. Európio 5. Fotônica I. Universidade de São Paulo. Escola Politécnica. Departamento de Engenharia de Sistemas Eletrônicos II. t. 


\section{AGRADECIMENTOS}

Agradeço à Profa Dra Lilia Coronato Courrol por acreditar em nosso trabalho.

À Escola Politécnica da USP, em especial ao departamento de Engenharia Elétrica e ao LSI.

Ao IPEN e à UNIFESP.

À FAPESP, pela concessão da bolsa de mestrado, processo número 05/57403-3, e ao CNPq pelo apoio financeiro.

Ao Prof ${ }^{\circ}$ Ronaldo Mansano pelo seu apoio e ajuda.

Aos Drs. Nilson, Luiz e Laércio pela utilização da infraestrutura dos laboratórios.

Ao André, Daniel, Jair e Leonardo pela grande ajuda prestada e, claro, pela grande amizade.

À Profa Dra Maria Helena Bellini por me aceitar como aprendiz em seu laboratório e às suas alunas, Ênia, Débora, Michelle, Flávia e Jéssica, pelos seus ensinamentos e amizade.

À minha família e amigos por sempre me apoiarem e incentivarem.

A todos os demais que de alguma forma me ajudaram a chegar até aqui.

E agradeço a Deus por todas as oportunidades em minha vida. 
É a possibilidade que me faz continuar e não a certeza. Uma espécie de aposta da minha parte. E embora me possam chamar sonhador, louco ou qualquer outra coisa, acredito que tudo é possível.

(Autor desconhecido) 


\section{RESUMO}

Neste trabalho estudou-se as propriedades ópticas do complexo EurópioTetraciclina (EuTc), determinando as melhores condições para se obter uma formação eficiente do complexo. Parâmetros ópticos como absorção, emissão, tempo de vida e índice de refração foram obtidos. Variação da concentração de európio no complexo, da temperatura, pH ótimo e tempo de reação das soluções foram analisados. Um aumento na banda de emissão do európio foi observado com adição de peróxido de hidrogênio (HP) na solução. As amostras foram preparadas com $\mathrm{pH}$ neutro e a luminescência visível do lantanídeo foi detectada após uma incubação das amostras por $30 \mathrm{~min}$. Um método direto para determinação de peróxido de uréia (PHU) e colesterol, em solução, usando a fluorescência do complexo EuTc é descrito. Os resultados mostram que o complexo é ainda mais sensível para o peróxido de uréia, aumentando a intensidade de emissão em até 40 vezes, do que para o peróxido de hidrogênio, que proporciona um aumento máximo de 15 vezes, quando comparados ao EuTc puro. É reportado também, pela primeira vez, que para a determinação do colesterol total, utilizando-se a sonda EuTc, não há necessidade de adição de enzima na solução, além de ser capaz de detectar frações de colesterol (LDL, VLDL e HDL), também sem adição de outros reagentes. Esse método mostra que o complexo pode ser usado como biossensor de alta sensibilidade, boa precisão, resposta rápida, baixo custo e resultados reprodutíveis para a determinação direta do peróxido de hidrogênio, do peróxido de uréia, de colesterol e LDL e para a determinação indireta da glicose. Uma proposta para a construção de um protótipo de equipamento para medidas de emissão do európio, miniaturizado, portátil, e de baixo custo, que possa ser utilizado com maior facilidade e rapidez, é apresentado.

Palavras-chave: Európio. Tetraciclina. Peróxido de Hidrogênio. Peróxido de Uréia. Colesterol. Glicose. LED. Fotodiodo. 


\begin{abstract}
In this work was studied the optical properties of Europium-Tetracycline complex (EuTc), determining the best conditions to obtain an efficient complex formation. Optical parameters as absorption, emission, lifetime and refractive index were obtained. Variation of europium complexes concentration, temperature, optimal pH and solutions time reaction were analyzed. An increase in the europium emission band was observed with the addition of hydrogen peroxide (HP) in the solution. The samples were prepared with neutral $\mathrm{pH}$ and the lanthanide visible luminescence was detected after a samples incubation of $30 \mathrm{~min}$. A direct method to determine urea hydrogen peroxide (PHU) and cholesterol, in solution, using a fluorescent EuTc complex is described. The results show that the complex is more sensitive for urea hydrogen peroxide, it is over fortyfold higher, while for hydrogen peroxide the increasing is fifteenfold higher when compared to pure EuTc complex emission intensity. It is also reported, for the first time, for the determination of cholesterol total, using the EuTc probe, the enzymatic reaction is not necessary, and also is possible to detect cholesterol fractions (LDL, VLDL and HDL), without the addition of other reagents. This method shows that the complex can be used as a biossensor of high sensibility, good accuracy, fast response, low cost and reproducible results to direct determination of hydrogen peroxide, urea hydrogen peroxide, cholesterol and LDL, and to indirect determination of glucose. A prototype for the construction of miniaturized equipment, portable, low cost, easier and faster to be used, is presented.
\end{abstract}

Keywords: Europium. Tetracycline. Hydrogen Peroxide. Urea Hydrogen Peroxide. Cholesterol. Glucose. LED. Photodiode. 


\section{LISTA DE ILUSTRAÇÕES}

Figura 1 - Diagrama de níveis de energia do európio. ............................................. 24

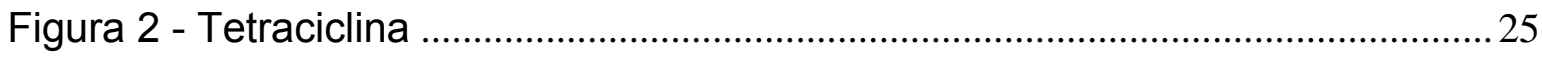

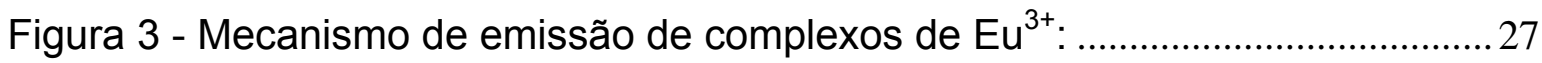

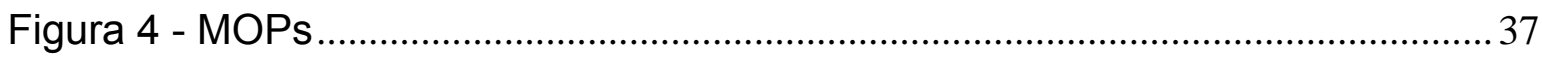

Figura 5 - Diagrama de montagem para medidas de emissão................................. 40

Figura 6 - Refratômetro de Abbé, e visão da amostra através das lentes do refratômetro. .................................................................................. 42

Figura 7 - Visualização frontal do sensor óptico...................................................... 43

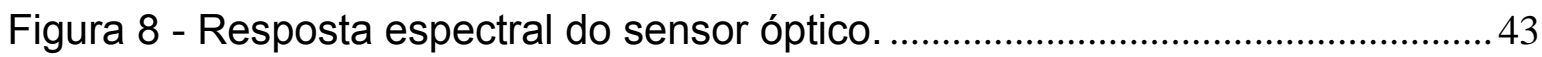

Figura 9 - Esquema do protótipo do equipamento de medida da intensidade do sinal emitido.

Figura 10 - Absorção óptica de todos os reagentes utilizados no complexo MOPs, Eu, Tc, EuTc e HP.

Figura 11 - Ampliação da região de absorção de 200 a 500nm, da Figura 10...... 47

Figura 12 - Absorção óptica da solução de tetraciclina com e sem európio. Tc Nova representa a solução de tetraciclina que fora preparada no mesmo dia da medida e Tc Antiga, a solução preparada cinco meses antes. Eu Antigo é a solução de európio em MOPs preparado também há cinco meses.

Figura 13 - Emissão da tetraciclina excitada em torno de $360 \mathrm{~nm}$........................... 48

Figura 14 - Emissão do complexo EuTc, quando excitado em $405 \mathrm{~nm}$. .................. 49

Figura 15 - Efeitos do pH na intensidade de emissão dos complexos EuTc. Cada ponto representa uma adição de $0,1 \mathrm{~mL}$ de solução alcalina na anterior. .50

Figura 16 - Perfil do tempo de vida da emissão do Eu no complexo EuTc. 52

Figura 17 - Absorção óptica do complexo EuTc, para variadas concentrações de európio $(1: 1 ; 1,5: 1 ; 2: 1 ; 2,5: 1 ; 3: 1 ; 3,5: 1$ e $4: 1)$.

Figura 18 - Espectro de emissão obtido excitando em 405 nm as amostras com diferentes concentrações molares de Eu no complexo Eu:Tc (1:1; $1,5: 1 ; 2: 1 ; 2,5: 1 ; 3: 1 ; 3,5: 1$ e 4:1), sem peróxido de hidrogênio. 
Figura 19 - Espectro de absorção da tetraciclina com adição de concentrações variadas de peróxido de hidrogênio. MHP refere-se à solução de $3 \mathrm{~mL}$ de HP puro em $7 \mathrm{~mL}$ de MOPs. HP puro é a solução de peróxido de hidrogênio sem prévia diluição.

Figura 20 - Espectro de absorção da tetraciclina (linha cheia) do complexo EuTc (círculo) e do complexo EuTc quando adicionado $10 \mu \mathrm{L}$ de HP à solução (quadrado).

Figura 21 - Absorção óptica das amostras em função da ordem de adição dos reagentes - tetraciclina, európio e HP - na solução. .56

Figura 22 - Espectro de emissão das amostras com diferentes concentrações molares de Eu no complexo Eu:Tc $(1: 1 ; 1,5: 1 ; 2,5: 1 ; 3: 1$; e 4:1), com peróxido de hidrogênio $(400 \mu \mathrm{M})$.

Figura 23 - Intensidade, normalizada, da luminescência do complexo EuTc-HP (solução peróxido de hidrogênio de $400 \mu \mathrm{M}$ ) em função da concentração de $\mathrm{Eu}^{3+}(1: 1 ; 1,5: 1 ; 2: 1 ; 3: 1$ e $4: 1)$. 58

Figura 24 - Espectro de emissão da solução 3Eu:1Tc acrescida de 10, 50, 100, 200, e $400 \mu \mathrm{M}$ de HP (solução V).

Figura 25 - Tempo de estabilização do HP no complexo EuTc.

Figura 26 - Tempo de vida da solução de EuTc sozinha e acrescida de $500 \mu \mathrm{L}$ da solução de HP $(200 \mu \mathrm{M})$.

Figura 27 - Dependência da intensidade do sinal de luminescência do európio com alteração na solução de EuTc acrescentando-se variadas concentrações de peróxido de uréia.

Figura 28 - Dependências da área, intensidade e a largura da banda em função da concentração de peróxido de uréia na solução.

Figura 29 - Alterações no índice de refração com o aumento da concentração de PHU na solução EuTc.

Figura 30 - Tempo de vida de complexos EuTc e EuTc-PHU. 64

Figura 31 - Espectro de absorção do colesterol, EuTc e EuTc + Colesterol. .65

Figura 32 - Espectro de emissão do EuTc, EuTc-Colesterol e EuTcColesterol+COx obtidos pela excitação do complexo em 405nm. .66

Figura 33 - Aumento da emissão do EuTc na presença do colesterol. a) Espectro de emissão em função da concentração do colesterol. b) Dependência 
da intensidade de emissão em $618 \mathrm{~nm}$ com a concentração de colesterol. A função linear foi plotada como curva de calibração.

Figura 34 - Dependência da intensidade de emissão em 618 nm com o tempo, mostrando uma estabilização após 1000s.

Figura 35 - Tempo de Vida das soluções EuTc e EuTc-Colesterol (IV e VIII, respectivamente) obtidos pela excitação pulsada em $420 \mathrm{~nm}$ com laser OPO.

Figura 36 - Emissão da solução EuTc acrescida de $5 \mu$ Le HDL, VLDL e LDL.... 70 Figura 37 - Absorção óptica de a) LDL (7,7 mg/mL) e OxLDL ( $6 \mathrm{mg} / \mathrm{mL})$; b) EuTc, EuTc:LDL e EuTc:OxLDL. 70

Figura 38 - a) Espectro de emissão das soluções EuTc e EuTc:LDL com diferentes concentrações da lipoproteína; b) Área integrada (S) do espectro de emissão em função da concentração de LDL. A linha sólida corresponde ao ajuste linear dos dados experimentais. .71

Figura 39 - a) Espectro de emissão das soluções EuTc e EuTc:OxLDL com diferentes concentrações da lipoproteína; b) Área integrada (S) do espectro de emissão em função da concentração de OxLDL. A linha sólida corresponde ao ajuste linear dos dados experimentais.

Figura 40 - Comparação entre as curvas de calibração LDL e OxLDL, intensidade de emissão $X$ concentração da lipoproteína.

Figura 41 - a) Aumento da luminescência do európio com a variação da concentração de LDL (3mg/mL) na solução EuTc. b) Dependência da área da banda de emissão do complexo, com a variação de LDL....... 73

Figura 42 - a) Aumento da luminescência do európio com a variação da concentração de OxLDL (3mg/mL) na solução EuTc. b) Dependência da área da banda de emissão do complexo, com a variação de OxLDL.

Figura 43 - Perfil do tempo de vida das soluções EuTc pura $(500 \mu \mathrm{L})$ e na presença de $5 \mu \mathrm{L}$ de LDL / OxLDL $(2,84 \mathrm{mg} / \mathrm{mL})$. .74

Figura 44 - Emissão do complexo EuTc com adição de Glicose. 76

Figura 45 - Solução EuTc: Glicose + GOx. Variação da glicose de 0 a $250 \mu \mathrm{L}$ para $5 \mu \mathrm{L}$ de GOx. 77

Figura 46 - Perfil de decaimento do tempo de vida das soluções de EuTc contendo variadas concentrações de glicose e $5 \mu \mathrm{L}$ de GOx. 
Figura 47 - Variação Temperatura

Figura 48 - Curva de calibração de intensidade e área do sinal em função da Temperatura $\left(32^{\circ} \mathrm{C}\right)$ para variados tempos de reação da solução EuTc:Glicose + GOx.

Figura 49 - LEDs com variadas intensidades e comprimentos de onda. E em pontilhado é mostrada a curva de absorção do complexo EuTc

Figura 50 - Intensidade de emissão do európio na solução EuTc-PHU para comprimentos de onda distintos

Figura 51 - Espectro obtido com o LED do protótipo do equipamento montado: variação de PHU na solução EuTc.

Figura 52 - Testes preliminares do LED para o protótipo do equipamento de emissão.

Figura 53 - Em detalhe, a lateral da cubeta com o complexo EuTc sendo excitado pelo LED violeta. 84

Figura 54 - Testes preliminares do sensor óptico: Concentração de PHU x Tensão. .85

Figura 55 - Testes do sensor óptico: (1) LED, (2) Cubeta, (3) Filtro, (4) Sensor Óptico. 86

Figura 56 - Vista lateral da cubeta, mostrando em detalhe a emissão do Eu no complexo EuTc na presença do PHU. 86

Figura 57 - Montagem completa para o teste do sensor óptico 87 


\section{LISTA DE TABELAS}

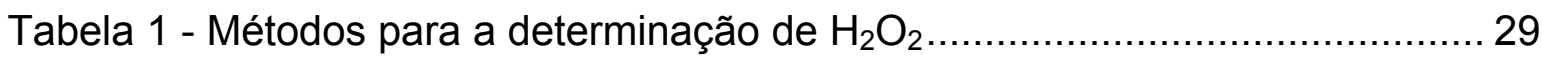

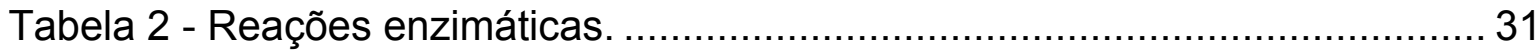

Tabela 3 - Parâmetros do ajuste das eq. (4) e eq. (5) para os dados experimentais

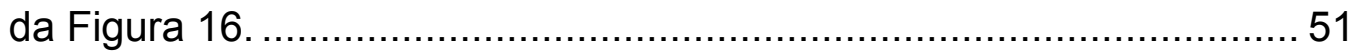

Tabela 4 - Parâmetros do ajuste das eq. (4) e eq. (5) para os dados experimentais da Figura 26 (amostras EuTc e EuTc-HP). .................................6 60

Tabela 5 - Parâmetros dos dados experimentais, da Figura 30 para o ajuste das

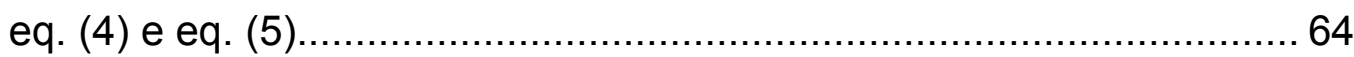

Tabela 6 - Parâmetros para o ajuste das eq. (4) e eq. (5) com os dados

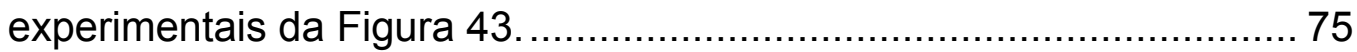

Tabela 7 - Tempo de vida total das soluções de $1 \mathrm{~mL}$ EuTc $+X \mu \mathrm{L}$ glicose $+5 \mu \mathrm{L}$

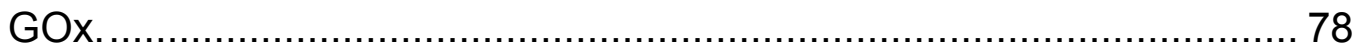

Tabela 8 - Resumo dos resultados obtidos para o biossensor EuTc................. 80 


\section{ABREVIAÇÕES}

$\begin{array}{ll}\text { COx } & \text { Enzima Colesterol Oxidase } \\ \text { Eu } & \text { Európio } \\ \text { EuTc } & \text { Európio-Tetraciclina } \\ \text { EuTc-HP } & \text { Európio-Tetraciclina-Peróxido de Hidrogênio } \\ \text { EuTc-PHU } & \text { Európio-Tetraciclina-Peróxido de Uréia } \\ \text { GOx } & \text { Enzima Glicose Oxidase } \\ \text { HP } & \text { Peróxido de Hidrogênio } \\ \text { HDL } & \text { Lipoproteína de Alta Densidade } \\ \text { LDL } & \text { Lipoproteína de Baixa Densidade } \\ \text { PBS } & \text { Soro bovino fetal } \\ \text { pH } & \text { Potencial Hidrogeniônico } \\ \text { PHU } & \text { Peróxido de Uréia } \\ \text { OxLDL } & \text { Lipoproteína de Baixa Densidade Oxidada } \\ \text { TBARS } & \text { Espécies reativas ao ácido tiobarbitúrico } \\ \text { TC } & \text { Tetraciclina } \\ \text { VLDL } & \text { Lipoproteína de Muito Baixa Densidade }\end{array}$




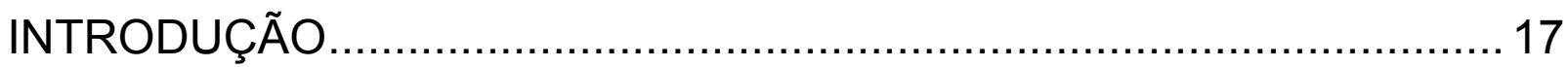

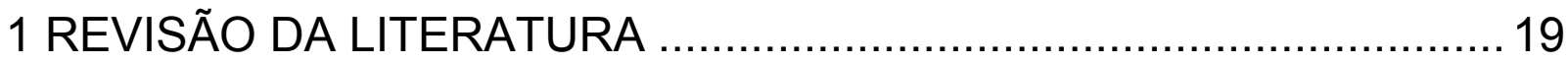

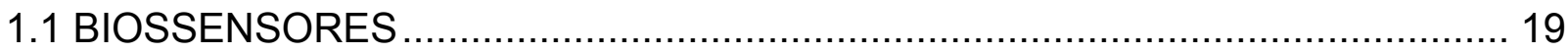

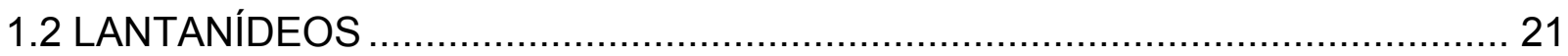

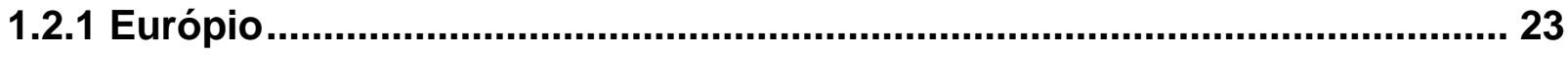

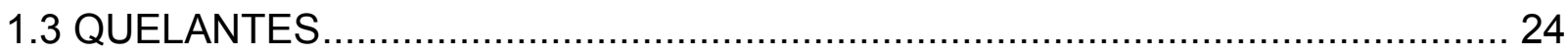

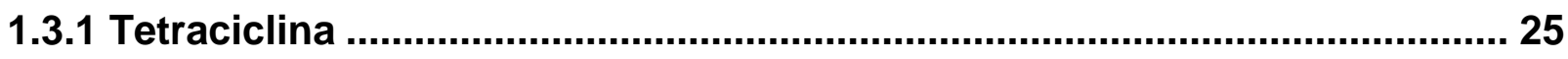

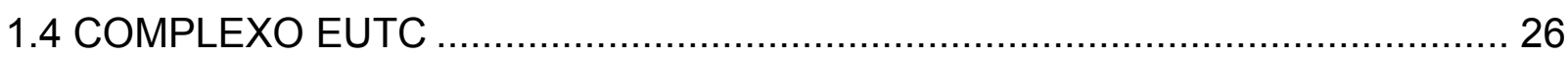

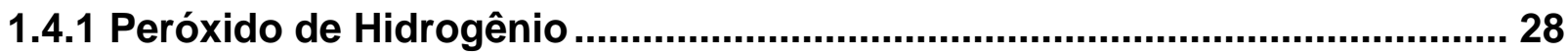

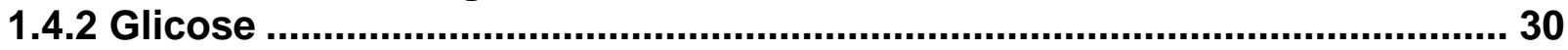

1.4.3 Colesterol total e suas frações .............................................................. 32

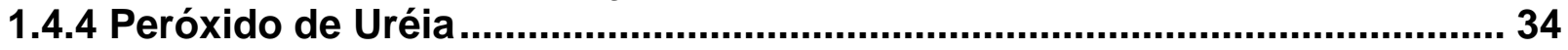

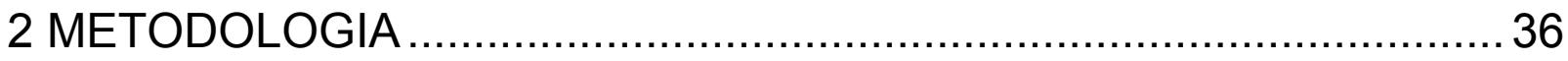

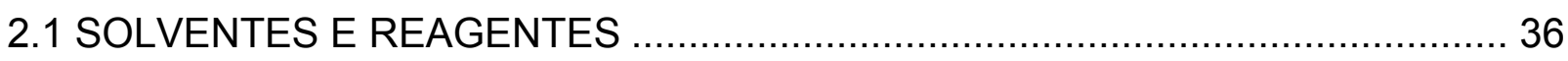

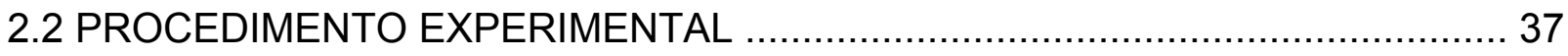

2.2.1 Preparação das soluções .................................................................... 37

2.2.2 Obtenção das Lipoproteínas .................................................................... 38

2.2.3 Obtenção dos espectros de absorção........................................................ 39

2.2.4 Obtenção dos espectros de emissão ........................................................ 39

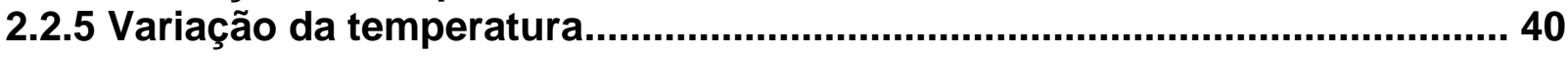

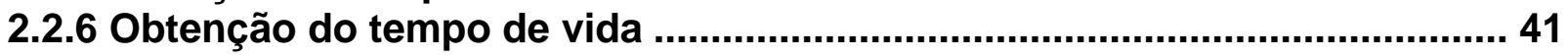

2.2.7 Obtenção do índice de refração ................................................................... 41

2.3 ESQUEMA DO PROTÓTIPO DO EQUIPAMENTO ….................................. 42

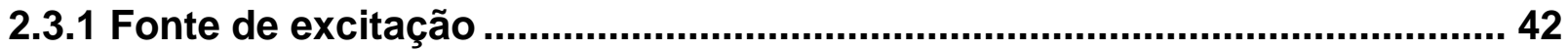

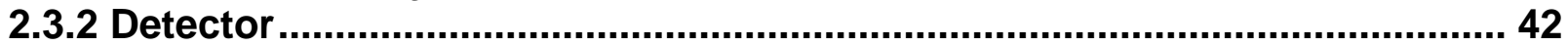

2.3.3 Protótipo do equipamento.................................................................... 44

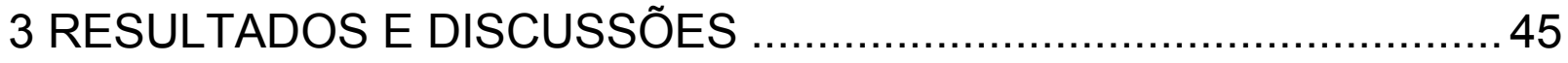

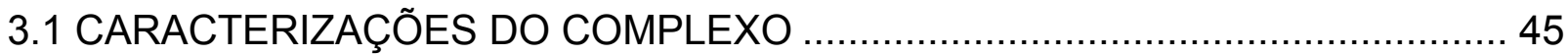

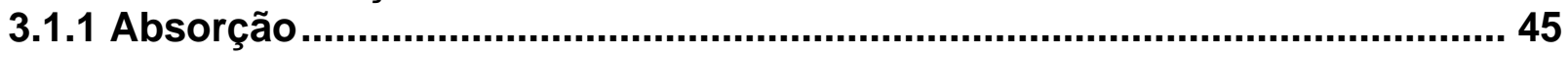

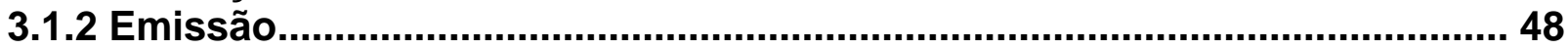

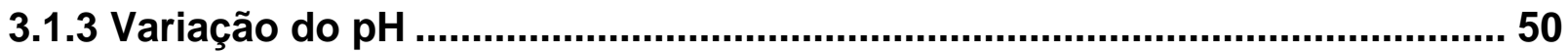

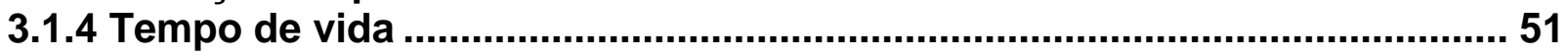

3.1.5 Variação da concentração de európio na solução ..................................... 52

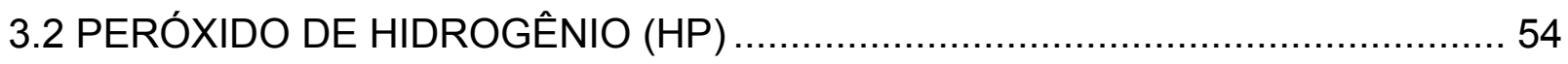

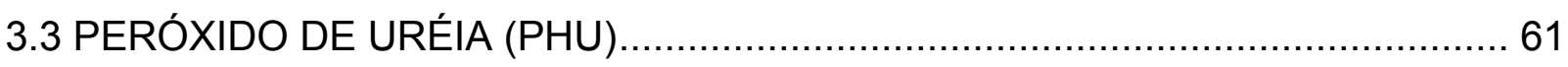

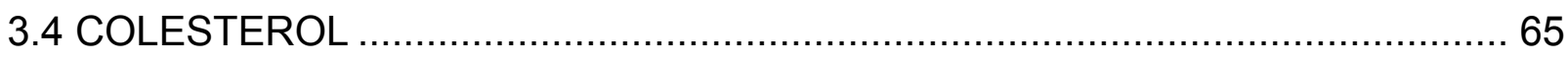

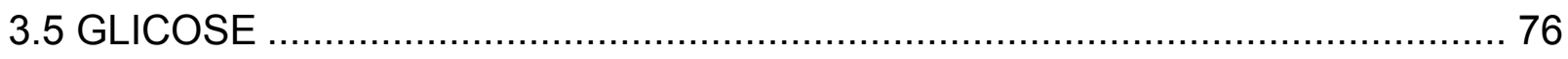




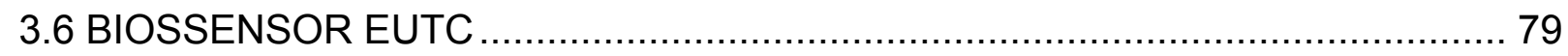

3.7 MONTAGEM E TESTES DO PROTÓTIPO DO EQUIPAMENTO …...................8 80

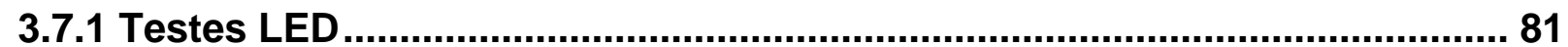

3.7.2 TESTES FOTODIODO (SENSOR ÓPTICO) .................................................. 84

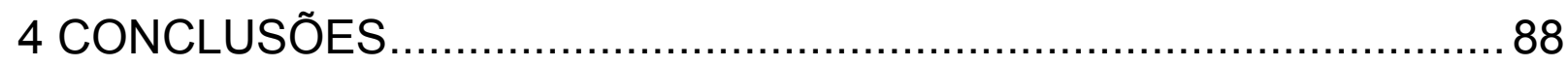

PUBLICAÇÕES E PARTICIPAÇÃO EM EVENTOS.............................90

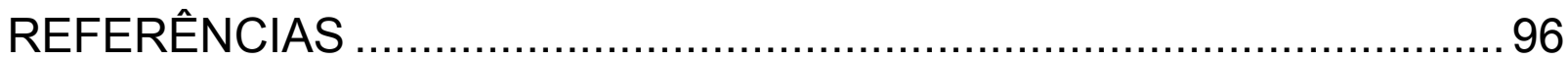




\section{INTRODUÇÃO}

O interesse nas propriedades ópticas de complexos de íons lantanídeos teve início com Weissman ${ }^{1}$ (1942), quando o mesmo noticiou que a absorção de luz ultravioleta por uma variedade de complexos $\beta$-dicetonatos resultou em linhas de emissão características do európio.

Vinte anos se passaram até o advento da espectroscopia, quando então se iniciaram vários estudos nesse ramo da ciência.

De lá para cá, os complexos de európio vêm sendo extensivamente utilizados em análises biomédicas ${ }^{2}$. As aplicações variam desde sondas luminescentes para diagnóstico clínico até terapia médica para doenças genéticas e câncer, entre outras. Várias técnicas vêm sendo empregadas, incluindo alterações, aumento ou diminuição, da intensidade de emissão do íon európio, transferência de energia e tempo de vida do complexo.

A luminescência do európio em solução aquosa é fraca, devido ao baixo coeficiente de absorção do íon e às vibrações $\mathrm{OH}$ do solvente que aumentam o processo de relaxação não-radiativa de estados excitados de vários lantanídeos, o chamado quenching pela água. Complexando esses íons na estrutura da tetraciclina é possível obter alta luminescência do complexo.

A tetraciclina é uma macromolécula que captura o íon da solução, absorve a energia de radiação incidente e, através do efeito antena ${ }^{3}$, transfere essa energia para o európio. Ela apresenta diversos grupos próton-ativos que oferecem possibilidades diferentes de complexação dos íons de lantanídeo, dependendo do $\mathrm{pH}^{4}$.

Complexos európio-tetraciclina tornaram-se atrativos por aumentarem a sensibilidade e seletividade em bioanálises devido às particularidades em suas características ópticas: grande deslocamento Stokes; grande intensidade de fluorescência; tempo de decaimento relativamente longo ${ }^{5,6,7}$; e foto-clareamento não mensurável.

Os objetivos deste trabalho são a síntese e a caracterização do complexo EuTc em solução aquosa, afim de se desenvolver biossensores para análises clínicas, de baixo custo, baseadas nas propriedades ópticas do európio. 
Para tal, as propriedades do complexo európio-tetraciclina foram estudadas a partir de técnicas de absorção óptica, fluorescência, tempos de decaimentos dos estados excitados e índice de refração. Alterações nessas propriedades ópticas decorrentes de variações da concentração de reagentes, temperatura, $\mathrm{pH}$ e adição de peróxido de hidrogênio, peróxido de uréia, glicose, colesterol total e suas frações foram investigadas.

Um aumento significativo na luminescência do európio nesses complexos foi observado na presença do peróxido de hidrogênio $(\mathrm{HP})^{8}$. Este efeito pode ser usado para melhorar os limites de detecção na determinação da tetraciclina ${ }^{9}$, e tem um potencial ainda maior na biomedicina, uma vez que quase todas as oxidases (enzimas) produzem $\mathrm{H}_{2} \mathrm{O}_{2}$ durante suas atividades ${ }^{10}$.

Foi observado que a luminescência do európio também é aumentada na presença de peróxido de uréia ${ }^{11}$, colesterol total ${ }^{12}$ e suas frações ${ }^{13}$.

E a proposta de construção do protótipo do equipamento miniaturizado e de baixo custo para as medidas de emissão do biossensor EuTc foi testada e os resultados demonstram ser possível o desenvolvimento do protótipo utilizando um LED violeta, como fonte de excitação, e um fotodiodo, como detector. 


\section{REVISÃO DA LITERATURA}

\subsection{BIOSSENSORES}

Biossensor é um sistema ou dispositivo analítico usado para a deteç̧ão de uma molécula ou biomolécula alvo, em conjunção com um transdutor físicoquímico, que converte o evento de reconhecimento biológico em um sinal de saída utilizável $^{14}$. São poderosas ferramentas que resultam em respostas rápidas e sensíveis, combinando a seletividade das reações bioquímicas com a simplicidade operacional e baixo custo.

Em qualquer tipo de combinação entre o transdutor e o elemento biológico, o objetivo principal a ser alcançado é a produção de um sinal que possa ser relacionado com a quantidade do analito no sistema ${ }^{15}$.

De acordo com o transdutor utilizado, o biossensor pode ser classificado como eletroquímico (potenciométrico, amperométrico, condutométrico, eletrodos íons seletivos (ISE) e transistor de efeito de campo sensível a íon (ISFET)), óptico (elipsometria, espectroscopia (luminescência, fosforescência, fluorescência, Raman), fibra óptica e guias de onda, interferometria (interferometria de luz branca, interferometria modal) e ressonância de plasma de superfície (SPR)), calorimétricos, piezoelétricos (relaciona a oscilação da freqüência dos cristais de quartzo com variação da massa) e acústicos ${ }^{16,17}$.

Dos biossensores eletroquímicos, os amperométricos constituem-se em dispositivos mantidos em potencial fixo e que propiciam sinais de corrente proporcionais à concentração do analito, em função de processos eletródicos que ocorrem na interface eletrodo/solução ${ }^{18}$. Para o sensor potenciométrico, um equilíbrio local é estabelecido na interface do sensor, onde os elétrodos ou membrana potencial medem o potencial gerado por íons, e a informação sobre a composição de uma amostra é obtida pela diferença deste potencial entre os elétrodos ${ }^{19}$. Já os sensores condutométricos estão envolvidos com a medida de condutividade. 
Os métodos que empregam sensores ópticos são baseados nas mudanças das propriedades ópticas no sistema utilizado, por meio de medidas de emissão, absorção, reflexão, dispersão, difusão de luz, interferência, refração e difração. Quando um destes fenômenos acontece, as mudanças nas propriedades ópticas resultam na modulação de uma ou mais das seguintes propriedades: comprimento de onda, amplitude, fase ou polarização ${ }^{20}$.

O biossensor piezoelétrico consiste em um disco confeccionado em cristal piezelétrico de quartzo revestido por eletrodos de metal (normalmente ouro, prata, níquel ou cobre $)^{17}$. Esses eletrodos são usados para induzir um campo elétrico alternado ao cristal, o que produz uma oscilação no centro do cristal piezelétrico. Diretamente ligado ao circuito oscilador aparece um contador de freqüência (freqüencímetro) responsável pelo monitoramento das variações na freqüência de oscilação do cristal $^{21}$. À medida que o potencial elétrico alternado é aplicado, promovendo um movimento vibracional no cristal, estabelece-se uma onda acústica transversa que se propaga através do cristal. Como resultado ocorre um deslocamento dos átomos do cristal paralelo à sua superfície ${ }^{21}$. Desta forma, se um material é depositado sobre a superfície do cristal ocorre uma redução no movimento de oscilação, resultando em diminuição da freqüência de ressonância do mesmo. Monitorando a freqüência do cristal é possível se investigar os fenômenos interfaciais e superficiais ${ }^{21}$.

A fabricação desses sensores em micro e nano escala compreendem os BioMEMS e BioMENS (Biomedical or Biological Micro/Nano-Electro-Mechanical Systems).

Cronologicamente, Nernst, em 1897, propôs o primeiro biossensor potenciométrico, usando um eletrodo de hidrogênio para medir a acidez de uma solução aquosa ${ }^{22}$, e em 1906, para a mesma finalidade, foi desenvolvido o eletrodo de vidro, por Cremer ${ }^{22}$.

Em 1935, as empresas Beckman e Radiometer comercializaram o primeiro medidor de $\mathrm{pH}^{22}$. Em 1957 iniciou-se a era dos eletrodos íons-seletivos (ISEs), com os trabalhos teóricos de Eisenman e Nikolski ${ }^{22}$. Moody, Oke e Thomas, em 1970, usaram, pela primeira vez, eletrodos de membrana líquida à base de polímero PVC, o que simplificou bastante a construção dos ISEs ${ }^{22}$.

Clark e Lyons (1962) foram os pioneiros no uso de transdutores enzimáticos, quando eles planejaram um eletrodo com enzima para detectar 
glicose no sangue de pacientes ${ }^{23}$. Eles imobilizaram glicose oxidase na ponta de um eletrodo de platina sensível a oxigênio. Quanto mais glicose no sangue do paciente, mais oxigênio era usado na reação enzimática e conseqüentemente menos oxigênio era medido no sangue do paciente ${ }^{17}$. Em 1975, a Yellow Springs Instruments Company comercializou o biossensor de glicose, que foi baseado na medida amperométrica do peróxido de hidrogênio ${ }^{17}$.

Guilbaut e Montalvo descreveram o eletrodo enzimático potenciométrico, um sensor de uréia baseado na imobilização da urease em um eletrodo de membrana ${ }^{24}$. O uso de transdutores térmicos para biossensores foi sugerido em 1974. Lubbers e Opitz usaram o termo optodo para o sensor de fibra óptica com um indicador imobilizado para a medida de oxigênio ou dióxido de carbono. $\mathrm{O}$ conceito foi expandido para determinação de álcool, medidas in vivo de $\mathrm{pH}, \mathrm{pCO}_{2}$, $\mathrm{pO}_{2}$, etc ${ }^{24}$.

Com o desenvolvimento do transistor de efeito de campo sensível a íon (ISFET), foi possível a miniaturização e a utilização dos processos da microeletrônica na microfabricação dos biossensores, permitindo a produção em massa $^{22}$.

Em 1999, foi descoberto, por Rakicioglu ${ }^{8}$, que o complexo EuTc poderia ser um biossensor de peróxido de hidrogênio. Em 2004, Wolfbeis e colaboradores usaram o complexo EuTc como biossensor de glicose ${ }^{10}$. Em 2005 desenvolvemos o biossensor de peróxido de uréia ${ }^{11}$ e em 2007 o biossensor para colesterol total ${ }^{12}$ e suas frações ${ }^{13}$, a partir do complexo EuTc.

Atualmente os biossensores apresentam aplicações nas mais diversas áreas: diagnóstico clínico, monitoramento intensivo da saúde, monitoramento em tempo real, indústria de alimentos, controle do meio ambiente, controle de infecções hospitalares, na biodefesa, entre outras.

\subsection{LANTANÍDEOS}

Os íons lantanídeos são os elementos químicos dispostos na tabela periódica com número atômico variando de 57 a 71 (lantânio ao lutécio) - também conhecidos como terras raras (incluindo o escândio (21) e o ítrio (39)). O termo 
terra rara foi atribuído devido a uma descoberta tardia, no final do século 18, de um mineral novo e incomum e às dificuldades iniciais na sua separação. Estes elementos não são escassos quando considerados em termos da abundância na crosta terrestre, pois o mais raro, o túlio, está presente em percentuais próximos ao da prata $^{25}$.

Os lantanídeos possuem uma estrutura eletrônica muito particular: apesar da presença de três elétrons nas camadas mais externas, no decorrer da série ocorre o preenchimento dos orbitais internos 4f, obtendo-se a configuração eletrônica $(\mathrm{Xe}) 4 \mathrm{f}^{\mathrm{n}} 5 \mathrm{~s}^{2} 5 \mathrm{p}^{6}(0<\mathrm{n}<14)$. Os íons lantanídeos são na maioria trivalentes com números de coordenação entre 6 e 12. Alguns lantanídeos apresentam a propriedade de luminescência: por exemplo, o európio trivalente $\left(\mathrm{Eu}^{3+}\right)$ apresenta emissão mais intensa na região do vermelho, o térbio trivalente $\left(\mathrm{Tb}^{3+}\right)$ na região do verde e o európio bivalente $\left(\mathrm{Eu}^{2+}\right)$ na região do azul.

As configurações eletrônicas $4 \mathrm{f}^{\mathrm{n}}$ dos íons lantanídeos possuem vários níveis energéticos determinados pela combinação de repulsão inter-eletrônica, acoplamento spin-órbita e o meio coordenante (campo cristalino) ${ }^{26}$.

A relaxação de um estado excitado pode ocorrer por decaimentos radiativos e/ou não radiativos. O decaimento radiativo ocorre com uma transição eletrônica de um nível de maior energia para um de menor energia, sendo esta energia emitida como radiação. Decaimentos não radiativos ocorrem através de transições vibracionais, com a energia perdida para o ambiente.

Os elétrons do orbital $4 \mathrm{f}$, por serem muito bem protegidos do seu ambiente químico pelos elétrons das últimas camadas, são minimamente envolvidos na interação dos lantanídeos com os ligantes, por isso as propriedades luminescentes dos íons são preservadas, como tempo de vida longo, e bandas de emissão estreitas. A variação do ambiente do íon provoca apenas pequenos desdobramentos nos níveis de energia e nas intensidades relativas das bandas ${ }^{27}$. As transições f-f são proibidas ${ }^{25}$ e, como resultado dessa proibição, o coeficiente de absorção é muito baixo. Como conseqüência, a excitação direta do íon de lantanídeo não é favorável. A rápida relaxação térmica da energia de excitação é um problema quando se utilizam íons lantanídeos para sistemas luminescentes ${ }^{28}$. Essa relaxação não radiativa pode ocorrer pela interação dos níveis eletrônicos do íon lantanídeo com os modos vibracionais ressonantes do solvente. Quando o solvente contém grupos $\mathrm{OH}$ na coordenação do íon lantanídeo, ocorre eficiente 
relaxação não radiativa devido ao acoplamento ressonante dos estados vibracionais dos osciladores $\mathrm{OH}^{5}$.

A eficiência do processo de emissão de radiação depende da diferença energética entre o estado excitado e fundamental, da energia vibracional do oscilador e da vizinhança ao redor do íon ${ }^{29}$.

Neste trabalho utilizou-se o íon európio entre os demais lantanídeos.

\subsubsection{Európio}

O európio foi descoberto em $1901^{30}$, na Dinamarca, tendo como símbolo a sigla Eu, número atômico 63 e peso atômico 151,96 g. É talvez o lantanídeo mais estudado de todos, principalmente quando se trata de sistemas biológicos, devido às suas propriedades fotofísicas ${ }^{31}$. Os níveis de energia envolvidos nas transições eletrônicas são não-degenerados. Seu estado emissivo mais baixo, ${ }^{5} D_{0}$, é 17.250 $\mathrm{cm}^{-1}$ acima do estado fundamental ${ }^{7} \mathrm{~F}_{0}$.

A emissão do európio pode sofrer supressão pelos grupos $\mathrm{OH}, \mathrm{NH}$ e $\mathrm{CH}$ do solvente, o que pode ser reduzido substituindo-se os hidrogênios por outro elemento. $\mathrm{O}$ número de grupos $\mathrm{OH}$ coordenados da água ou metanol pode ser estimado por alterações no tempo de vida pela equação de Horrocks ${ }^{32,33}$, porém essa relação não é muito precisa quando o número de grupos $\mathrm{OH}$ na primeira esfera de coordenação é pequeno.

O encapsulamento desses íons por agentes quelantes aumenta o rendimento quântico da emissão e o tempo de vida do complexo comparado com o íon livre. Além disso, a luminescência, mecanismo tipicamente explorado em ambiente aquoso, aumenta com a diminuição do número de moléculas de $\mathrm{H}_{2} \mathrm{O}$ na coordenação do európio após a complexação com o quelante. O $\mathrm{Eu}^{3+}$ apresenta de 8 a 9 sítios de ligação com moléculas de água em sua coordenação.

A transferência de energia do estado triplete excitado de ligantes aromáticos ao estado emissivo, ${ }^{5} \mathrm{D}_{0}$, do európio, ocorre em complexos em que o ligante tenha seu estado triplete logo acima do estado ${ }^{5} \mathrm{D}_{0}$.

Os níveis de energia mostrados a seguir (na Figura 1) relacionam as raias espectrais do európio: 


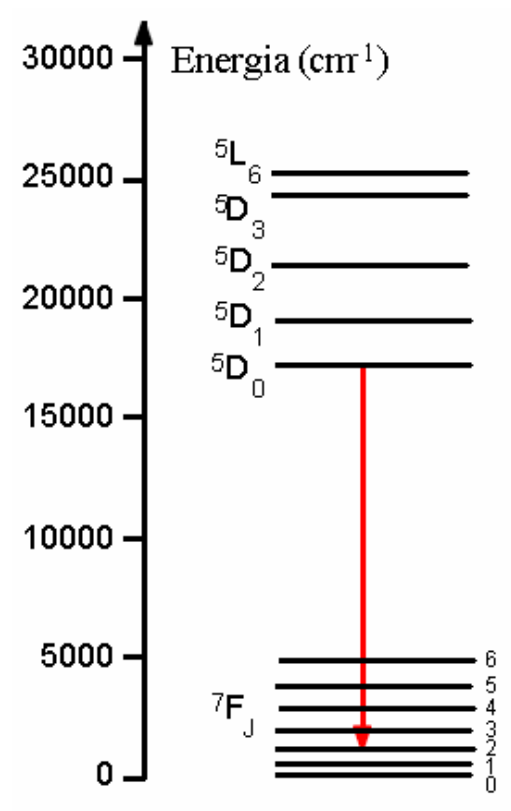

\section{$\mathrm{Eu}^{3+}$}

Figura 1 - Diagrama de níveis de energia do európio (adaptado da Ref. 34).

Apesar de em solução aquosa os íons lantanídeos apresentarem fracos coeficientes de absorção, a preparação com agentes quelantes ou encapsuladores de lantanídeos resulta em materiais que apresentam forte luminescência ${ }^{7}$, permitindo que os complexos com lantanídeos sejam usados como sondas fluorescentes em várias aplicações biomédicas.

\subsection{QUELANTES}

Agentes quelantes são macromoléculas que seqüestram íons de metais polivalentes formando duas ou mais ligações coordenadas ou uma combinação de ligações coordenadas e/ou iônicas ${ }^{35}$.

A complexação é uma atração eletrostática entre um íon e um agente quelante de modo que não há transferência de elétrons entre estes. Quanto às cargas, a estrutura final terá como carga a somatória das cargas individuais de cada participante do complexo.

O agente complexador a ser explorado nesse trabalho é a tetraciclina. 


\subsubsection{Tetraciclina}

Tetraciclina (Tc, Figura 2) é um antibiótico com um amplo espectro, usado em tratamento de diversas infecções bacterianas. Embora Tc seja considerada como relativamente não-tóxica, o uso freqüente resulta na acumulação de resíduos e resistência de bactérias ao antibiótico. Isso também produz um grande número de efeitos adversos para indivíduos sensíveis, como dor na boca, coceira perineal, vertigem, dor de cabeça, diarréia e fotossensibilidade. Conseqüentemente, a permissão de resíduos de Tc em alimentos é regulada e monitorada rotineiramente ${ }^{36,37}$.

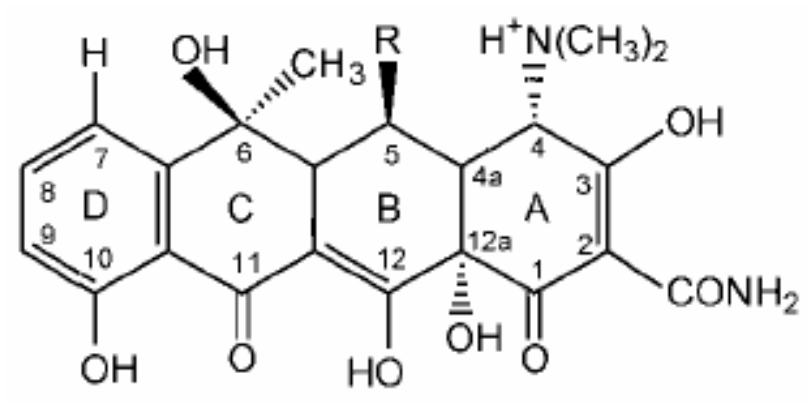

Figura 2 - Tetraciclina

As tetraciclinas são derivadas de um sistema de quatro anéis de seis carbonos cada, arranjados linearmente. Esse sistema representa a união de dois cromóforos distintos: o anel A e o anel BCD.

Muitas pesquisas têm sido feitas na tentativa de entender a química de coordenação das tetraciclinas ${ }^{38,39,40}$ com diferentes metais. Esse aspecto da química da tetraciclina é bastante complexo por causa da existência de três ou mais sítios de ligação e quatro a cinco sítios de dissociação prototrópica em cada molécula e por causa da afinidade desses sítios com íons dependendo do $\mathrm{pH}^{41}$.

As tetraciclinas são fortes agentes quelantes. Os sítios de complexação incluem o sistema $\beta$-dicetonatos (posição 11 e 12) do anel BCD e os grupos enol (posição 1 e 3) e carboxamido (posição 2) do anel $A^{42,43}$.

A tetraciclina apresenta uma fluorescência molecular intrínseca. A formação de um complexo com íons lantanídeos, por exemplo, o $\mathrm{Eu}^{3+}$, permite a 
transferência de energia intramolecular do estado excitado da tetraciclina para o nível de emissão do íon de lantanídeo.

Os primeiros trabalhos envolvendo o íon európio e a tetraciclina ocorreram no sentido de utilizar o íon európio como sonda fluorescente na detecção de traços de tetraciclina no organismo ${ }^{9}$.

\subsection{COMPLEXO EUTc}

O estudo do complexo EuTc iniciou-se em 1982 com Richardson ${ }^{44}$, quando ele verificou alterações nas bandas de absorção da tetraciclina na ausência e na presença do íon európio indicando a complexação do íon. Em 1984, Hirschy et al $^{45}$ estudaram as propriedades luminescentes do complexo e em um artigo subseqüente explicaram as propriedades de formação do complexo ${ }^{41}$.

O európio absorve pouco na região espectral do visível e ultravioleta, mas com a complexação com a tetraciclina sua eficiência é aumentada. A tetraciclina pode ser usada para excitar o európio pelo mecanismo apresentado na Figura 3.

A emissão de complexos EuTc é o resultado de diversos processos como mostrado na Figura 3 (diagrama de Jablonski). No estágio da excitação, a tetraciclina absorve a energia fornecida por uma radiação externa e é levada ao primeiro estado singlete excitado $\left(S_{1}\right)$ a partir do estado fundamental $\left(S_{0}\right)$ (a denominação de estado eletrônico singlete está relacionada com a multiplicidade de spins eletrônicos, segundo a equação $2 S+1$, sendo $S$ a soma dos spins dos elétrons. No caso dos estados singlete, o valor da multiplicidade é igual a 1, que é a situação mais comumente encontrada para moléculas orgânicas no estado eletrônico fundamental, para as quais todos os elétrons ocupam os estados de menor energia e os elétrons possuem spins desemparelhados ${ }^{46}$ ). A conversão de $\mathrm{S}_{1}$ ao primeiro estado triplete, $\mathrm{T}_{1}$, ocorre através do cruzamento intersistema onde o elétron atinge o estado triplete mediante a inversão do spin do elétron singlete (cerca de $75 \%$ dos elétrons excitados singlete migram para o estado triplete, que é mais estável por possuir menor energia ${ }^{47}$ ) e a transição do $T_{1}$ ao estado fundamental é proibida, uma vez que sua taxa de decaimento é lenta ${ }^{48}$ 
(fosforescência), e por ser lenta é mais susceptível a ser desativada através de processos não radiativos ${ }^{46}$.

Os processos que envolvem estados eletrônicos com mesma multiplicidade de spin (envolvem estados singlete) são sempre permitidos, mesmo aqueles que são não radiativos, enquanto que os que envolvem estados com multiplicidades de spins diferentes são sempre proibidos. É por isso que, exceto em condições muito especiais, não se observa a absorção direta para estado triplete ${ }^{46}$.

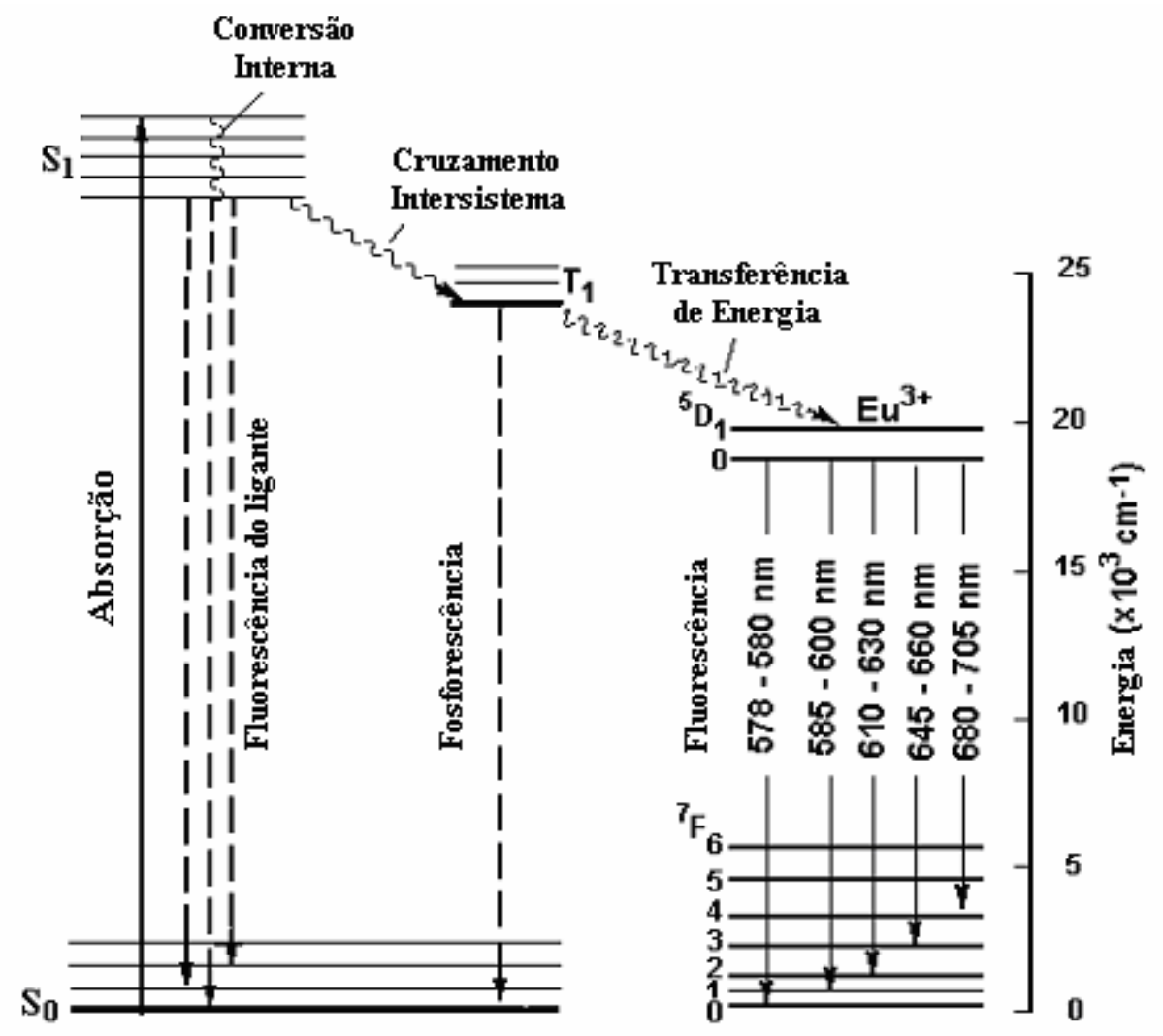

Figura 3 - Mecanismo de emissão de complexos de $\mathrm{Eu}^{3+}$ :

$\mathrm{S}_{0}, \mathrm{~S}_{1}$ e $\mathrm{T}_{1}$ estado singlete fundamental, estado singlete excitado, e estado triplete, respectivamente [adaptado da Ref. 49].

Após absorver a radiação incidente, a tetraciclina, prossegue na conversão interna e então transfere essa energia para o $\mathrm{Eu}^{3+}$. A eficiência desse processo de conversão de energia, ou seja, a seqüência absorção $\rightarrow$ transferência $\rightarrow$ emissão, depende da intensidade de absorção do ligante, da eficiência de transferência de energia ligante-íon e da eficiência de luminescência do íon ${ }^{50}$.

Além disso, esse processo de emissão do complexo EuTc apresenta múltiplas emissões ${ }^{49}$ provenientes das várias transições eletrônicas do európio: ${ }^{5} D_{0} \rightarrow{ }^{7} F_{J}(J=0,1,2,3,4)$ e ${ }^{5} D_{1} \rightarrow{ }^{7} F_{J}(J=1,2,3,5,6)$. As transições mais 
intensas são ${ }^{5} \mathrm{D}_{0} \rightarrow{ }^{7} \mathrm{~F}_{2}$ e ${ }^{5} \mathrm{D}_{0} \rightarrow{ }^{7} \mathrm{~F}_{1}$ com emissões em torno de 610-630 nm e 585$600 \mathrm{~nm}$, respectivamente ${ }^{49}$.

As três principais características do complexo EuTc ${ }^{44,49,51}$ são as seguintes: 1) Devido à dissipação da energia durante a conversão interna, o cruzamento intersistema e a transferência de energia intramolecular ${ }^{52}$ a energia do fóton emitido pelo complexo EuTc é significativamente diferente daquela da radiação da excitação, e conseqüentemente o deslocamento Stokes é grande, cerca de 210 $\mathrm{nm}^{49}$. A excitação da tetraciclina é no ultravioleta $(\sim 395 \mathrm{~nm})$, e pode ser realizada tipicamente utilizando-se laser, lâmpada ou um LED violeta. A linha de emissão mais intensa do európio é no vermelho ( $615 \mathrm{~nm})$. Esse grande deslocamento Stokes permite a fácil discriminação da luz de excitação.

2) A emissão do Európio no vermelho é estreita $(\sim 10 \mathrm{~nm})$. Isso acontece por causa da proteção dos orbitais $f$ pelos orbitais preenchidos mais elevados $s$ e $p$ do lantaníde ${ }^{49}$. E a intensidade de fluorescência da banda principal do complexo de európio é muito forte, embora seu rendimento quântico seja geralmente mais baixo do que aquele dos fluoróforos convencionais. A razão disso é que a energia transferida é fortemente emitida por uma banda estreita e bem definida ${ }^{47}$.

3) O tempo de decaimento da fluorescência é longo ( 20 $\mu \mathrm{s})$. As transições eletrônicas f-f do lantanídeo são proibidas, conduzindo para longo tempo de decaimento do estado excitado ${ }^{49}$. Os tempos de decaimento de complexos de európio são altamente sensíveis ao ambiente do ligante, em especial ao número de moléculas de água que ocupam locais internos da coordenação do íon ${ }^{47}$.

O complexo EuTc tem se mostrado versátil em bioanálise como sensor de: peróxido de hidrogênio ${ }^{8}$, glicose ${ }^{10}$, leticina ${ }^{53}$, heparina ${ }^{54}$, fosfato ${ }^{55}$, albumina de soro humano ${ }^{56}$, citrato e outros intermediários do ciclo do ácido cítrico ${ }^{57}$, entre outros. A seguir será descrito com maior profundidade algumas possibilidades de utilização do complexo EuTc como biossensor.

\subsubsection{Peróxido de Hidrogênio}

O peróxido de hidrogênio é um dos oxidantes mais versáteis que existe, superior ao cloro, dióxido de cloro e permanganato de potássio ${ }^{58}$. Os peróxidos 
aparecem em muitas reações enzimáticas e atmosféricas. Na atmosfera, os peróxidos fazem o papel de substâncias reativas devido à formação de radicais pela irradiação com luz solar. Estes radicais são os prováveis responsáveis pela degradação da camada de ozônio, que protege contra raios UV, na atmosfera ${ }^{59,60}$.

Apesar do poder de reação, peróxido de hidrogênio é um metabólito natural em muitos organismos o qual, quando decomposto, resulta em oxigênio molecular e água ${ }^{58}$. Mas em processos celulares $\circ \mathrm{H}_{2} \mathrm{O}_{2}$ liberado é muito tóxico. Além disso, o peróxido usado em indústrias normalmente é liberado no meio ambiente em grandes quantidades ${ }^{61}$. É também importante nas áreas envolvidas com alimentos, medicamentos, monitoramento de processos, entre outras ${ }^{58}$. Conseqüentemente, a determinação de baixas concentrações de peróxidos é um objetivo importante tanto na bioanálise quanto em análise ambiental ${ }^{10}$.

Muitos métodos foram desenvolvidos para a quantificação de peróxido de hidrogênio, como métodos amperométricos ${ }^{62,63}$, potenciométricos ${ }^{64} \mathrm{e}$ $\operatorname{condutométricos}^{65}$, quimiluminescência ${ }^{66}$, fluorescência ${ }^{67}$, volumetria ${ }^{68}$, cromatografia líquida ${ }^{69}$, entre outros.

O biossensor EuTc foi primeiramente descrito por Rakicioglu ${ }^{8}$. O limite de detecção do método utilizando o EuTc ${ }^{70}$ pode ser comparado ao obtido por outros métodos conforme visto na Tabela 1.

Tabela 1 - Métodos para a determinação de $\mathrm{H}_{2} \mathrm{O}_{2}$ :

\begin{tabular}{lcl}
\hline \multicolumn{1}{c}{ Método } & $\begin{array}{c}\text { Escala } \\
\text { Linear }\end{array}$ & $\begin{array}{c}\text { Limite de } \\
\text { Detecção }\end{array}$ \\
\hline Biossensor Amperométrico (carbono vítreo) & $0,01-1,5 \mathrm{mmol} . \mathrm{L}^{-1}$ & $5 \mu \mathrm{mol} . \mathrm{L}^{-1}$ \\
Biossensor Potenciométrico (eletrodo redox) & $1,98-9,86 \mathrm{~mol} . \mathrm{L}^{-1}$ & $0,4 \mu \mathrm{mol} . \mathrm{L}^{-1}$ \\
Biossensor Condutométrico (ouro) & $5-300 \mu \mathrm{mol} . \mathrm{L}^{-1}$ & - \\
Biossensor de Fibra Óptica & $0,05-1,2 \mathrm{mmol} . \mathrm{L}^{-1}$ & $25 \mu \mathrm{mol} . \mathrm{L}^{-1}$ \\
Quimiluminescência (Luminol e Peroxidase) & $0,1-0,3 \mathrm{mmol} . \mathrm{L}^{-1}$ & $0,67 \mathrm{mmol} . \mathrm{L}^{-1}$ \\
UV-Vis (Ferro e Porfirina) & $3,5-70 \mu \mathrm{mol} . \mathrm{L}^{-1}$ & $1 \mu \mathrm{mol} . \mathrm{L}^{-1}$ \\
Volumetria & $41-200 \mu \mathrm{mol} . \mathrm{L}^{-1}$ & $3 \mu \mathrm{mol} . \mathrm{L}^{-1}$ \\
Cromatografia Líquida & $0,5-5 \mu \mathrm{mol} . \mathrm{L}^{-1}$ & $0,15 \mu \mathrm{mol} . \mathrm{L}^{-1}$ \\
EuTc & $2-400 \mu \mathrm{mol} . \mathrm{L}^{-1}$ & $0,96 \mu \mathrm{mol} . \mathrm{L}^{-1}$ \\
\hline
\end{tabular}


A possibilidade da determinação luminescente do peróxido de hidrogênio é também promissora para a determinação indireta da glicose $\mathrm{e}^{10,71,72}$.

\subsubsection{Glicose}

A glicose é um dos carboidratos mais importante na biologia e é o principal combustível utilizado pelas células para produzir energia e crescimento. A glicose é um açúcar proveniente da dieta ${ }^{73}$. Uma vez ingerido, é absorvido pelo intestino, passando à circulação sangüínea, onde fica disponível para as células, porém, para que as células possam usá-la, faz-se necessário a intervenção da insulina e quando a quantidade de insulina não é adequada, a maior parte das células não consegue utilizar a glicose, que permanece no sangue, atingindo níveis excessivamente altos e extremamente prejudiciais à saúde ${ }^{73}$.

Valores normais de glicemia (níveis de glicose no sangue) são aqueles que oscilam entre 80 e $110 \mathrm{mg} / \mathrm{dL}^{73}$.

De acordo com dados do Ministério da Saúde, aproximadamente 7,6\% da população brasileira entre 35 e 69 anos de idade devem ser portadores de diabetes. Isso equivale a cerca de 11 milhões de pessoas, sendo que boa parte dessas pessoas ignora sua condição e, portanto, não recebe qualquer tipo de cuidado $^{73,74}$.

Embora se associe o diabetes ao idoso e ao obeso, ele é a principal causa de doenças crônicas na infância. O diabetes é uma síndrome caracterizada pela presença de níveis elevados de glicose no sangue.

A determinação do nível glicêmico, é de grande importância em virtude do papel que desempenha no tratamento de diabetes (hiperglicosúria e hiperglicemia).

A metodologia de quantificação de glicose mais comum consiste na utilização de uma enzima, glicose oxidase (GOx), que na quebra da glicose produz $\mathrm{H}_{2} \mathrm{O}_{2}$ :

$$
\text { Glicose }+\mathrm{O}_{2} \stackrel{\mathrm{GOx}}{\rightarrow} \text { D-gluconolactone }
$$


D- gluconolactone $+\mathrm{H}_{2} \mathrm{O} \rightarrow$ D-gluconate $+\mathrm{H}_{2} \mathrm{O}_{2}+\mathrm{H}^{+}$

Considerando a reação enzimática e a informação que:

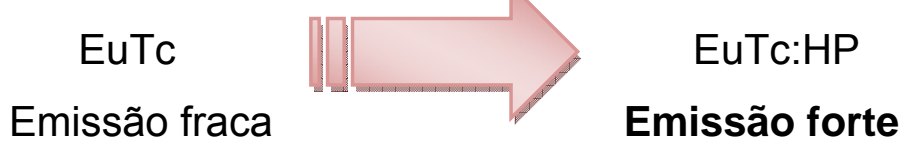

É possível se determinar indiretamente a quantidade de glicose presente em uma determinada solução utilizando o complexo EuTc. Foram publicados vários trabalhos onde o complexo EuTc foi utilizado como sonda para glicose e cujos limites de detecção são os seguintes: considerando medidas de intensidade de fluorescência: Limite de detecção de 12,8 mUnid/mL e faixa de linearidade de 12,8 - 27,1 $\mathrm{mUnid} / \mathrm{mL}$. Para medidas utilizando diferenças de tempo de decaimento: Limite de detecção de 3,1 $\mathrm{mUnid} / \mathrm{mL}$ e faixa de linearidade de 3,1 $27,1 \mathrm{mUnid} / \mathrm{mL}^{71}$.

Além da glicose, e seguindo princípio semelhante pelo método enzimático, é de grande interesse o acompanhamento dos índices de lactose $^{75} \mathrm{e}_{\text {álcool }}{ }^{72}$, e a monitoração de processos biotecnológicos, tais como a preparação de fermentados, a produção de insulina e antibióticos ${ }^{10}$.

Tabela 2 - Reações enzimáticas ${ }^{71}$.

\begin{tabular}{|c|c|c|}
\hline Substância & Enzima & Reação Enzimática \\
\hline Álcool & Álcool oxidase & Etanol $+\mathrm{O}_{2} \rightarrow$ Acetaldeído $+\mathrm{H}_{2} \mathrm{O}_{2}$ \\
\hline D-Glicose & Glicose Oxidase & $\beta$-D-Glicose $+\mathrm{O}_{2} \rightarrow$ Ácido Glicônico $+\mathrm{H}_{2} \mathrm{O}_{2}$ \\
\hline Lactose & Galactose oxidase & Lactose $+\mathrm{O}_{2} \rightarrow$ Galactose dialdeído $+\mathrm{H}_{2} \mathrm{O}_{2}$ \\
\hline L-Lactato & L-Lactato oxidase & L-Lactato $+\mathrm{O}_{2} \rightarrow$ Piruvato $+\mathrm{H}_{2} \mathrm{O}_{2}$ \\
\hline Amido & $\begin{array}{l}\text { Amiloglicosidase } \\
\text { Glicose oxidase }\end{array}$ & $\begin{array}{l}\text { Amido }+\mathrm{H}_{2} \mathrm{O} \rightarrow \beta \text {-D-Glicose } \\
\beta \text {-D-Glicose }+\mathrm{O}_{2} \rightarrow \text { Ácido Glicônico }+\mathrm{H}_{2} \mathrm{O}_{2}\end{array}$ \\
\hline \multirow{3}{*}{ Sacarose } & Invertase & Sacarose $+\mathrm{H}_{2} \mathrm{O} \rightarrow \alpha$-D-Glicose $+\beta$-DFrutose \\
\hline & Mutarotase & $\alpha-D$-Glicose $\rightarrow \beta$-D-Glicose \\
\hline & Glicose oxidase & $\beta$-D-Glicose $+\mathrm{O}_{2} \rightarrow$ Ácido Glicônico $+\mathrm{H}_{2} \mathrm{O}_{2}$ \\
\hline Catalase & Catalase & $2 \mathrm{H}_{2} \mathrm{O}_{2} \rightarrow 2 \mathrm{H}_{2} \mathrm{O}+\mathrm{O}_{2}$ \\
\hline
\end{tabular}


São mostradas, na Tabela 2, algumas reações que liberam $\mathrm{H}_{2} \mathrm{O}_{2}$ e por isso podem ser determinadas através do método enzimático ${ }^{76,77,78,79,80,81,82,83,84,85}$, utilizando-se o complexo EuTc. Para determinadas substâncias são necessárias mais de uma enzima para a produção do peróxido de hidrogênio. No caso da catalase o método é invertido, baseado na fluorescência mínima em relação à fluorescência máxima, já que há quebra da molécula de $\mathrm{H}_{2} \mathrm{O}_{2}$.

Entre as várias substâncias capazes de serem detectadas indiretamente, através do método utilizando o complexo EuTc, encontra-se também o colesterol, considerando-se que:

$$
\text { Colesterol }+\mathrm{O}_{2} \stackrel{\mathrm{COx}}{\rightarrow} \text { Colesterona }+\mathrm{H}_{2} \mathrm{O}_{2}
$$

\subsubsection{Colesterol total e suas frações}

O colesterol é uma substância complexa do tipo lipídio-esteróide. Na sua forma pura, é um sólido cristalino, branco e inodoro. O colesterol é um composto essencial para a vida, estando presente nos tecidos de todos os animais. Além de fazer parte da estrutura das membranas celulares, é também um reagente de partida para a biossíntese de vários hormônios ${ }^{86}$ (cortisol, aldosterona, testosterona, progesterona, estradiol), dos sais biliares e da vitamina D.

É obtido por meio de síntese celular (colesterol endógeno - 70\%) e da dieta (colesterol exógeno - 30\%). O excesso dele no sangue resulta da grande ingestão de colesterol e gorduras saturadas.

O colesterol endógeno é sintetizado pelo fígado, em um processo regulado por um sistema compensatório: quanto maior for a ingestão de colesterol vindo dos alimentos, menor é a quantidade sintetizada pelo fígado ${ }^{87}$.

Como é insolúvel em água (por possuir apenas um grupo hidroxila, sendo este a única parte polar da molécula) e, conseqüentemente, no sangue, para ser transportado na corrente sanguínea liga-se a algumas proteínas e outros lipídios através de ligações não-covalentes em um complexo chamado lipoproteína. 
Existem diferentes tipos de lipoproteínas, que são classificadas dependendo da sua densidade. Uma delas é a Lipoproteína de Baixa Densidade (LDL - Low-Density Lipoprotein), que é a principal carregadora de colesterol no plasma $^{88}$.

O LDL é o "mau" colesterol, estando associado com maior risco de doenças cardíacas, pois quando depositado na parede das artérias, dá início ao processo chamado aterosclerose (acúmulo de lipídios dentro e ao redor das células, que provocam o estreitamento do lúmem do vaso). Este fenômeno é responsável por 500.000 ataques cardíacos por ano ${ }^{89}$. As LDL representam $50 \%$ da massa total de lipoproteínas circulantes. São partículas bem pequenas, que mesmo quando em grande quantidade não são capazes de turvar o plasma. O colesterol representa metade da massa da LDL. Cerca de $25 \%$ são proteínas e o restante é constituído de fosfolipídios e triglicerídeos. É a lipoproteína que mais carrega colesterol. Tem a função de transportá-lo para locais onde ele exerce uma função fisiológica, como por exemplo a síntese de esteróides ${ }^{90}$. O colesterol LDL mantém uma relação direta com a prevalência de enfermidade coronariana, incluindo aterosclerose e hipertensão, entre outras ${ }^{91,92}$. Deste modo, valores elevados de colesterol LDL estão associados com risco aumentado dessas doenças. Pesquisas recentes suportam a idéia de que o LDL oxidado (OxLDL) pode ser um antígeno para a aterosclerose ${ }^{93}$. Além disso, as lipoproteínas oxidadas são capturadas pelos macrófagos $^{94,95}$.

A HDL (Lipoproteínas de Alta Densidade) é o colesterol "bom", pois altas concentrações no sangue estão associadas com um baixo risco de ataque cardíaco. As HDL são pequenas partículas constituídas por cerca de $50 \%$ de proteína, $20 \%$ de colesterol, $30 \%$ de triglicerídeos e traços de fosfolipídio, ajudando a remover o colesterol das células do organismo para o fígado, para ser reutilizado, convertido em ácidos biliares ou descartado na bile ${ }^{90}$.

Lipoproteínas de Muito Baixa Densidade - VLDL - são partículas grandes constituídas por $50 \%$ de triglicerídeos, $40 \%$ de colesterol e fosfolipídios e $10 \%$ de proteínas. Têm como função o transporte dos triglicerídeos endógenos e do colesterol, desde o fígado e, em menor quantidade, do intestino delgado para os tecidos periféricos para serem armazenados ou utilizados como fonte de energia ${ }^{90}$.

O excesso de colesterol no sangue é um dos principais riscos de desenvolvimento de doenças cardíacas, incluindo aterosclerose e hipertensão, 
entre outras ${ }^{91,92}$. De acordo com a American Heart Association, níveis normais de colesterol total sanguíneo encontram-se abaixo de $200 \mathrm{mg} / \mathrm{dL}$, enquanto que concentrações acima de $240 \mathrm{mg} / \mathrm{dL}$ são fatores de alto risco para doenças coronarianas $^{96}$. Por essas razões o colesterol se tornou um dos principais parâmetros a ser determinado em diagnóstico clínico de rotina. Vários esquemas têm sido propostos, na literatura, para a determinação de concentrações de colesterol $^{97,98,99,100}$.

Em geral, a determinação de colesterol é baseada em espectrofotometria, mas esse método requer procedimentos complicados e de alto custo, devido à utilização de enzimas caras em várias etapas do ensaio ${ }^{101}$. Hoje, o complexo európio-tetraciclina pode ser utilizado como biossensor de colesterol total ${ }^{12}$ e de suas lipoproteínas ${ }^{13}$.

\subsubsection{Peróxido de Uréia}

Peróxido de uréia (PHU), ou peróxido de carbamida, em seu nome obsoleto, é uma forma estável do $\mathrm{H}_{2} \mathrm{O}_{2}$ e um potencial agente citotóxico ${ }^{102}$. Problemas renais e cardíacos estão relacionados a níveis alterados de PHU no sangue ${ }^{103}$.

E assim como o HP, o PHU apresenta efeitos nocivos a várias células ${ }^{102}$, incluindo as do coração e as dos rins. Níveis renais e cardíacos de PHU são próximos da concentração de pentosidina da Reação Maillard ${ }^{103}$ e por essa razão é importante o controle de níveis de PHU no corpo. Sabendo-se que a insuficiência renal crônica está relacionada com o aumento do $\mathrm{PHU}$, e com o processo de glicoxidação da matriz renal e cardíaca, é possível administrar essas toxinas para retardar danos funcionais do coração e a destruição dos rins em pacientes em pré-diálises ou para melhorar os tratamentos pelo desenvolvimento de procedimentos mais efetivos para pacientes antes da diálise ${ }^{104}$.

A uréia ligada ao peróxido de hidrogênio dá origem ao peróxido de uréia. $A$ uréia é produzida primeiramente no fígado e secretada pelos rins e é o principal produto final do metabolismo animal. É o veículo preliminar para a remoção da amônia tóxica do corpo. A determinação da uréia é muito útil para que o médico 
avalie a função do rim dos pacientes. Em geral, aumentos no nível da uréia são associados a nefrite, isquemia renal, obstrução do aparelho urinário, e determinadas doenças extra renais, doenças de fígado e diabetes. Os níveis diminuídos indicam a insuficiência hepática aguda ${ }^{103}$.

Até agora a determinação de níveis de PHU era feito por métodos muito indiretos, com várias etapas e reagentes ${ }^{105}$. O EuTc pode ser um sensor para $\mathrm{PHU}^{11}$, tornando a determinação da concentração do peróxido em fluídos corpóreos, além de simplificada, precisa e rápida, também barata e direta. 


\section{METODOLOGIA}

Nesse capítulo serão abordados os materiais e os métodos adotados para a preparação das amostras e para as medidas realizadas. Toda a instrumentação utilizada encontra-se localizada no Centro de Lasers e Aplicações (CLA) no Instituto de Pesquisas Energéticas e Nucleares (IPEN)/USP, exceto o refratômetro de Abbé, o qual está locado na Faculdade de Tecnologia de São Paulo (FATEC$\mathrm{SP})$.

\subsection{SOLVENTES E REAGENTES}

> Cloridrato de Európio Hexahidratado

> Cloridrato de Tetraciclina

$>$ Ácido propanesulfônico 3 (N-Morpholino) - MOPs

$>$ Peróxido de Hidrogênio (HP)

$>$ Peróxido de Uréia (PHU)

$>$ Colesterol total

$>$ Colesterol Oxidase

$>$ LDL, VLDL, HDL

$>$ Glicose

$>$ Glicose Oxidase

$>$ Cloreto de Sódio

Todos os sais inorgânicos usados apresentavam pureza analítica e foram obtidos da Sigma Aldrich e Molecular Probe. Todas as soluções foram preparadas em 10 mmol.L ${ }^{-1}$ de ácido propanesulfônico 3 (N-Morpholino) - MOPs (da Carl Roth, Germany). A tetraciclina- $\mathrm{HCl}$ usada era padrão secundário obtido pela Indústria Farmacêutica Bunker Ltda. Usou-se peróxido de hidrogênio $30 \%$, da Lafan, Química Fina Ltda e como peróxido de uréia usou-se uma composição de $98 \%$ de peróxido de uréia, da Sigma. Os Kits enzimáticos da glicose e do colesterol foram gentilmente fornecidos pela LaborLab. 


\subsection{PROCEDIMENTO EXPERIMENTAL}

\subsubsection{Preparação das soluções}

Tomando-se os devidos cuidados com cada reagente (utilizando assim, luvas, avental, capela, etc), preparou-se as seguintes soluções:

Solução l: misturou-se 2,09 g de MOPs (Figura 4) a $1000 \mathrm{~mL}$ de água bideionizada e ajustou-se o pH para 6.9 adicionando $\mathrm{NaOH}$, pois a solução encontrava-se muito ácida pelo fato do MOPs ter $\mathrm{pH} 3,5$.

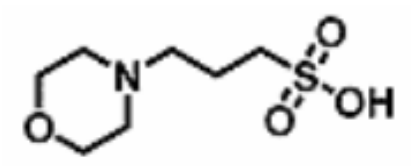

Figura 4 - MOPs

Fórmula: $\mathrm{C}_{4} \mathrm{H}_{8} \mathrm{ONC}_{3} \mathrm{H}_{6} \mathrm{SO}_{3} \mathrm{H}$

Solução II: variação da concentração de $\mathrm{Eu}^{3+}$

a) $21 \mu \mathrm{mol} . \mathrm{L}^{-1}$ solução de $\mathrm{Eu}^{3+} ; 0,79 \mathrm{mg}$ de $\mathrm{EuCl}_{3} \cdot 6 \mathrm{H}_{2} \mathrm{O}$ em $10 \mathrm{~mL}$ solução I.

b) $31,5 \mu \mathrm{mol} . \mathrm{L}^{-1}$ solução de $\mathrm{Eu}^{3+} ; 1,16 \mathrm{mg}$ de $\mathrm{EuCl}_{3} \cdot 6 \mathrm{H}_{2} \mathrm{O}$ em $10 \mathrm{~mL}$ solução I.

c) $42 \mu \mathrm{mol} . \mathrm{L}^{-1}$ solução de $\mathrm{Eu}^{3+} ; 1,50 \mathrm{mg}$ de $\mathrm{EuCl}_{3} \cdot 6 \mathrm{H}_{2} \mathrm{O}$ em $10 \mathrm{~mL}$ solução I.

d) $52,5 \mu \mathrm{mol} . \mathrm{L}^{-1}$ solução de $\mathrm{Eu}^{3+} ; 1,98 \mathrm{mg}$ de $\mathrm{EuCl}_{3} \cdot 6 \mathrm{H}_{2} \mathrm{O}$ em $10 \mathrm{~mL}$ solução I.

e) $63 \mu \mathrm{mol} . \mathrm{L}^{-1}$ solução de $\mathrm{Eu}^{3+} ; 2,29 \mathrm{mg}$ de $\mathrm{EuCl}_{3} \cdot 6 \mathrm{H}_{2} \mathrm{O}$ em $10 \mathrm{~mL}$ solução I.

f) $73,5 \mu \mathrm{mol} . \mathrm{L}^{-1}$ solução de $\mathrm{Eu}^{3+} ; 2,71 \mathrm{mg}$ de $\mathrm{EuCl}_{3} \cdot 6 \mathrm{H}_{2} \mathrm{O}$ em $10 \mathrm{~mL}$ solução I.

g) $84 \mu \mathrm{mol} . \mathrm{L}^{-1}$ solução de $\mathrm{Eu}^{3+} ; 3,10 \mathrm{mg}$ de $\mathrm{EuCl}_{3} \cdot 6 \mathrm{H}_{2} \mathrm{O}$ em $10 \mathrm{~mL}$ solução I.

Solução III: $21 \mu \mathrm{mol} . \mathrm{L}^{-1}$ de cloridrato de tetraciclina em $10 \mathrm{~mL}$ da solução I.

Solução IV: solução EuTc, que corresponde à mistura da solução II e da solução III, completada com MOPs a um volume de $100 \mathrm{~mL}$.

Solução V: HP diluído: $1 \mathrm{~mL}$ de HP puro diluído em $10 \mathrm{~mL}$ de água destilada (solução A). 
$50 \mu \mathrm{L}$ da solução A diluídos em $100 \mathrm{~mL}$ de água destilada.

Solução VI: PHU diluído: 0,001g de peróxido de uréia diluído em $100 \mathrm{~mL}$ de água destilada.

Solução VII: $1 \mathrm{~mL}$ de EuTc acrescida de variadas concentrações de HP (solução V) ou PHU (solução VI), conservando-se um volume fixo (completado com a solução MOPs).

Solução VIII: EuTc-Colesterol $-1 \mathrm{~mL}$ da solução IV com $x \mu \mathrm{L}(x=10,20,30,40$, $50,60,70,80,90,100)$ da solução de colesterol $(200 \mathrm{mg} / \mathrm{dL})$.

Solução IX: EuTc:LDL e EuTc:OxLDL - $1 \mathrm{~mL}$ da solução IV com $10 \mu \mathrm{L}$ LDL $(0,7$; 1,5; 3,0; 5,6 e 7,7 mg/mL) ou OxLDL (0,7; 1,5 e 3,0 mg/mL). E EuTc:HDL e EuTc: VLDL.

Solução X: EuTc-Glicose $-1 \mathrm{~mL}$ da solução IV com $x \mu \mathrm{L}(x=10,20,40,100,150$, 200 e 250$)$ da solução de Glicose (100 mg/dL), acrescentando-se MOPs para completar o volume total da solução em $1,5 \mathrm{~mL}$.

Solução XI: EuTc-Glicose-GOx - Solução IX acrescida de $5 \mu \mathrm{L}$ de GOx.

Foram preparadas seis soluções contendo $1 \mathrm{~mL}$ de EuTc e $5 \mu \mathrm{L}$ de GOx cada, e variadas concentrações de glicose $(10,30,50,70$ e $100 \mu \mathrm{L})$, fixando o volume total em 1,15 mL (adicionando-se MOPs, quando necessário).

\subsubsection{Obtenção das lipoproteínas}

As amostras foram gentilmente fornecidas pelo Dr. Magnus A. Gidlund e o procedimento foi realizado por sua aluna Andréa M. Monteiro do Instituto de Ciências Biomédicas da Universidade de São Paulo (ICB-USP). Coletou-se sangue de doadores voluntários saudáveis normolipidêmicos em jejum (12h). $\mathrm{O}$ plasma foi obtido após centrifugação a $103 \mathrm{~g}$, a $4^{\circ} \mathrm{C}$, por 15 minutos. Depois disso 
foi adicionado, ao plasma, benzamidine $(2 \mathrm{mM})$, gentamicina $(0.5 \%)$, cloranfenicol $(0.25 \%)$, PMSF (fenil-metil-sulfonil-fluoreto) $(0.5 \mathrm{mM})$, e aprotinina $(0.1 \mathrm{unid} / \mathrm{mL})$. As lipoproteínas do plasma foram então isoladas por ultracentrifugação seqüencial. Para isolamento seqüencial a densidade do plasma foi ajustada para VLDL $d<1,006 \mathrm{~g} / \mathrm{mL}$, LDL $d=1.030-1.063 \mathrm{~g} / \mathrm{mL}$ e HDL $d=1.063-1.21 \mathrm{~g} / \mathrm{mL}$ e então centrifugado a $105 \mathrm{~g}$, à $4^{\circ} \mathrm{C}$, por 20 horas, usando rotor $75 \mathrm{Ti}$ (Beckman Instruments). Imediatamente após a obtenção, as lipoproteínas foram dialisadas durante 48h (PBS-EDTA 0,01\%) e filtradas $\left(0,22 \mu \mathrm{m}\right.$ de diâmetro, Millipore $\left.{ }^{\circledR}\right)$. A concentração de proteínas foi quantificada utilizando o kit BCA (PIERCE) de acordo com as instruções do fabricante.

Oxidação das lipoproteínas por íons cobre: As amostras também foram gentilmente fornecidas pelo Dr. Magnus A. Gidlund e o procedimento foi realizado por sua aluna Andréa $M$. Monteiro do Instituto de Ciências Biomédicas da Universidade de São Paulo (ICB-USP). Para obtenção de LDL oxidada por íons cobre (OxLDL), a lipoproteína foi dialisada de um dia para o outro em PBS, sem EDTA, seguida de incubação com $\mathrm{CuSO}_{4}, 20 \mathrm{mM} / \mathrm{mg}$ de proteína da $\mathrm{LDL}$, à $37^{\circ} \mathrm{C}$, de um dia para o outro. Obteve-se uma completa oxidação das lipoproteínas definida por uma fase platô, medida pelo ensaio de TBARS. O processo de oxidação foi finalizado pela adição de 1 mM de EDTA.

\subsubsection{Obtenção dos espectros de absorção}

Os espectros de absorção de todas as amostras foram medidos em temperatura ambiente na escala de $200 \mathrm{~nm}$ - 2200nm usando um espectrômetro Varian Spectrometer Cary $17 \mathrm{D}$.

\subsubsection{Obtenção dos espectros de emissão}

Os espectros de emissão foram obtidos excitando as amostras com uma lâmpada Xenônio de 300 Watts. As emissões das amostras foram analisadas com 
um primeiro monocromador de 0,25 $\mathrm{m}$ (Jarrel-Ash) e um segundo monocromador Spex de 0,5 m, fixando-se, nesse caso, o primeiro monocromador em $405 \mathrm{~nm}$ e variando o segundo. A detecção do sinal foi realizada com uma fotomultiplicadora EMI de catodo S-20. O sinal foi amplificado com um EG\&G 7220 lock-in, que se utiliza da mesma freqüência do modulador para que sinais externos como, por exemplo luz ambiente, não sejam detectados, e, então, processado por um computador.

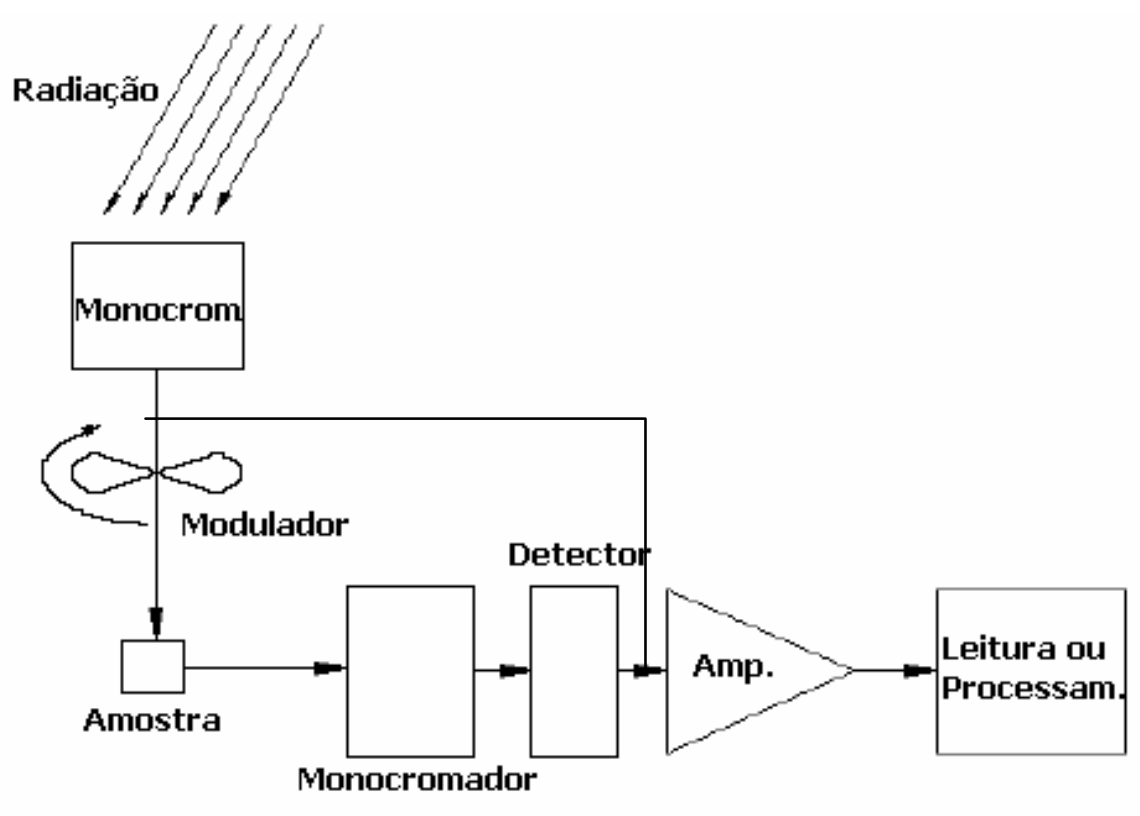

Figura 5 - Diagrama de montagem para medidas de emissão.

Algumas medidas de emissão foram realizadas à temperatura ambiente, no espectrômetro de fibra da Newport, série OSM, com visor LCD, utilizando como fonte de excitação um LED violeta.

Para as medidas de emissão as soluções foram colocadas em uma cubeta de caminho óptica de $1 \mathrm{~mm}$. A luz de excitação foi sempre focalizada fora do centro da cubeta e próxima a sua borda e a luz emitida foi sempre coletada a 90 graus com a excitação.

\subsubsection{Variação da temperatura}


Para a variação da temperatura utilizou-se o equipamento Thermolyne, tipo 17600 Banho Seco, agregando a ele, um termômetro para a marcação da temperatura, a qual variou de $22^{\circ} \mathrm{C}$ (temperatura ambiente) a $85^{\circ} \mathrm{C}$.

\subsubsection{Obtenção do tempo de vida}

Para determinar os tempos de vida foi usado um sistema de excitação que consiste em um oscilador paramétrico óptico ajustável (OPO de OPOTEK) bombeado pelo segundo e terceiro harmônicos de um laser Nd-YAG Q-switched da Quantel. Este sistema laser entrega pulsos de $20 \mathrm{~mJ}$ com duração de tempo de 4 ns e taxa da repetição de $10 \mathrm{~Hz}$, e pode ser ajustado de 0,41 $\mu \mathrm{m}$ a 2,0 $\mu \mathrm{m}$. Os tempos de vida da luminescência dos lantanídeos foram detectados por uma fotomultiplicadora S-20 e analisados usando um signal-processing boxcar averager (PAR 4402), e osciloscópio digital de $200 \mathrm{MHz}$ Tektronix TDS 410. Os erros relativos nas medidas da emissão foram estimados $<5 \%$ enquanto que os erros nas medidas do tempo de vida são $<10 \%$.

\subsubsection{Obtenção do índice de refração}

No refratômetro de Abbé (Figura 6) se mediu o ângulo limite de reflexão total. Os principais componentes do aparelho são o prisma de medição, que trabalha em uma faixa de índice (para o equipamento de laboratório de 1,300 < n $<1,700)$, a objetiva de focalização e o círculo graduado de cristal com microscópio de leitura. 

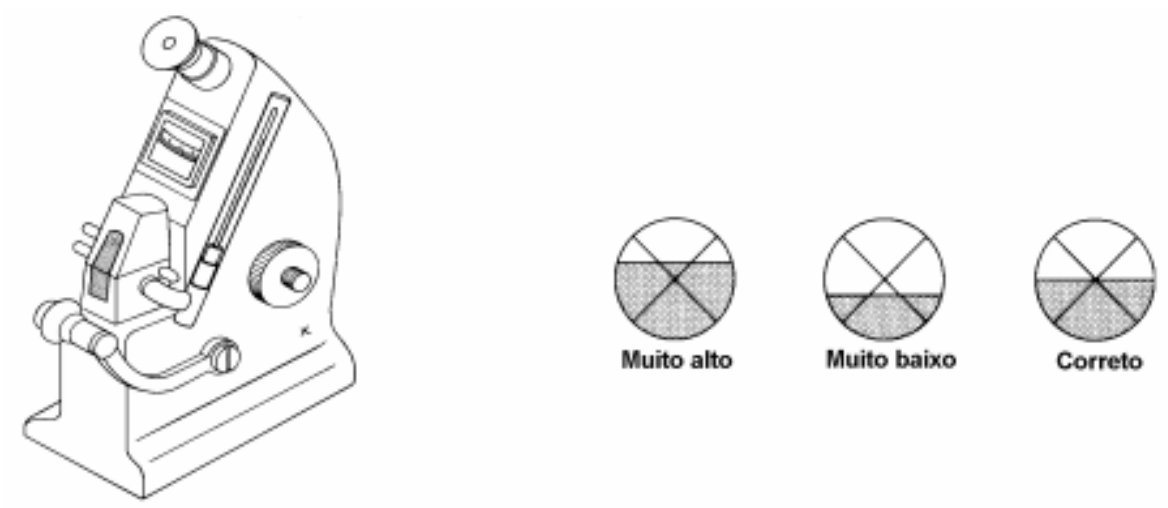

Figura 6 - Refratômetro de Abbé, e visão da amostra através das lentes do refratômetro.

Na medida por transmissão, a luz passa através da amostra sobre a face medidora do prisma de medição. Parte da luz incide rasante $(\lambda=589,26 \mathrm{~nm}$ ) chega a se refletir abaixo do ângulo limite da reflexão total e se observa na ocular como uma linha limite entre o campo escuro e claro.

\subsection{ESQUEMA DO PROTÓTIPO DO EQUIPAMENTO}

\subsubsection{Fonte de excitação}

- LED violeta

Foi montado o circuito para o LED, com a resistência, o potenciômetro e a fonte estabilizada, para serem efetuados os testes preliminares.

Para os testes com o LED, que são mostrados a seguir, nos resultados, foi utilizado um espectrômetro de fibra da Newport, que permite resultados rápidos e sensíveis.

\subsubsection{Detector}

- Sensor óptico 
Como detector foi escolhido um sensor óptico conversor de luz em tensão (TSL251R-LF): que é composto por um fotodiodo com amplificador de transimpedância em silício monolítico.

A tensão de saída é diretamente proporcional à intensidade de luz no sensor óptico.

Na Figura 7 é representada a vista frontal do sensor óptico, onde GND é o terminal Terra, OUT é a voltagem de saída e VDD a voltagem de alimentação.

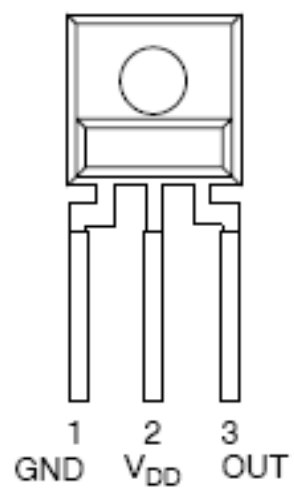

Figura 7 - Visualização frontal do sensor óptico.

Na Figura 8 é mostrado o gráfico da resposta espectral do sensor óptico, comprovando que ele abrange a região do comprimento de onda utilizado nesse estudo, justificando por tanto sua escolha.

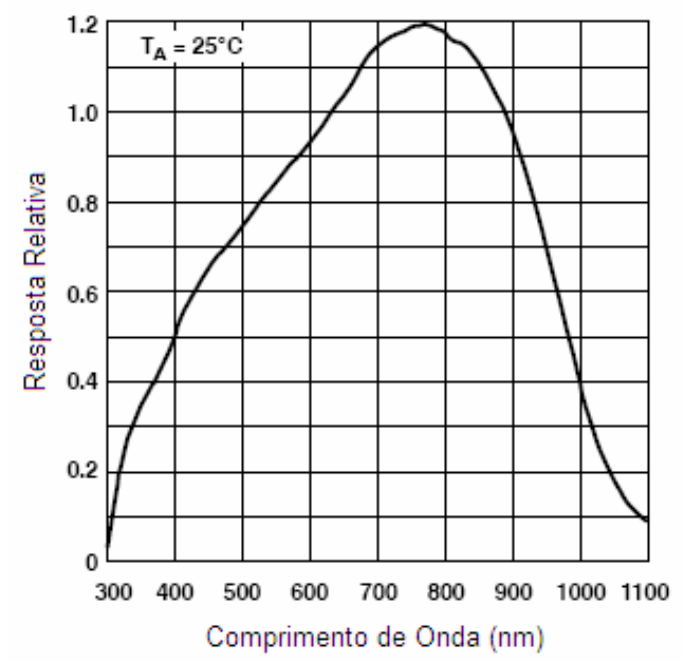

Figura 8 - Resposta espectral do sensor óptico. 
Para testar se o detector escolhido apresentava a sensibilidade necessária para captar o sinal emitido pela amostra, foi construído um circuito com uma bateria de $9 \mathrm{~V}$ e um regulador de tensão, para a tensão no fotodiodo ser sempre de 5V, e utilizando-se do conversor USB 6009 da National Instruments os sinais de tensão detectados pelo fotodiodo são transmitidos ao notebook e analisados através do software LabView.

\subsubsection{Protótipo do equipamento}

Abaixo (Figura 9) é apresentado o esquema do protótipo do equipamento, para a medida da intensidade do sinal emitido.

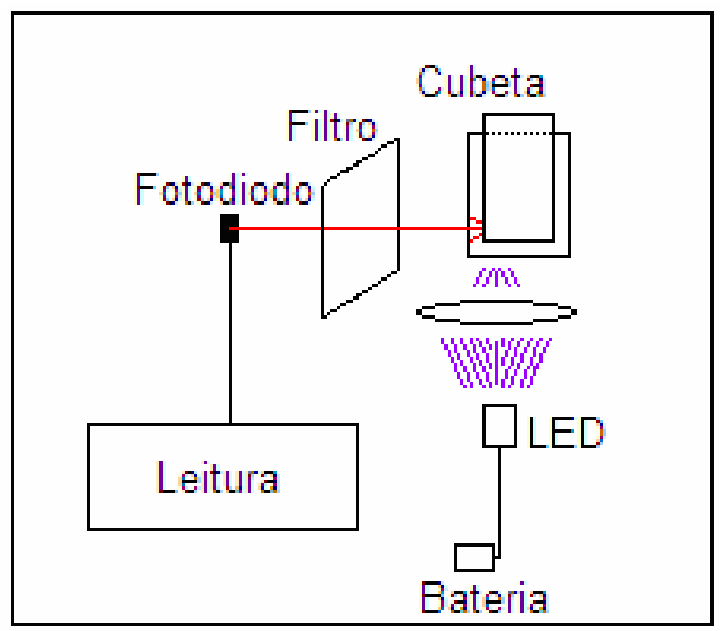

Figura 9 - Esquema do protótipo do equipamento de medida da intensidade do sinal emitido.

O filtro utilizado foi um filtro de banda passante (Oriel, 10BPF10-610) em $610 \pm 2 \mathrm{~nm}$, com largura de banda de $10 \mathrm{~nm}$. 


\section{RESULTADOS E DISCUSSÕES}

Uma caracterização do complexo EuTc, tanto sozinho quanto na presença de peróxido de hidrogênio (EUTc-HP), peróxido de uréia (EuTc-PHU), colesterol (EuTc-Colesterol), LDL (EuTc:LDL), HDL (EuTc:HDL), VLDL (EuTc:VLDL) e glicose (EuTc-Glicose), foi realizada através do estudo da absorção e emissão dos reagentes, variação das concentrações, do tempo de reação e da ordem de preparação das soluções, e é mostrada a seguir:

\subsection{CARACTERIZAÇÕES DO COMPLEXO}

\subsubsection{Absorção}

A absorção óptica das soluções I a V, de 200 - 2200 nm, (Figura 10) mostra que o MOPs não apresenta absorção, comprovando a pureza do sal. O MOPs é utilizado uma vez que uma solução tampão é necessária para que o $\mathrm{pH}$ da solução permaneça constante independente da reação que houver entre os reagentes (liberação ou consumo de $\mathrm{H}^{+}$). É necessário que seja um sal que não interfira no resultado do composto, reagindo com o európio e/ou a tetraciclina, por exemplo. Isso torna a calibração reprodutível.

O íon európio apresenta baixo coeficiente de absorção, resultado das transições proibidas f-f e alta probabilidade de relaxação não radiativa devido à interação dos níveis eletrônicos do íon com os modos vibracionais do solvente ${ }^{28}$, por isso não se verifica nenhuma banda de absorção no espectro correspondente ao íon európio.

A tetraciclina apresenta bandas largas de absorção, em 247, 274 e 358 nm. $\mathrm{Na}$ presença do íon európio um deslocamento para maiores comprimentos de onda é observado para a segunda e terceira ( $400 \mathrm{~nm}$ ) bandas, e um 
deslocamento da primeira banda para aproximadamente $230 \mathrm{~nm}$, demonstrando que efetivamente a complexação ocorre.

As bandas, em todos os espectros, em torno de $1450 \mathrm{~nm}$ e $1950 \mathrm{~nm}$, referem-se à absorção da água ${ }^{106}$.

O espectro do peróxido de hidrogênio também é mostrado e as únicas alterações em relação à absorção da água é uma segunda banda em aproximadamente 2000 nm e a verificação da absorção do HP na região abaixo de $350 \mathrm{~nm}$.

Essas observações podem ser melhor vistas na ampliação da região de absorção entre 200 e 500 nm, plotada na Figura 11.

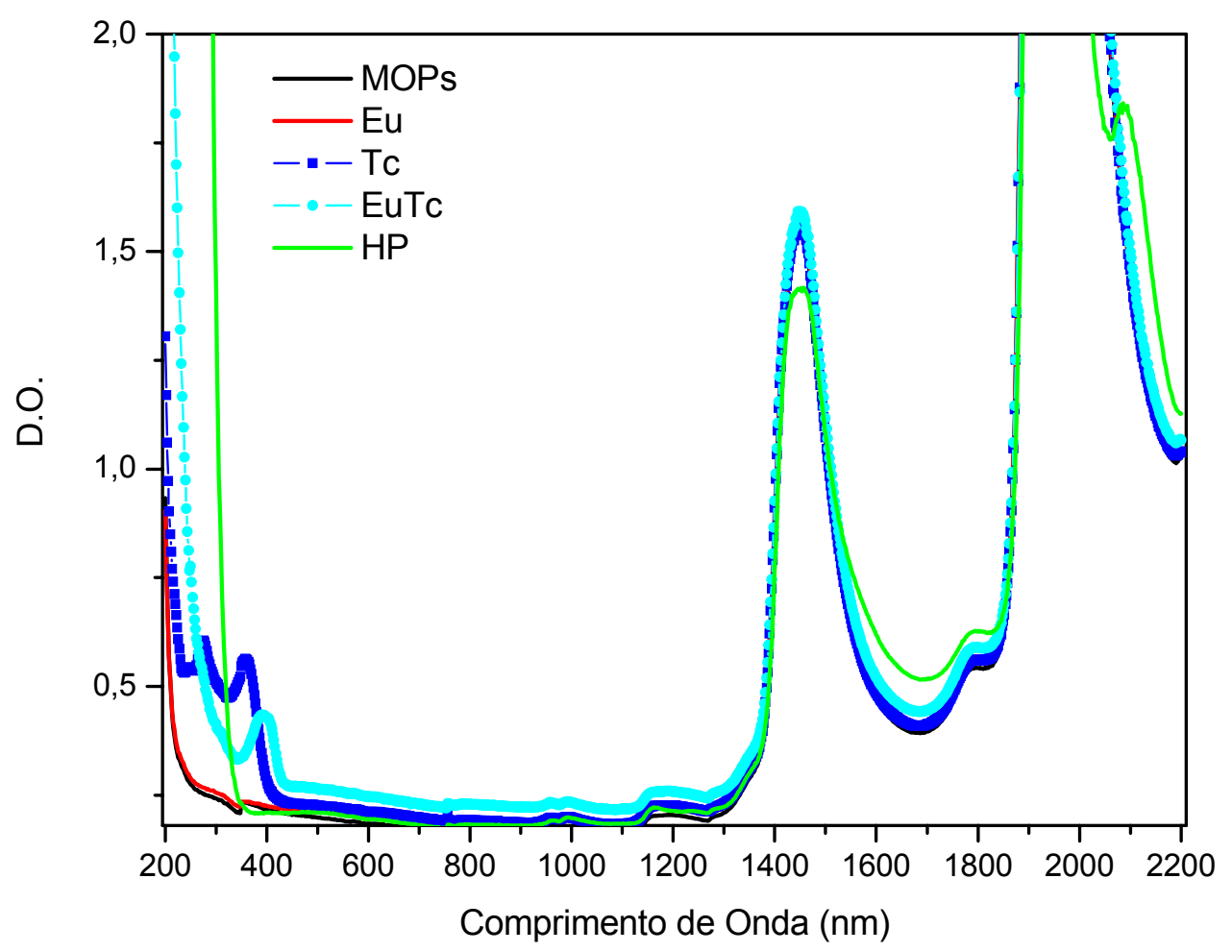

Figura 10 - Absorção óptica de todos os reagentes utilizados no complexo - MOPs, Eu, Tc, EuTc e HP.

A seguir, na Figura 12, é possível observar que a tetraciclina, sem o európio, em solução, não é estável e possivelmente sofre uma oxidação gradativa, que é identificada também pela alteração na coloração da solução com o passar dos dias. 


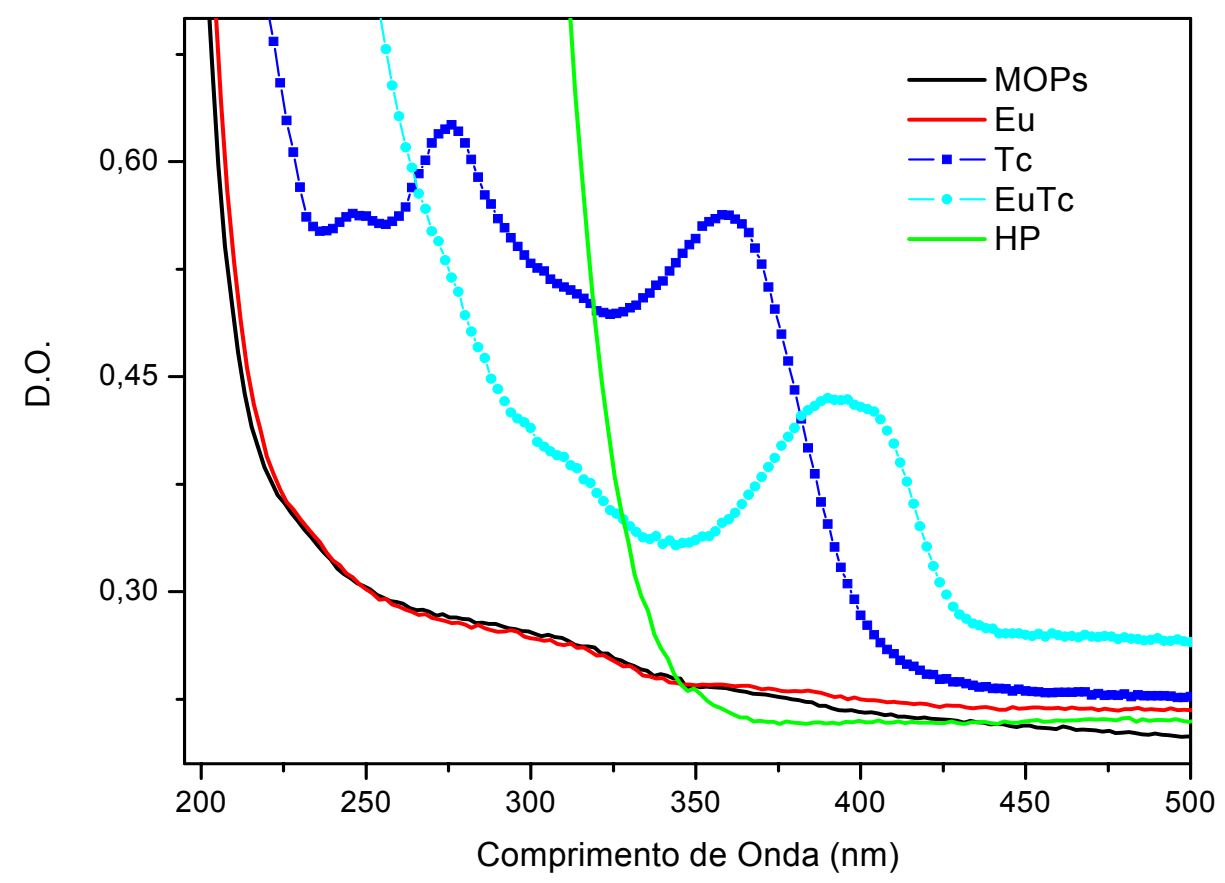

Figura 11 - Ampliação da região de absorção de 200 a 500nm, da Figura 10.

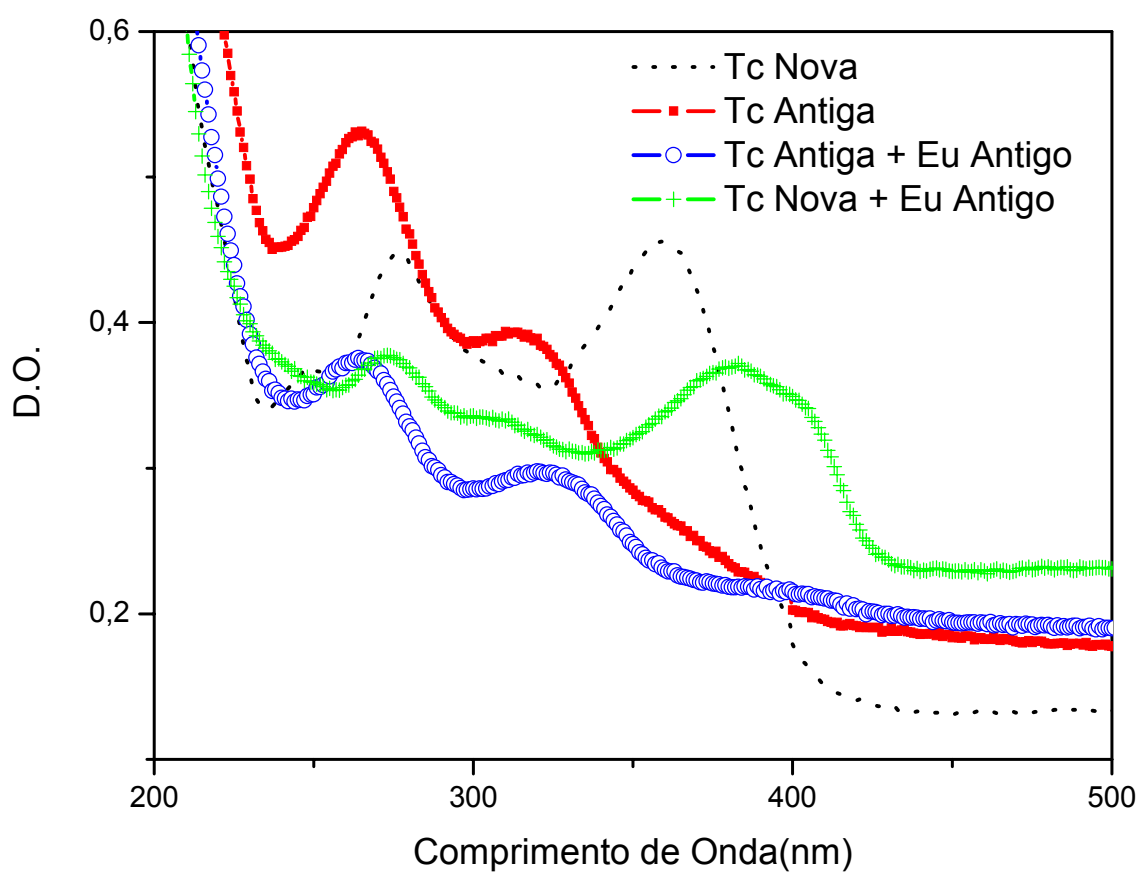

Figura 12 - Absorção óptica da solução de tetraciclina com e sem európio. Tc Nova representa a solução de tetraciclina que fora preparada no mesmo dia da medida e Tc Antiga, a solução preparada cinco meses antes. Eu Antigo é a solução de európio em MOPs preparado também há cinco meses. 
A banda em 358 nm (Tc Nova) apresenta uma significante diminuição da intensidade e no comprimento de onda, deslocando-se para $315 \mathrm{~nm}$ (Tc Antiga). Quando se adiciona a solução de európio à solução Tc Nova, ocorre a complexação e há o deslocamento para 400 nm, já com a Tc Antiga há um deslocamento da banda de $315 \mathrm{~nm}$ para $325 \mathrm{~nm}$.

A solução EuTc é estável por vários meses.

\subsubsection{Emissão}

A tetraciclina, em MOPs, emite luz em torno de $520 \mathrm{~nm}$, ou seja, $19.230 \mathrm{~cm}^{-1}$, quando excitada em 360 nm, como pode ser visto na Figura 13.

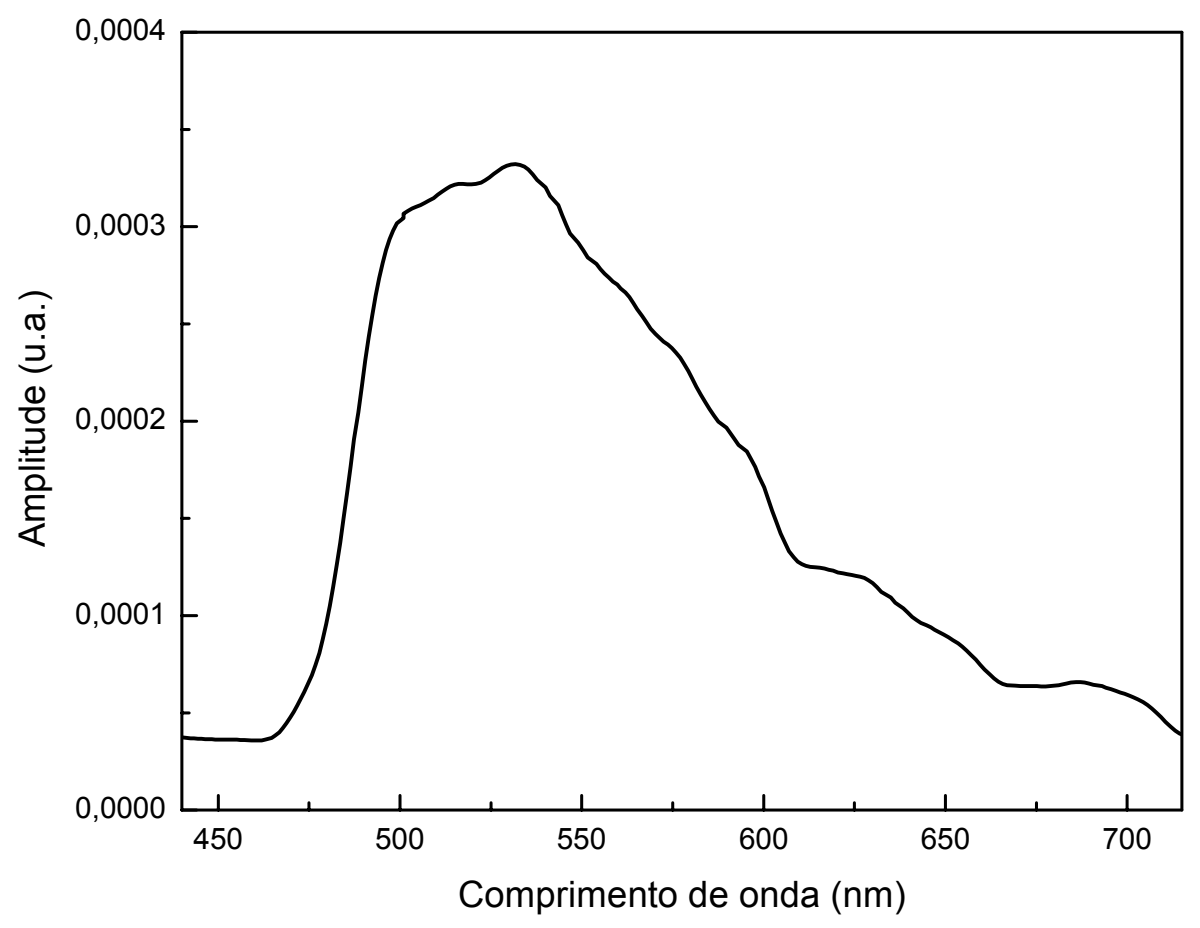

Figura 13 - Emissão da tetraciclina excitada em torno de $360 \mathrm{~nm}$. 
Porém, quando a tetraciclina está complexando o európio, a energia absorvida pelo quelante é transferida ao íon lantanídeo que emite esta radiação com suas características próprias (Figura 14).

A intensidade de luminescência do európio, cujos níveis de energia são mostrados na Figura 1, origina-se da transferência de energia intramolecular através do estado excitado da tetraciclina ao nível de emissão do $\mathrm{Eu}^{3+}$. Como o európio tem seu nível de emissão, ${ }^{5} \mathrm{D}_{0}$, na mesma faixa de energia em que ocorre a emissão da tetraciclina $\left(19.230 \mathrm{~cm}^{-1}\right)$, isso significa que a absorção do $\mathrm{Eu}^{3+}$ tem muita ressonância com a emissão da Tc; por outro lado o próximo nível de energia do európio, ${ }^{7} F_{6}$, está distante o suficiente para que haja uma grande probabilidade da energia ser emitida em forma de fóton, ou seja, ocorrer uma transição radiativa.

A transição do európio com maior intensidade, ${ }^{5} \mathrm{D}_{0} \rightarrow{ }^{7} \mathrm{~F}_{2}$, apresenta energia de aproximadamente $16.210 \mathrm{~cm}^{-1}(617 \mathrm{~nm})$, ou seja, menor que a da Tc, permitindo assim a ocorrência da conversão interna na molécula para a posterior transferência de energia através do cruzamento intersistemas.

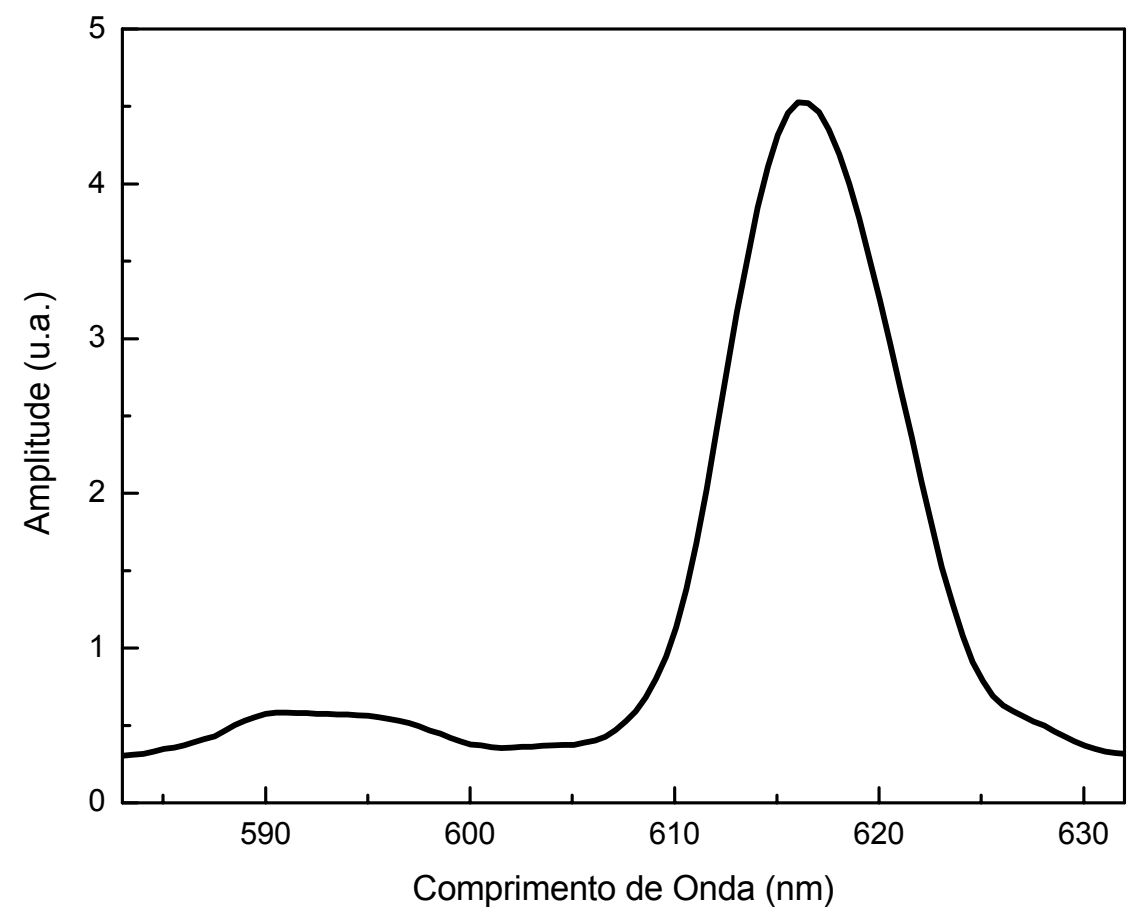

Figura 14 - Emissão do complexo EuTc, quando excitado em 405 nm. 


\subsubsection{Variação do pH}

Como já é sabido a complexação do íon à Tc depende do $\mathrm{pH}$ da solução ${ }^{4}$. Afim de se verificar qual o melhor $\mathrm{pH}$, foi realizado um estudo onde se adicionou volumes controlados de $\mathrm{NaOH}$ à solução IV e obteve-se a medida de fluorescência (Figura 15) a cada variação.

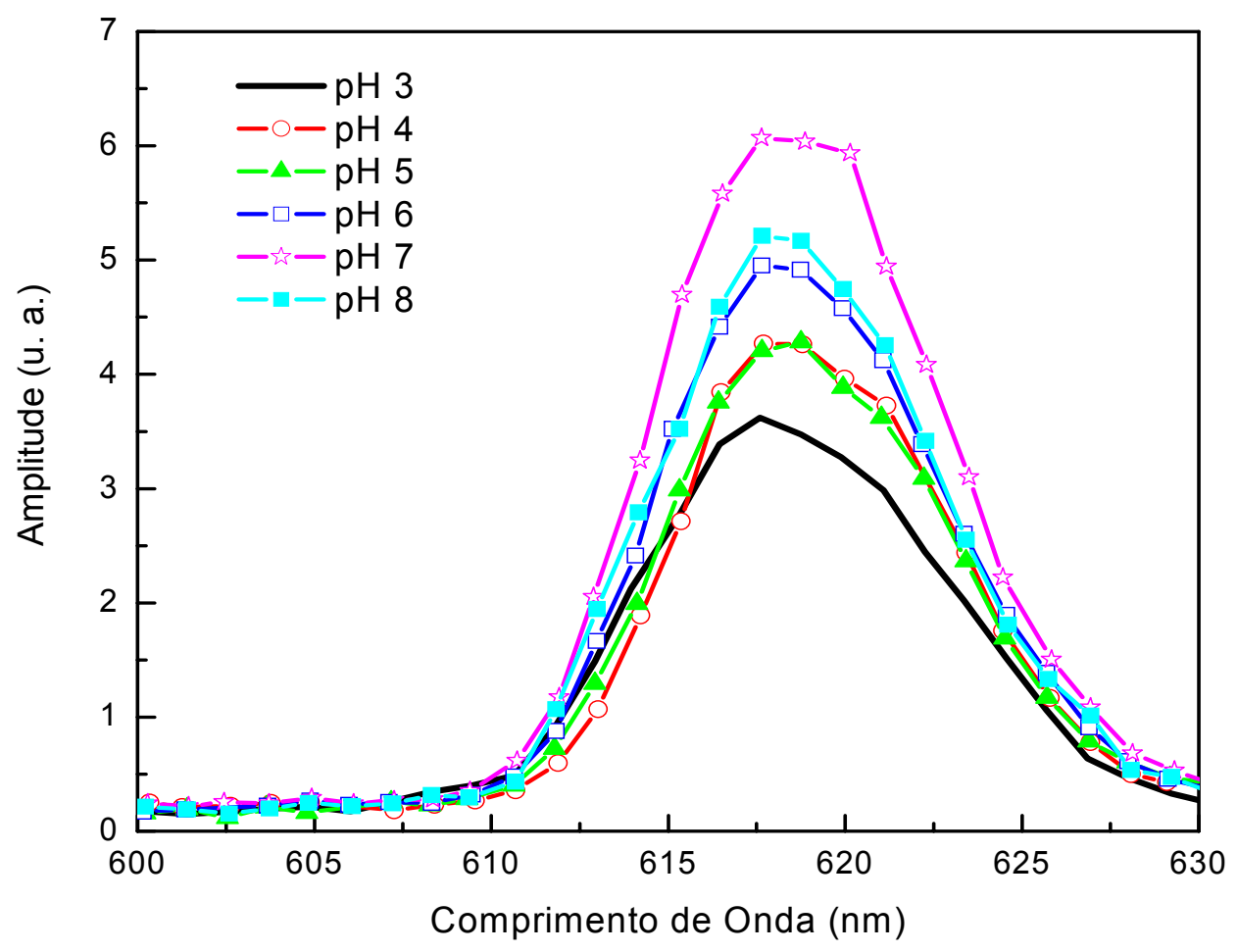

Figura 15 - Efeitos do pH na intensidade de emissão dos complexos EuTc. Cada ponto representa uma adição de $0,1 \mathrm{~mL}$ de solução alcalina na anterior.

A deprotonação da tetraciclina com a variação do $\mathrm{pH}$ aumenta a capacidade de complexação do európio à molécula ${ }^{41}$.

$\mathrm{Em} \mathrm{pH}>7,5$ ocorre a precipitação de $\mathrm{Eu}(\mathrm{OH})_{3}$ ocasionando uma diminuição na luminescência ${ }^{41}$.

O melhor pH é o neutro, o que facilita a utilização do complexo em análises clínicas. 


\subsubsection{Tempo de vida}

Assim como pela absorção e emissão, o complexo EuTc também pode ser estudado a partir do seu tempo de vida, ou seja, o tempo que o sistema demora para retornar ao estado fundamental, quando excitado.

O tempo de decaimento da amostra EuTc é mostrado na Figura 16. Geralmente sistemas complexos podem apresentar múltiplas espécies fluorescentes, e sendo assim, o perfil de decaimento da intensidade de fluorescência não pode ser ajustado por uma função exponencial simples. Dessa forma, foi ajustado por uma exponencial dupla com a eq. (4), onde o eixo y representa a intensidade do sinal (u.a.) e o eixo $x$ representa o tempo ( $\mu$ s), $\tau_{1}$ e $\tau_{2}$ são os tempos de decaimento e $A_{1}$ e $A_{2}$ são as amplitudes do sinal ${ }^{10}$.

$$
y=A_{1} e^{\left(\frac{-x}{\tau_{1}}\right)}+A_{2} e^{\left(\frac{-x}{\tau_{2}}\right)}
$$

No caso de decaimentos com múltiplas exponenciais, a média do tempo de vida $\left(\tau_{a v}\right)$, que é proporcional a área total abaixo da curva de decaimento da fluorescência ${ }^{10}$, é definida por:

$$
\tau_{a v}=\frac{\sum_{i} \mathrm{~A}_{i} \tau_{i}^{2}}{\sum_{i} \mathrm{~A}_{i} \tau_{i}}
$$

Os parâmetros obtidos no ajuste são apresentados na Tabela 3.

Tabela 3 - Parâmetros do ajuste das eq. (4) e eq. (5) para os dados experimentais da Figura 16.

\begin{tabular}{ccccccc}
\hline Complexo & & Parâmetros & Erros $( \pm)$ & Amplitude(\%) & $\tau_{\text {av }}(\mu \mathrm{s})$ \\
& & & & & \\
& $\mathrm{A}_{1}$ & 216.57996 & 15.0014 & $(17.7 \%)$ & $\mathrm{Chi}^{\wedge} 2$ & \\
\multirow{2}{*}{ EuTc } & $\tau_{1}$ & $3.48728 \mathrm{E}-6$ & $3.9547 \mathrm{E}-7$ & & 235.86443 & \\
& $\mathrm{~A}_{2}$ & 1006.3940 & 14.5471 & $(82.3 \%)$ & $\mathrm{R}^{\wedge} 2$ & 20,85 \\
& $\tau_{2}$ & $2.08547 \mathrm{E}-5$ & $2.3851 \mathrm{E}-7$ & & 0.99666 & \\
\hline
\end{tabular}




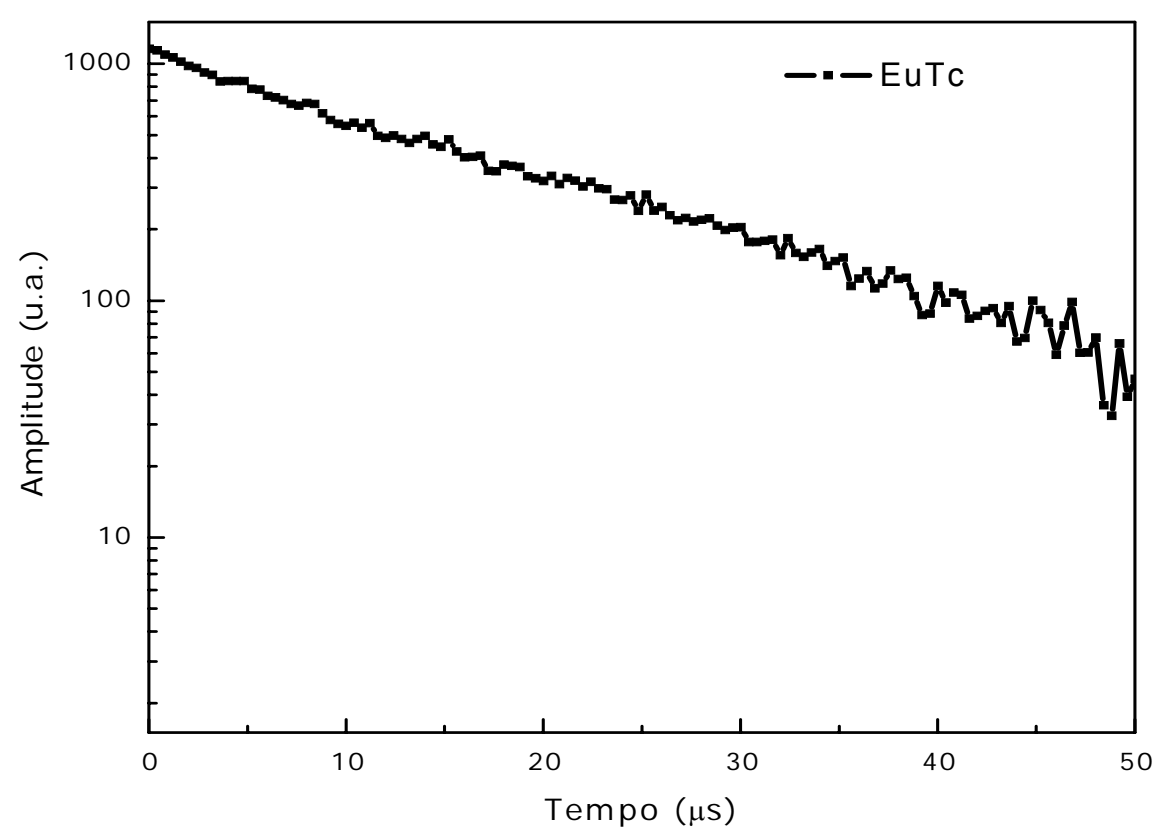

Figura 16 - Perfil do tempo de vida da emissão do Eu no complexo EuTc.

\subsubsection{Variação da concentração de európio na solução}

Para a determinação da melhor concentração de európio para a formação do complexo EuTc foram preparadas 7 soluções EuTc, com variadas concentrações micro-molares de európio: $1 ; 1,5 ; 2 ; 2,5 ; 3 ; 3,5$ e 4 , para uma concentração fixa de $1 \mu \mathrm{mol}$ de tetraciclina.

Na Figura 17, o espectro de absorção dessas soluções, mostra que não há alterações apreciáveis, exceto um pequeno deslocamento da banda dos $400 \mathrm{~nm}$ para comprimentos de ondas maiores, uma divisão da segunda banda nas soluções que contêm concentrações de európio entre $1-2,5 \mu \mathrm{mol}$ para $1 \mu \mathrm{mol}$ de Tc, mas quando temos concentração acima de $3 \mu \mathrm{mol}$ de $\mathrm{Eu}^{3+}$ há somente uma banda larga, e o aumento da intensidade da banda em torno dos $230 \mathrm{~nm}$. O deslocamento da segunda banda sugere a complexação no anel $A$ e o deslocamento da terceira banda para comprimentos de onda mais longos sugere a complexação do cromóforo BCD ( $\beta$ dicetonatos $)^{41}$. 


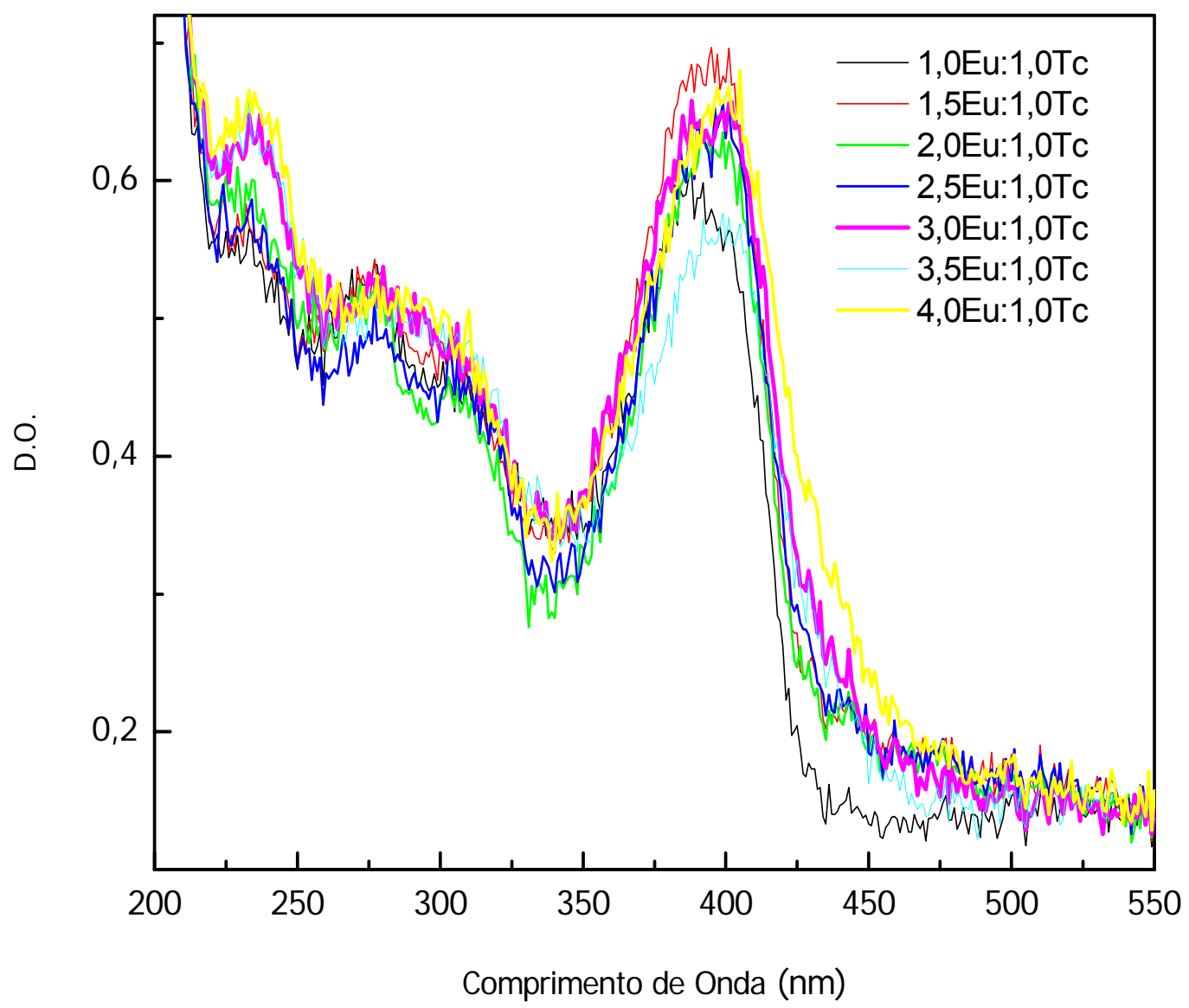

Figura 17 - Absorção óptica do complexo EuTc, para variadas concentrações de európio (1:1; $1,5: 1 ; 2: 1 ; 2,5: 1 ; 3: 1 ; 3,5: 1$ e $4: 1)$.

Continuando o estudo da melhor concentração de európio em relação à tetraciclina, excitou-se as amostras com uma lâmpada Xenônio e um monocromador em $405 \mathrm{~nm}$. Na Figura 18 é apresentado o espectro de emissão das soluções com relação molar do Eu:Tc de 1:1; 1,5:1; 2:1; 2,5:1; 3:1; 3,5:1 e 4:1. Como pode-se observar, a composição estequiométrica que apresentou maior intensidade no espectro de emissão é 1:1. Isto está de acordo com o estudo de outros autores ${ }^{107}$. 


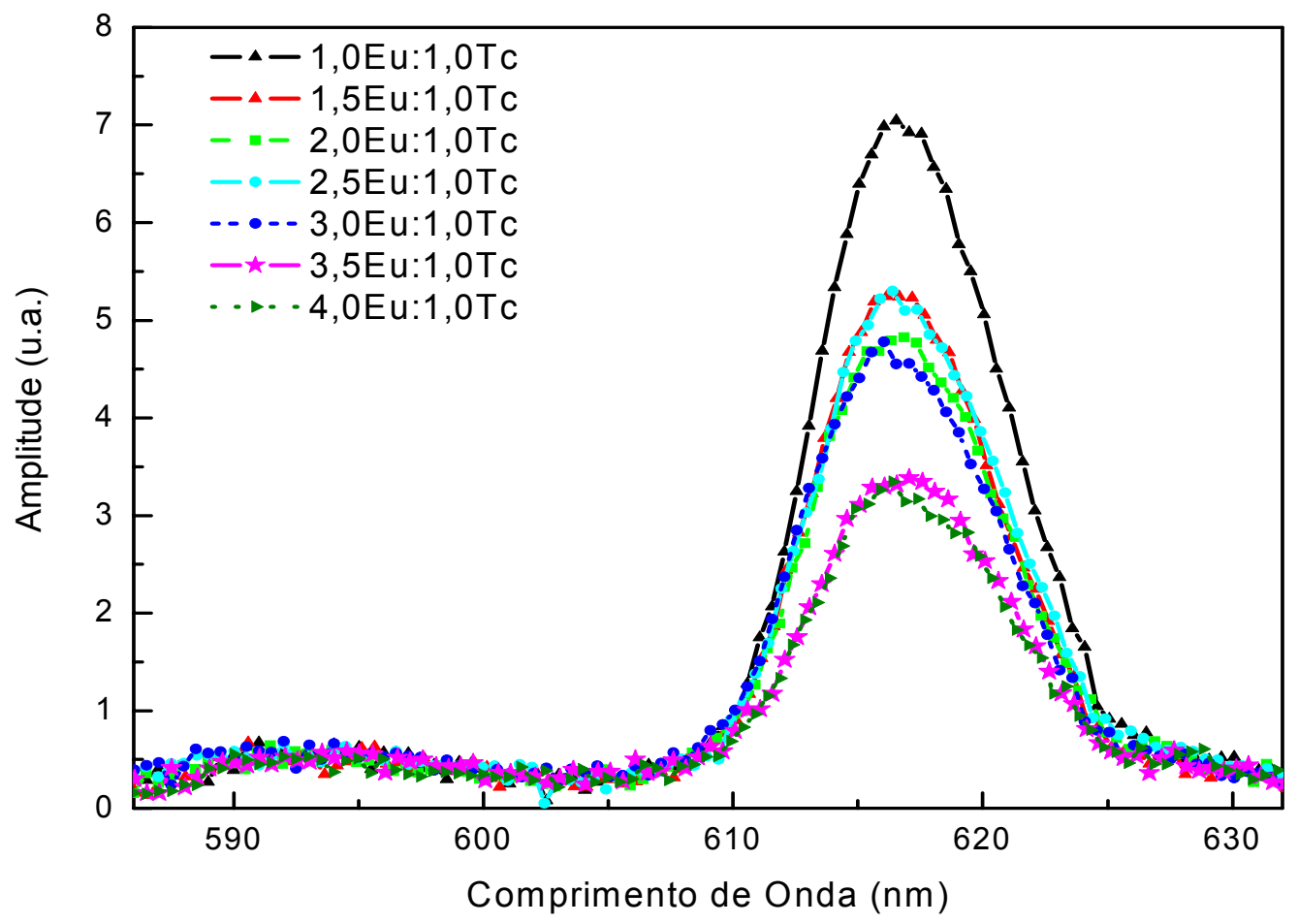

Figura 18 - Espectro de emissão obtido excitando em $405 \mathrm{~nm}$ as amostras com diferentes concentrações molares de Eu no complexo Eu:Tc $(1: 1 ; 1,5: 1 ; 2: 1 ; 2,5: 1 ; 3: 1 ; 3,5: 1$ e 4:1), sem peróxido de hidrogênio.

\subsection{PERÓXIDO DE HIDROGÊNIO (HP)}

O HP foi estudado tanto sozinho (Figura 10) quanto adicionado separadamente a cada reagente:

Quando adicionado à tetraciclina (Figura 19) se observam algumas alterações no espectro: há um maior espalhamento de luz nas amostras contendo HP; o pico principal e a largura das bandas são preservados, embora haja uma diminuição na intensidade dos mesmos, ainda mais expressiva na banda de absorção em aproximadamente $358 \mathrm{~nm}$ na amostra onde foi adicionado HP puro, indicando uma alteração na molécula de tetraciclina.

Adicionando-se concentrações variadas de HP à solução de európio não há alterações no espectro (gráfico não incluso). 


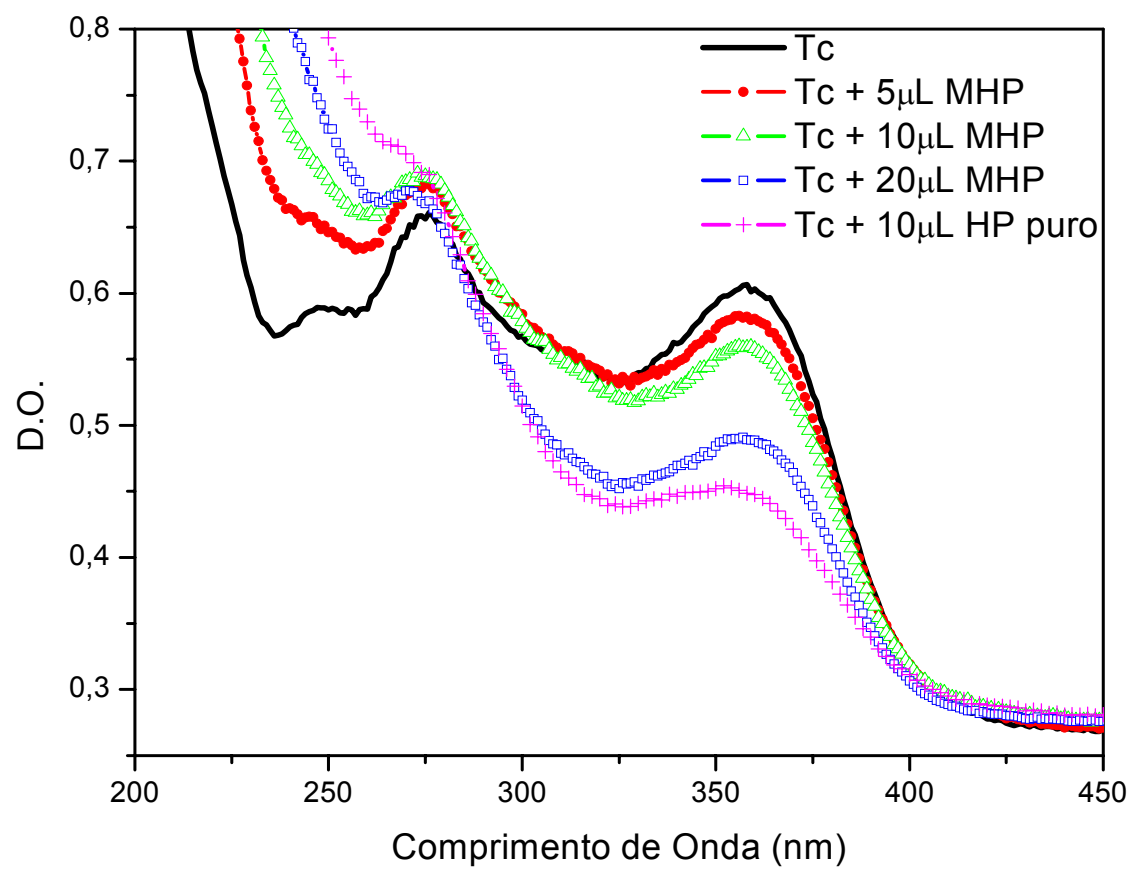

Figura 19 - Espectro de absorção da tetraciclina com adição de concentrações variadas de peróxido de hidrogênio. MHP refere-se à solução de $3 \mathrm{~mL}$ de HP puro em $7 \mathrm{~mL}$ de MOPs. HP puro é a solução de peróxido de hidrogênio sem prévia diluição.

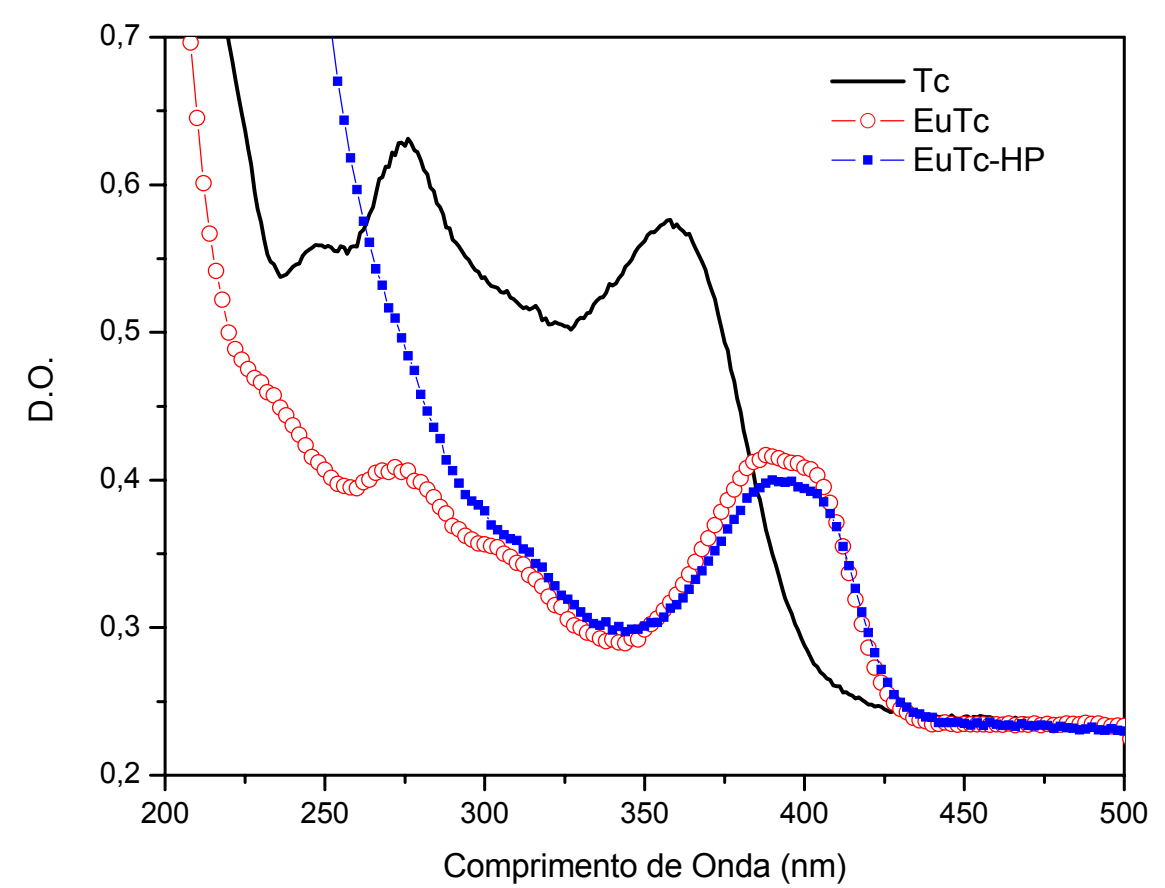

Figura 20 - Espectro de absorção da tetraciclina (linha cheia) do complexo EuTc (círculo) e do complexo EuTc quando adicionado $10 \mu \mathrm{L}$ de HP à solução (quadrado). 
Na Figura 20 é mostrado o que ocorre quando se adiciona HP à solução EuTc: uma pequena diminuição na intensidade da banda, porém sem efeitos mais consideráveis que comprovem uma oxidação da molécula. Mesmo fenômeno observado para a Tc sozinha.

Um fato interessante a ser observado é que dependendo da ordem de adição dos reagentes (tetraciclina, európio e peróxido de hidrogênio) pode haver ou não a formação do complexo EuTc (Figura 21). Quando o peróxido de hidrogênio $(10 \mu \mathrm{L})$ é adicionado a $1 \mathrm{~mL}$ da solução de európio (EuHP), o HP provavelmente substitui moléculas de água na coordenação do európio, o que impede a subseqüente ligação do európio à tetraciclina, ao misturar-se a solução de tetraciclina à solução EuHP. Para os demais casos, tetraciclina com HP (TcHP) mais európio, ou EuTc mais HP, não só ocorre a complexação como a ordem de adição dos reagentes não interfere no resultado.

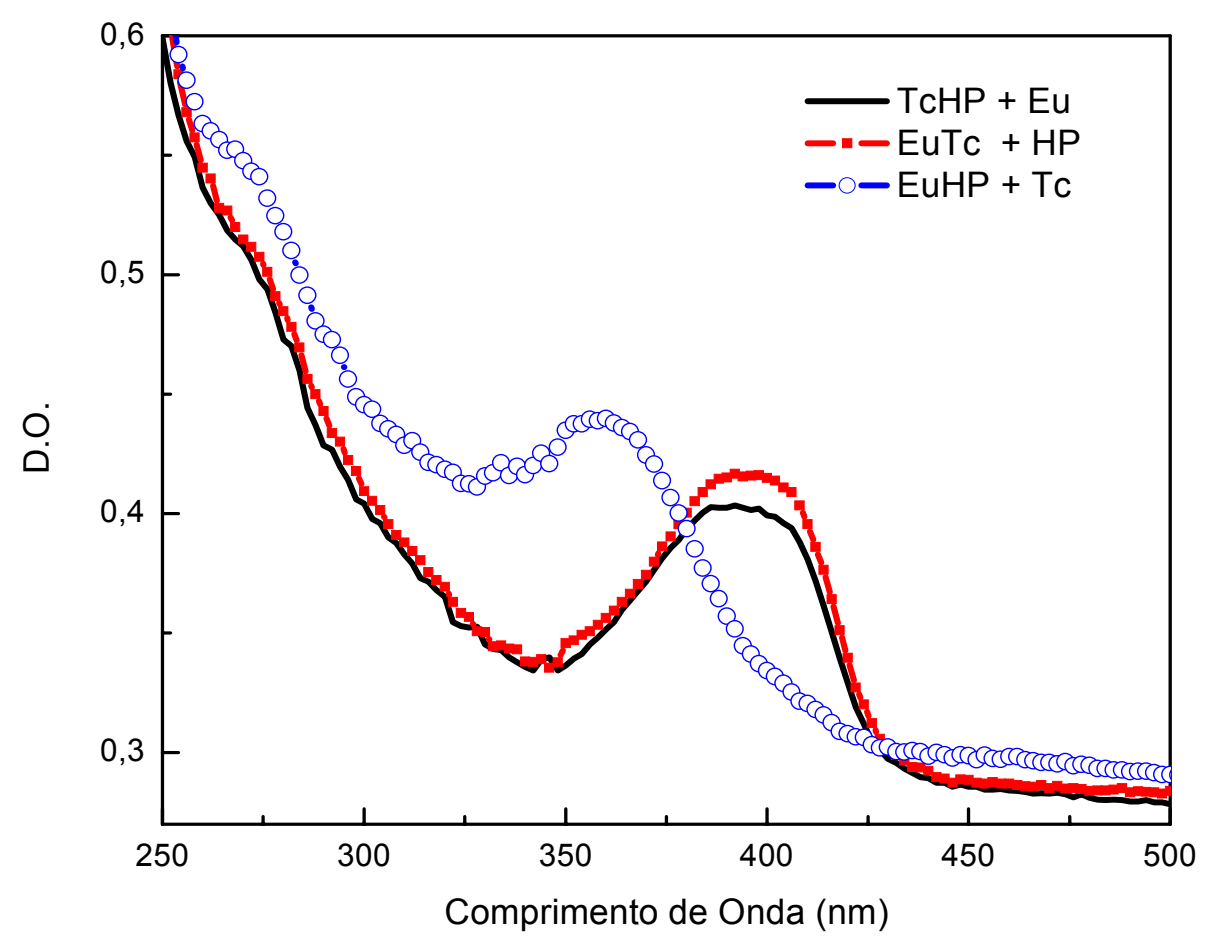

Figura 21 - Absorção óptica das amostras em função da ordem de adição dos reagentes tetraciclina, európio e HP - na solução.

Quando se faz a variação da concentração de európio em relação à tetraciclina, na presença de $\mathrm{HP}(400 \mu \mathrm{M})$ a melhor relação molar do Eu:Tc deixa 
de ser 1:1 (como ocorre na ausência de HP (Figura 18)), e passa a ser 3:1 (Figura 22).

A intensidade, normalizada, da emissão do complexo EuTc-HP (400 $\mu \mathrm{M}$ de peróxido de hidrogênio)/(1:1; 1,5:1; 2,5:1; 3:1 e 4:1) EuTc em função da concentração de $\mathrm{Eu}^{3+}$ é mostrada na Figura 23. Nesse caso, a intensidade de fluorescência das concentrações 3:1 e 4:1 são quase equivalentes, então foi considerada a estequiometria 3:1 (3Eu:1Tc) a melhor composição para quantificar HP nos experimentos, o que além de estar de acordo com estudos anteriores ${ }^{108}$, ainda possibilita uma menor utilização de reagentes, o que reduz custos.

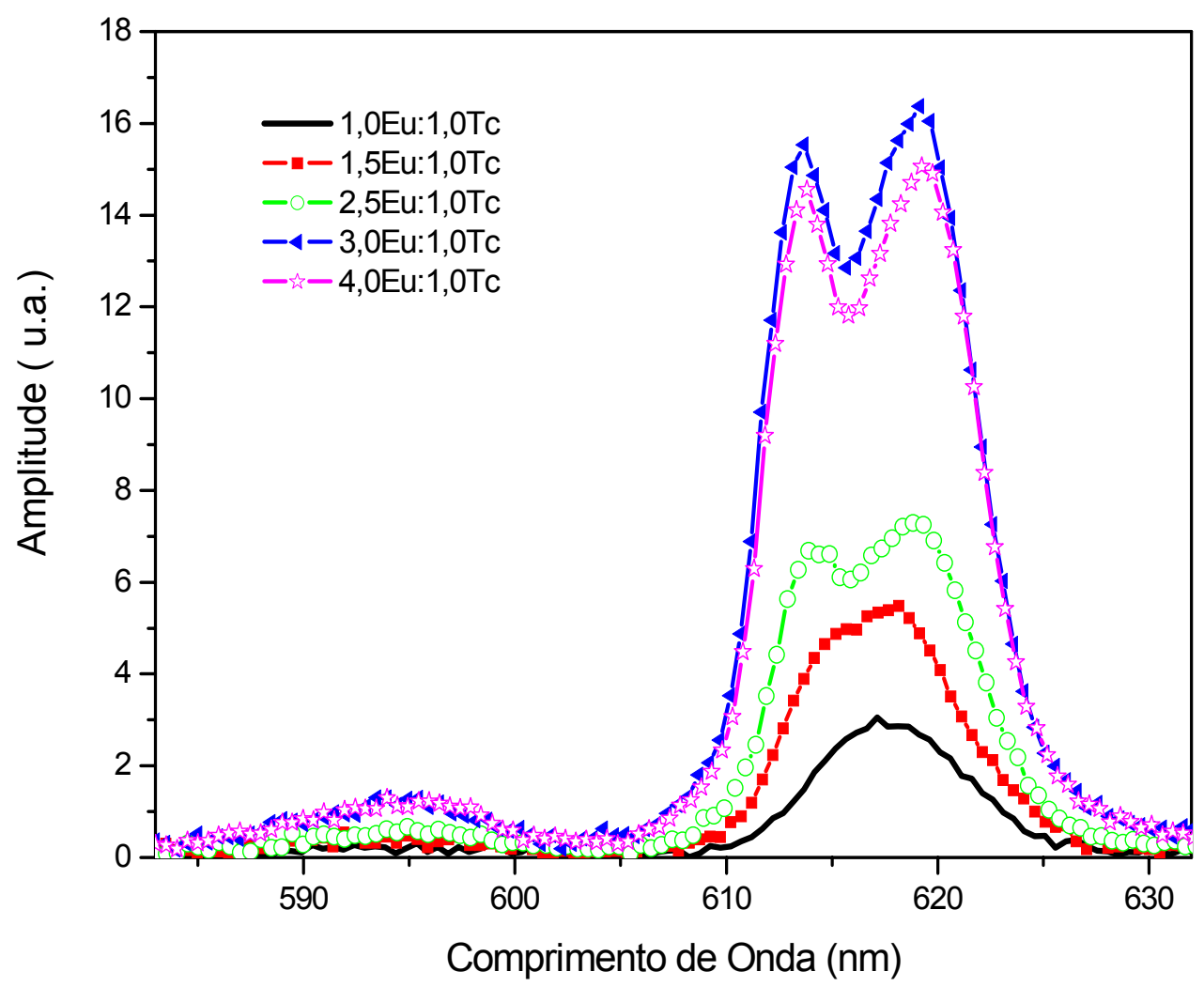

Figura 22 - Espectro de emissão das amostras com diferentes concentrações molares de Eu no complexo Eu:Tc (1:1; 1,5:1; 2,5:1; 3:1; e 4:1), com peróxido de hidrogênio (400 $\mu \mathrm{M})$.

Na Figura 24 é apresentado o aumento da intensidade de emissão do európio com o aumento da concentração de $\operatorname{HP}$, solução $V(10,50,100,200$ e $400 \mu \mathrm{M})$, na solução 3Eu:1Tc. 


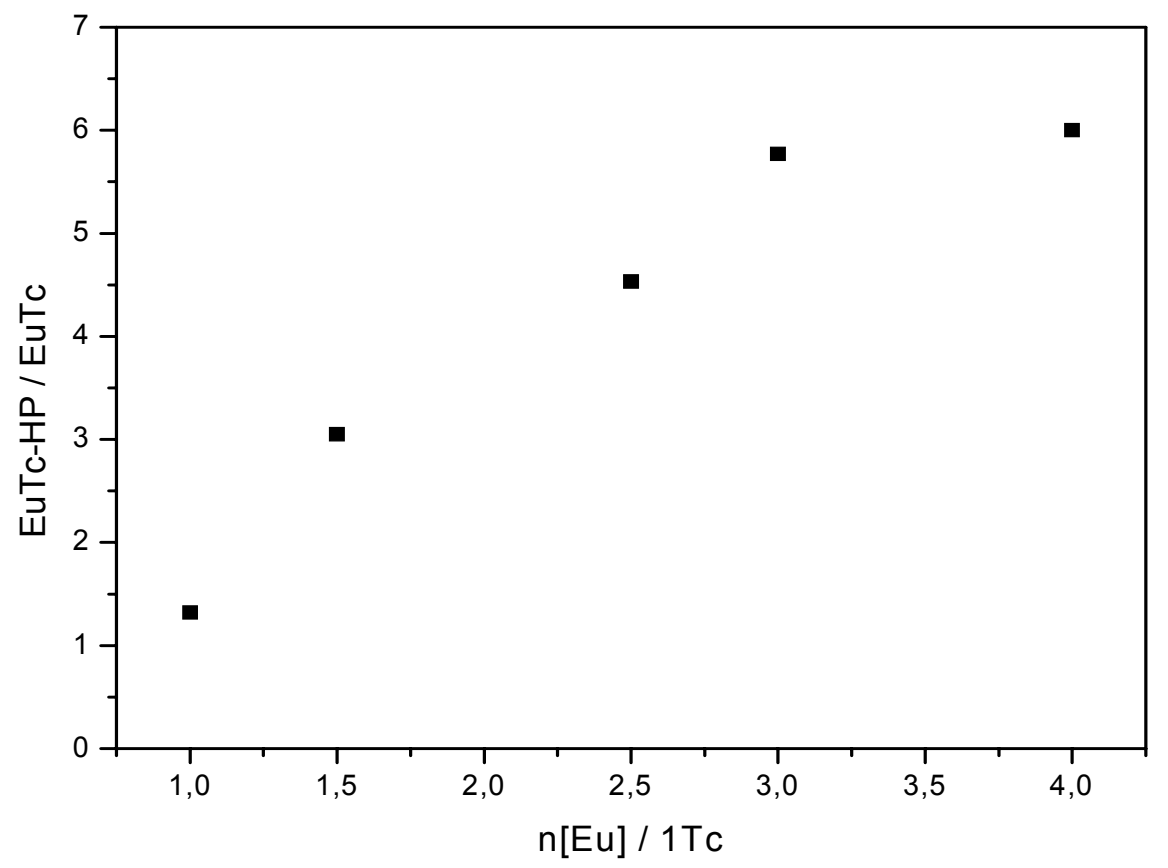

Figura 23 - Intensidade, normalizada, da luminescência do complexo EuTc-HP (solução peróxido de hidrogênio de $400 \mu \mathrm{M})$ em função da concentração de $\mathrm{Eu}^{3+}(1: 1 ; 1,5: 1 ; 2: 1 ; 3: 1$ e 4:1).

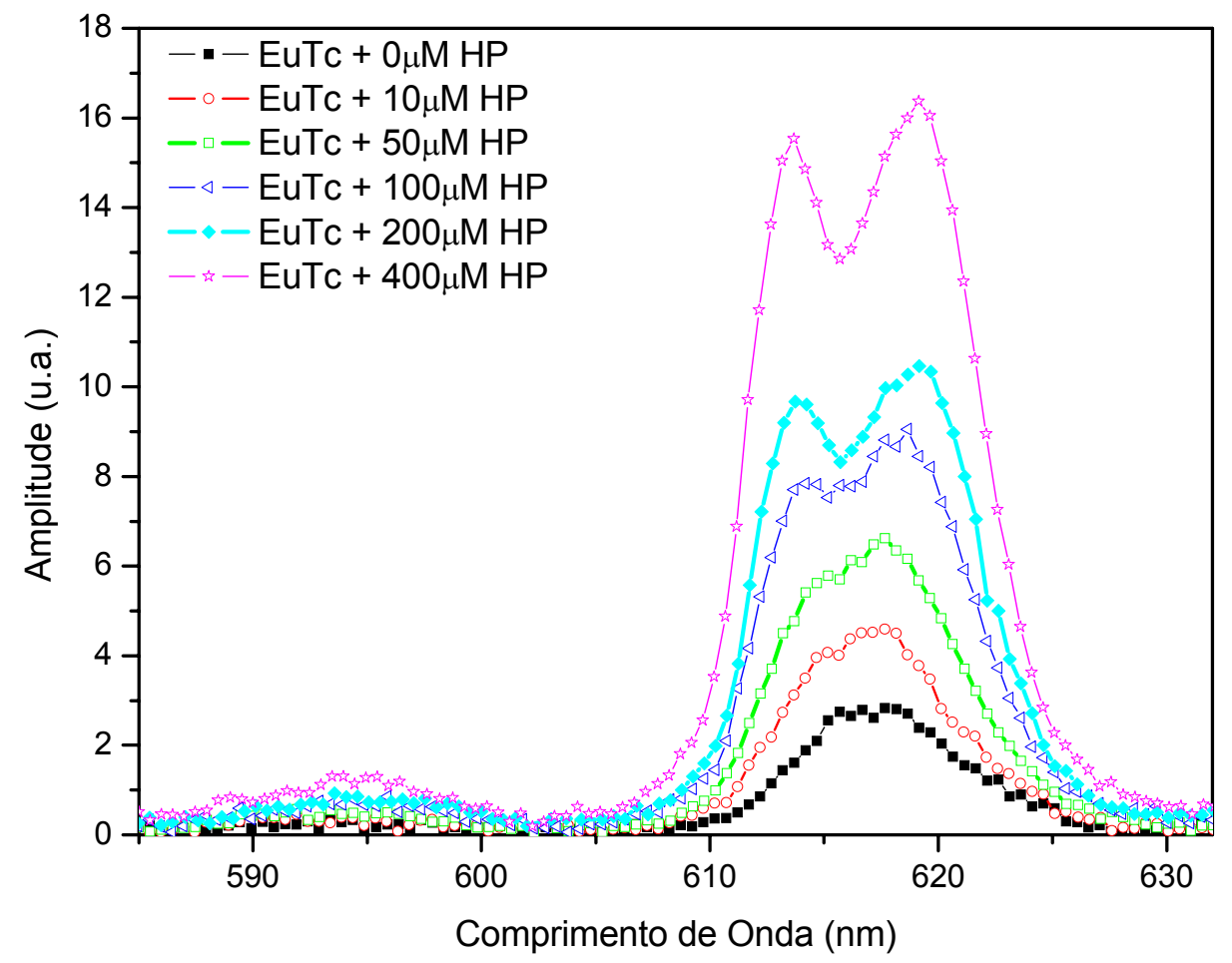

Figura 24 - Espectro de emissão da solução 3Eu:1Tc acrescida de 10, 50, 100, 200, e $400 \mu \mathrm{M}$ de HP (solução V). 
A divisão (splitting) da banda da transição ${ }^{5} \mathrm{D}_{0} \rightarrow{ }^{7} \mathrm{~F}_{2}$ no espectro sugere que o európio ocupa sítios diferentes na molécula orgânica, na presença do HP, uma vez que com o peróxido de hidrogênio cada molécula de tetraciclina é capaz de complexar três íons $\mathrm{Eu}^{3+}$. Sem o peróxido, independente da concentração de Eu, observa-se apenas uma banda (Figura 18), indicando que o európio tem um sítio preferencial de ocupação no ligante.

O aumento da luminescência é devido à substituição de moléculas de água na coordenação do európio pelo HP. Além disso, o $\mathrm{H}_{2} \mathrm{O}_{2}$ é conhecido por ser um forte agente oxidante que leva a uma oxidação do ligante ${ }^{109}$, provado pela alteração da coloração da solução de amarelada para transparente alguns dias após a preparação do complexo EuTc-HP.

As amostras quando preparadas têm um tempo de reação, de aproximadamente 12 minutos, para a estabilização entre o HP e a água na coordenação do íon até que as moléculas de água sejam substituídas pelas do peróxido e então a emissão do complexo alcance a intensidade máxima. Esse tempo de reação pode ser observado na Figura 25.

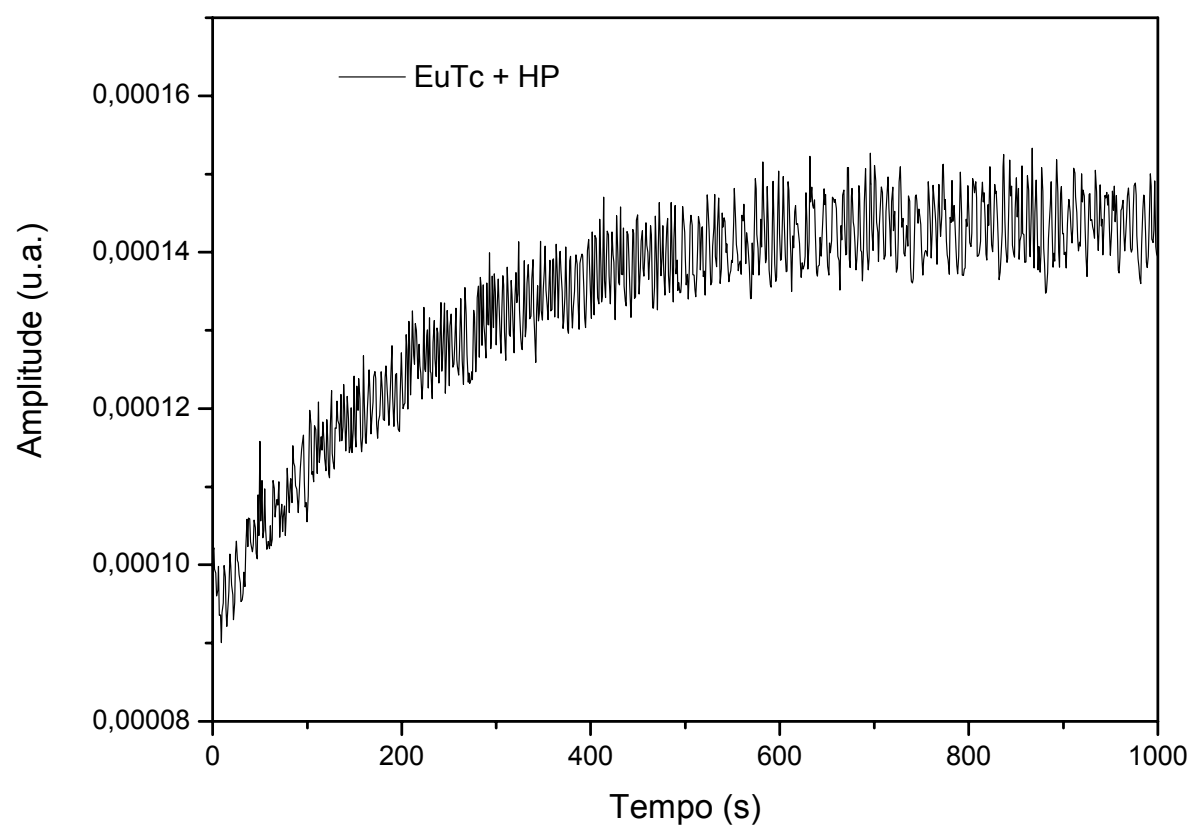

Figura 25 - Tempo de estabilização do HP no complexo EuTc. 
Abaixo, na Figura 26 e na Tabela 4 pode ser visto que a adição de HP à solução EuTc também aumenta o tempo de vida do complexo, de 21 $\mu$ s (sem HP) para 48,5 us (com HP).

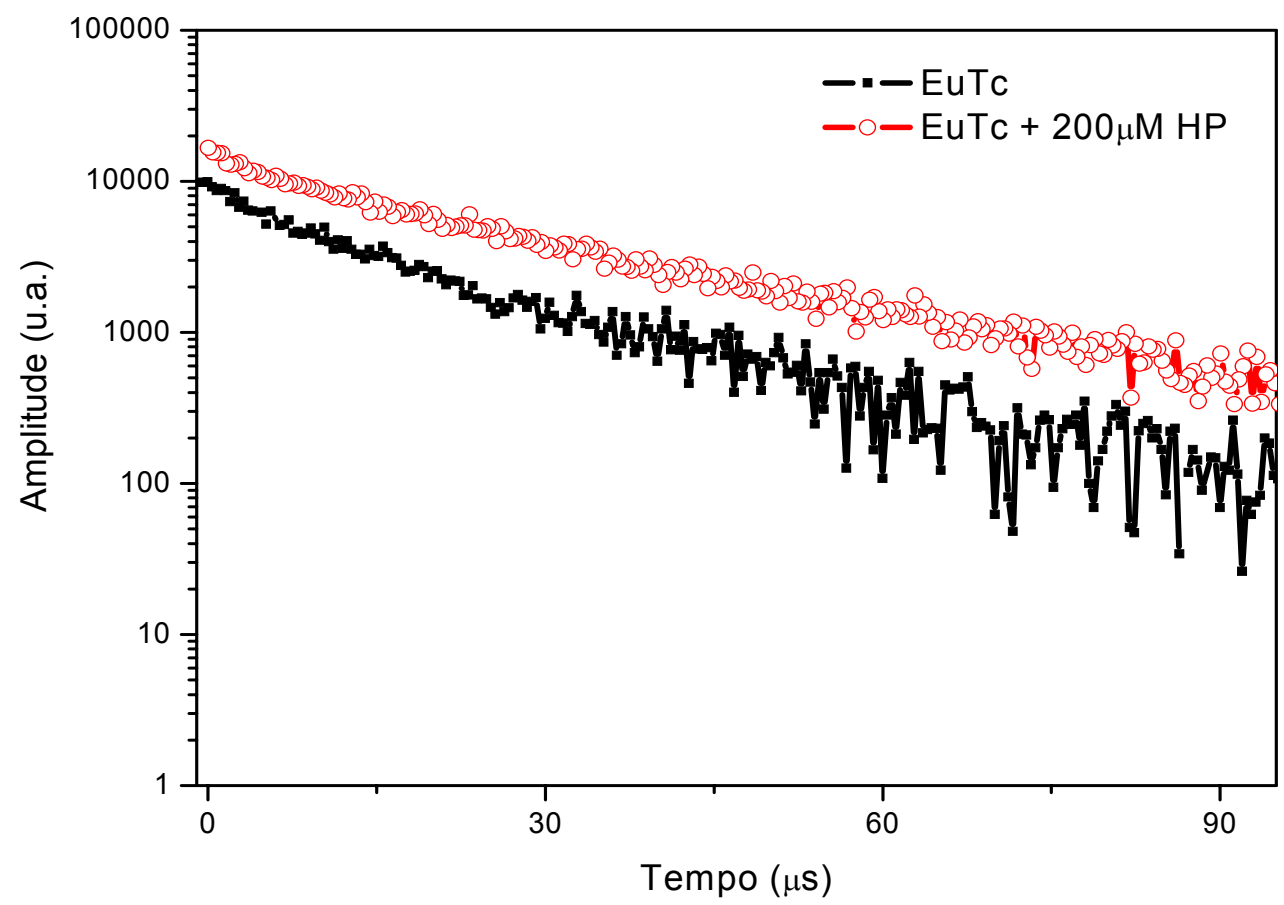

Figura 26 - Tempo de vida da solução de EuTc sozinha e acrescida de $500 \mu \mathrm{L}$ da solução de HP $(200 \mu \mathrm{M})$.

Tabela 4 - Parâmetros do ajuste das eq. (4) e eq. (5) para os dados experimentais da Figura 26 (amostras EuTc e EuTc-HP).

\begin{tabular}{|c|c|c|c|c|c|c|}
\hline Complexo & & Parâmetros & Erros $( \pm)$ & Amplitude (\%) & & $\tau_{a v}(\mu s)$ \\
\hline \multirow[t]{4}{*}{ EuTc } & $A_{1}$ & 216.5799 & 15.0014 & $(17.7 \%)$ & Chi^2/DoF & \multirow{4}{*}{20,8} \\
\hline & $\tau_{1}$ & 3.487E-6 & 3.9547E-7 & \multirow{3}{*}{$(82.3 \%)$} & 235.86443 & \\
\hline & $A_{2}$ & 1006.394 & 14.5471 & & $\mathrm{R}^{\wedge} 2$ & \\
\hline & $\tau_{2}$ & $2.0855 E-5$ & 2.3851E-7 & & 0.99666 & \\
\hline \multirow[t]{4}{*}{ EuTc-HP } & A1 & 4741.678 & 193.39799 & $(52,7 \%)$ & Chi^2/DoF & \\
\hline & $\tau_{1}$ & 3.887E-6 & 3.0412E-7 & & 86449.2257 & \\
\hline & $\mathrm{A} 2$ & 11624.72 & 173.49638 & $(47,3 \%)$ & $\mathrm{R}^{\wedge} 2$ & 48,5 \\
\hline & $\tau_{2}$ & 0.00003 & 4.462E-7 & & 0.99612 & \\
\hline
\end{tabular}




\subsection{PERÓXIDO DE URÉIA (PHU)}

$\mathrm{Na}$ condição de $\mathrm{pH}$ ideal foi observado, um aumento na luminescência do európio com adição do peróxido de uréia na solução ${ }^{11}$. Na Figura 27 é mostrada a dependência da intensidade do sinal de luminescência do európio com alteração da solução EuTc, acrescentando-se peróxido de uréia.

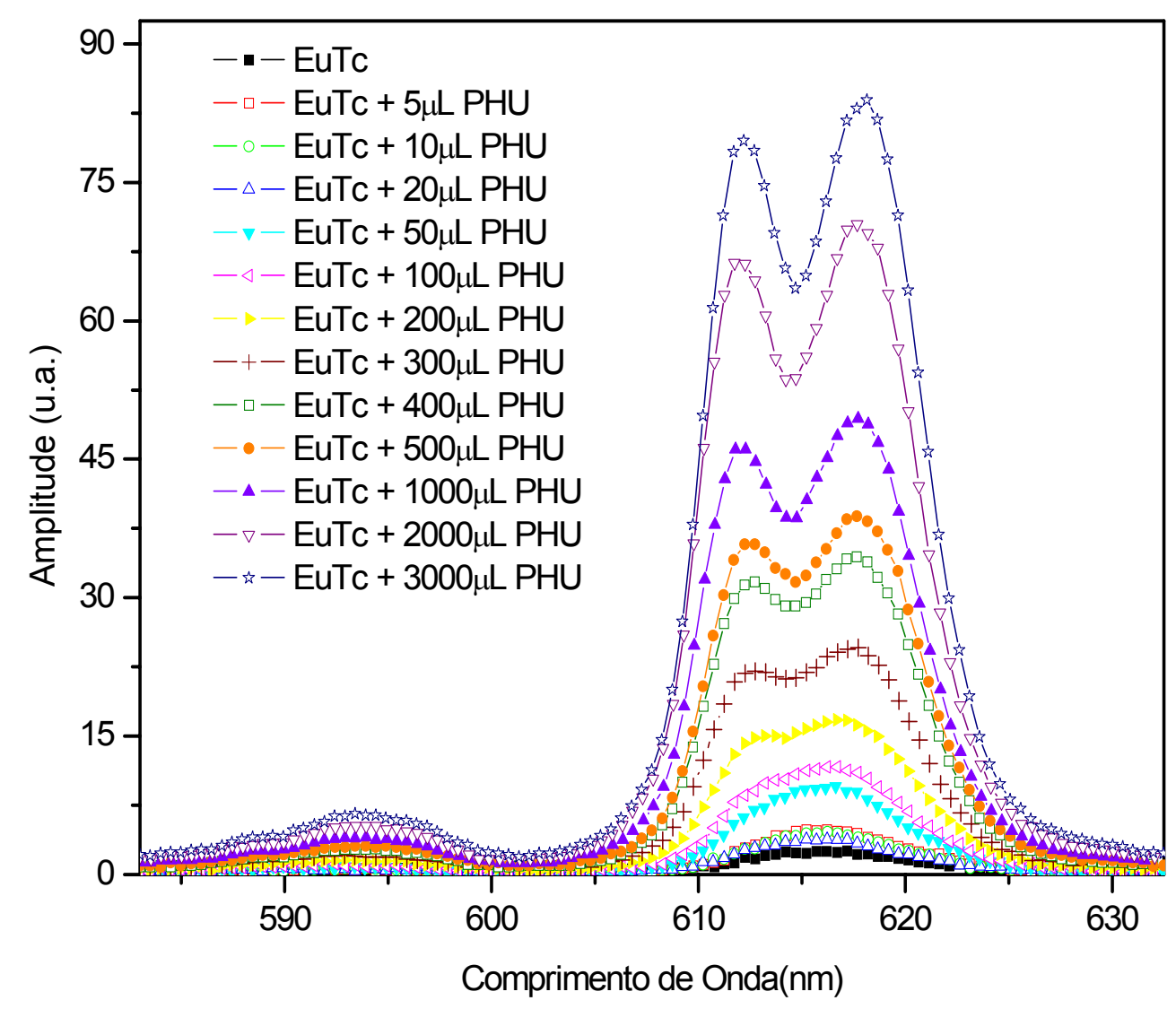

Figura 27 - Dependência da intensidade do sinal de luminescência do európio com alteração na solução de EuTc acrescentando-se variadas concentrações de peróxido de uréia.

Observando-se a largura, a intensidade da banda e sua área, foi possível ajustar o gráfico da Figura 28. Estes três parâmetros podem ser utilizados para a quantificação de peróxido de uréia em solução. 

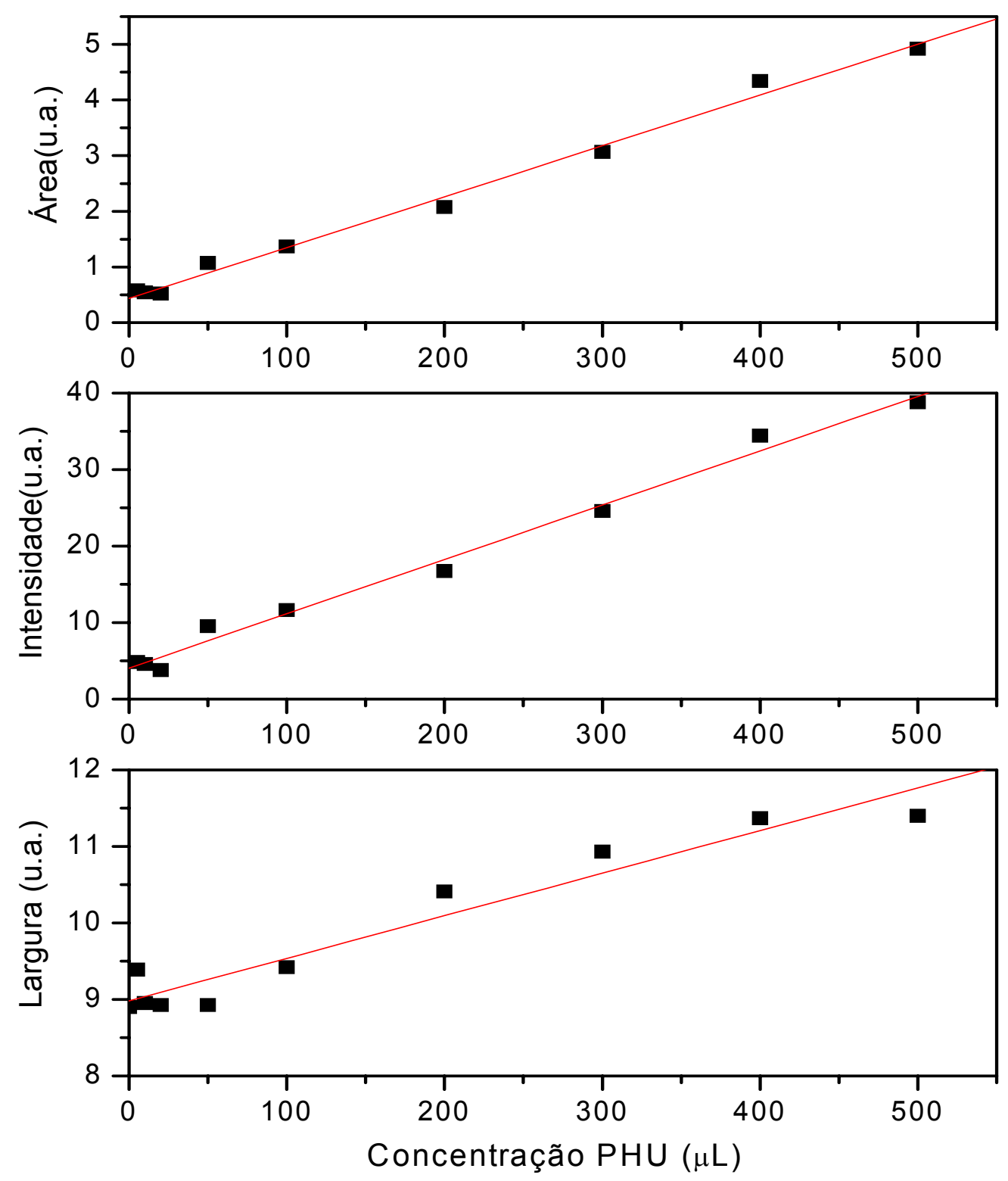

Figura 28 - Dependências da área, intensidade e a largura da banda em função da concentração de peróxido de uréia na solução.

A concentração de PHU também pode ser determinada pela medida do índice de refração da solução, como mostrado na Figura 29.

Para estudar a dependência do índice de refração com a concentração do peróxido foi utilizada a solução IV, adicionando-se concentrações variadas de PHU. Pode-se observar, para o índice de refração, uma dependência linear com a concentração do PHU. Este comportamento linear pode ser explicado 
considerando que o aumento da concentração de PHU promove um aumento da densidade da solução e, conseqüentemente, uma diminuição da velocidade da luz no meio, aumentando, assim, o índice de refração.

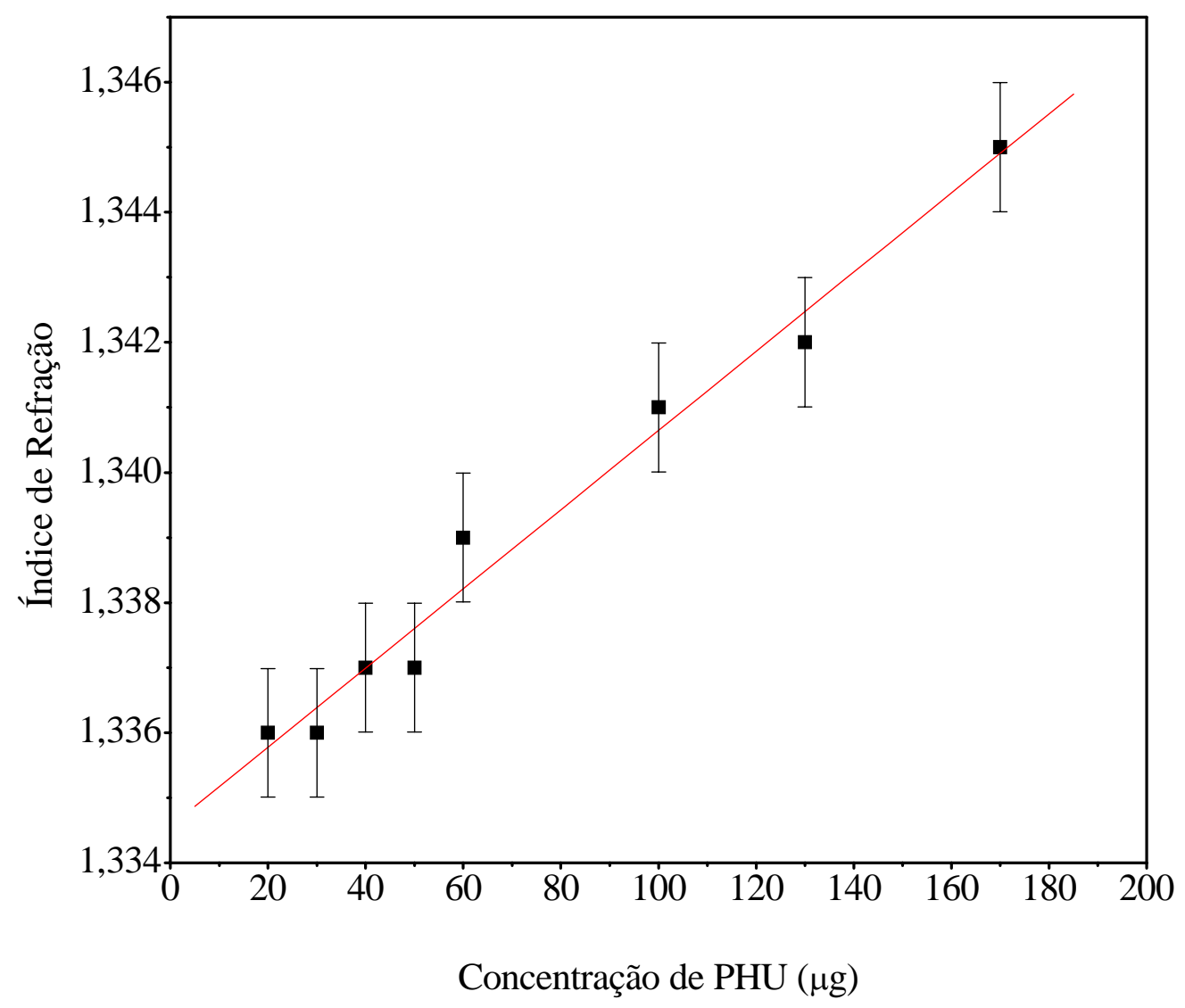

Figura 29 - Alterações no índice de refração com o aumento da concentração de PHU na solução EuTc.

Na presença do peróxido de uréia não ocorre a degradação da molécula da tetraciclina. Esse fato é confirmado pela estabilidade e a mesma coloração da solução EUTc-PHU por vários meses (amarelada).

N Figura 30 e na Tabela 5 é mostrada a correlação dos tempos de decaimento do európio com alteração da solução EuTc, adicionando-se PHU.

Observa-se que a amostra que contem o peróxido apresenta um tempo de vida mais longo, mesmo fenômeno observado para o EuTc na presença do HP. 


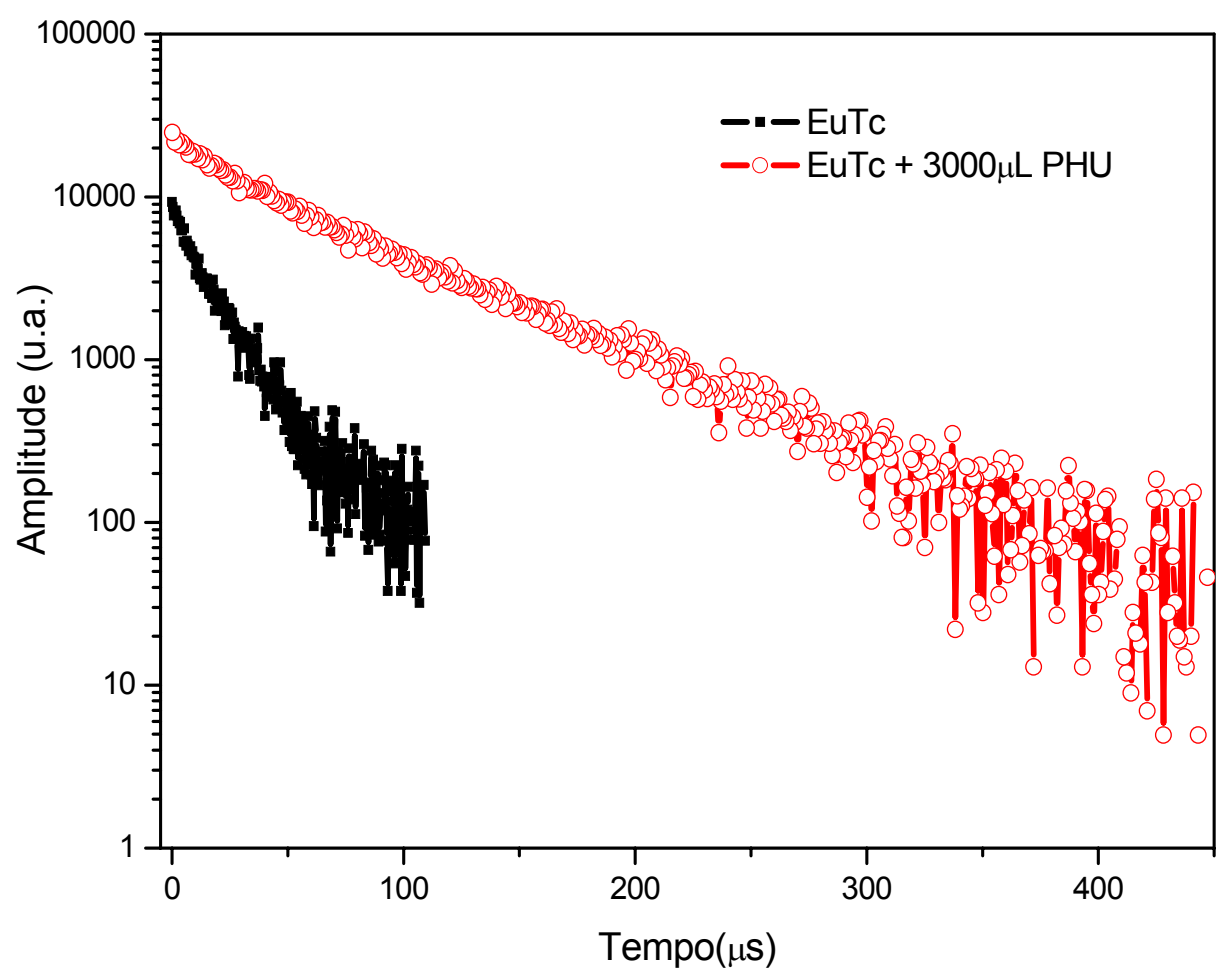

Figura 30 - Tempo de vida de complexos EuTc e EuTc-PHU.

Tabela 5 - Parâmetros dos dados experimentais, da Figura 30 para o ajuste das eq. (4) e eq. (5).

\begin{tabular}{|c|c|c|c|c|c|c|}
\hline Complexo & & Parâmetros & Erros $( \pm)$ & Amplitude(\%) & & $\tau_{a v}(\mu s)$ \\
\hline \multirow[t]{4}{*}{ EuTc } & $A_{1}$ & 216.57996 & 15.0014 & $(17.7 \%)$ & $\mathrm{Chi}^{\wedge} 2 / \mathrm{DoF}$ & \multirow{4}{*}{20,8} \\
\hline & $\tau_{1}$ & $3.48728 \mathrm{E}-6$ & 3.9547E-7 & \multirow{3}{*}{$(82.3 \%)$} & 235.8644 & \\
\hline & $A_{2}$ & 1006.3941 & 14.5471 & & $\mathrm{R}^{\wedge} 2$ & \\
\hline & $\tau_{2}$ & $2.0855 E-5$ & $2.3851 \mathrm{E}-7$ & & 0.99666 & \\
\hline \multirow[t]{5}{*}{ EuTc-PHU } & A1 & 16740.101 & 464.1959 & $(51,1 \%)$ & $\mathrm{Chi}^{\wedge} 2 / \mathrm{DoF}$ & \multirow{5}{*}{64,8} \\
\hline & $\tau_{1}$ & 0.00007 & 1.5905E-6 & \multirow{4}{*}{$(48,9 \%)$} & 86449.225 & \\
\hline & $\mathrm{A} 2$ & 6728.4540 & 444.81586 & & 7 & \\
\hline & $\tau_{2}$ & 0.00002 & 1.4195E-6 & & $\mathrm{R}^{\wedge} 2$ & \\
\hline & & & & & 0.99612 & \\
\hline
\end{tabular}


Da mesma forma que o peróxido de hidrogênio, acredita-se que o aumento da luminescência do complexo EuTc na presença de peróxido de uréia é devido à substituição de moléculas de água na coordenação do európio pelo peróxido de uréia.

\subsection{COLESTEROL}

Como já fora mencionado, é possível determinar a quantidade de peróxido de hidrogênio liberado na solução após a reação enzimática do colesterol com a enzima colesterol oxidase (eq. (3)).

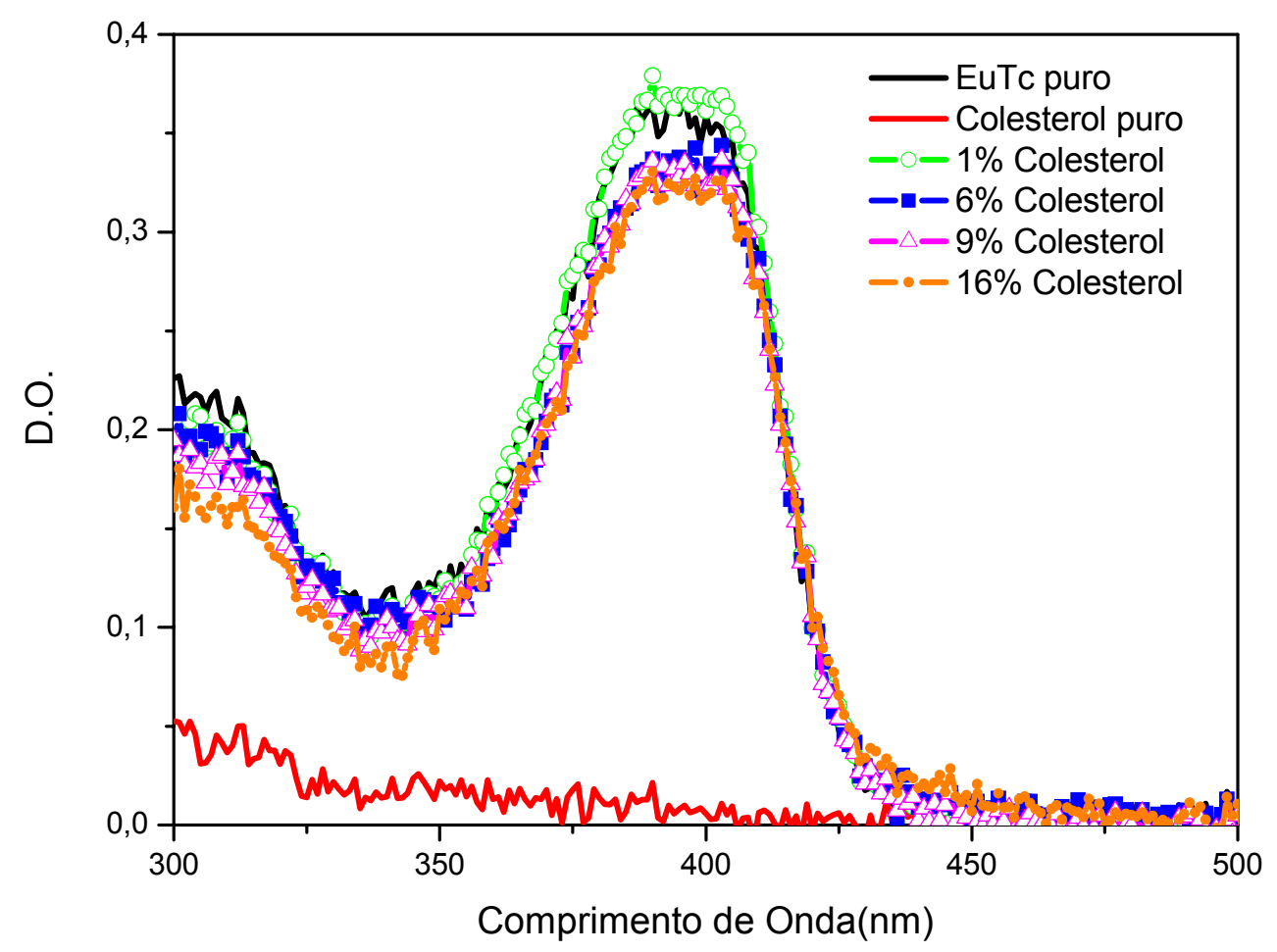

Figura 31 - Espectro de absorção do colesterol, EuTc e EuTc + Colesterol.

Para esse estudo do colesterol, primeiramente, a absorção do EuTc foi verificada na presença do lipídio. Na Figura 31 é mostrado o espectro de absorção do EuTc sozinho, do colesterol puro e da solução EuTc-Colesterol com diferentes 
concentrações do lipídio. Nesse gráfico é observado que o colesterol sozinho não apresenta absorção na região de $300 \mathrm{~nm}-500 \mathrm{~nm}$. A adição de colesterol à solução EuTc não traz alterações significativas nem à forma e nem à posição da banda do EuTc, em aproximadamente $400 \mathrm{~nm}$.

$\mathrm{Na}$ Figura 32, o espectro de emissão da solução EuTc-Colesterol+COx, obtido pela excitação em 405nm, mostra um aumento da emissão em $618 \mathrm{~nm}$, em relação à solução do EuTc sozinho. Esse aumento é uma conseqüência direta da reação enzimática esquematizada na eq. (3). As moléculas de $\mathrm{H}_{2} \mathrm{O}_{2}$ liberadas na solução substituem as moléculas de água na coordenação do íon $\mathrm{Eu}^{3+}$, aumentando sua emissão. Uma vez que a quantidade de peróxido de hidrogênio é proporcional à quantidade de colesterol, a monitoração do aumento da emissão do európio pode ser usada como método para a determinação das concentrações de colesterol.

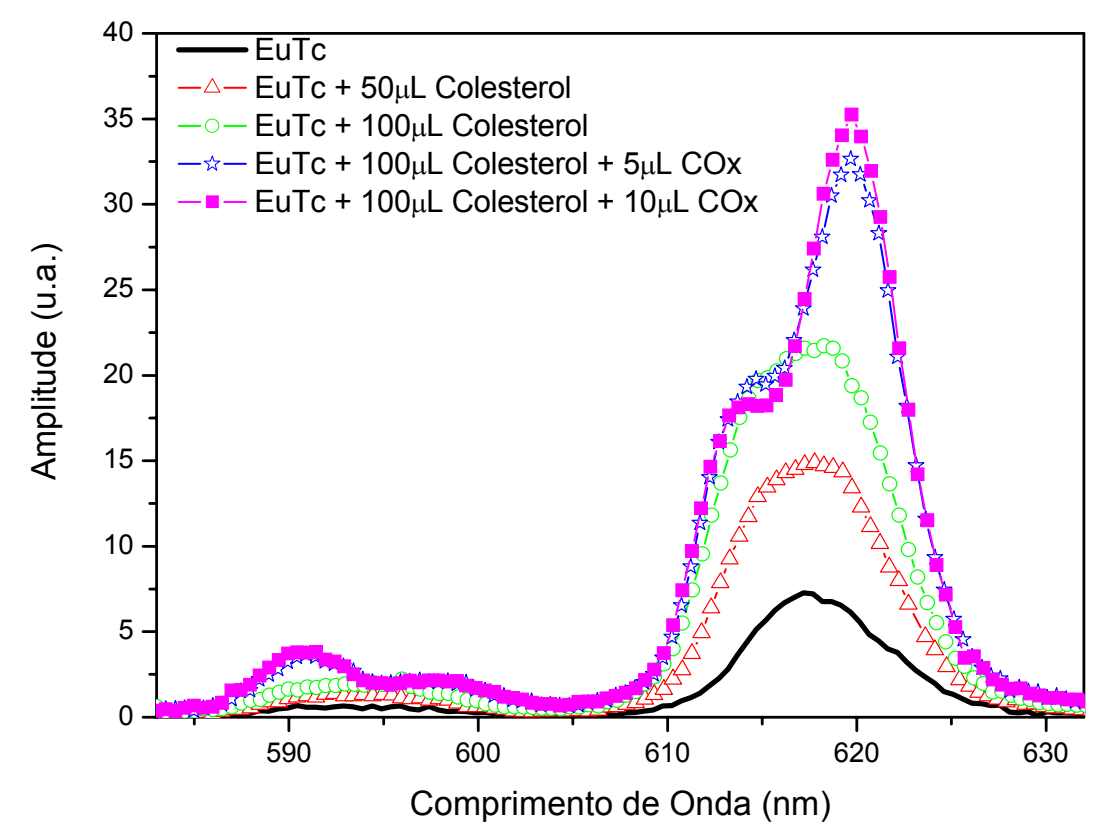

Figura 32 - Espectro de emissão do EuTc, EuTc-Colesterol e EuTc-Colesterol+COx obtidos pela excitação do complexo em 405nm.

Durante o estudo realizado variando-se a quantidade de colesterol e da enzima colesterol oxidase ( $\mathrm{COx}$ ) na solução EuTc, foi observado que o colesterol por si só já provocava um aumento na intensidade da luminescência da sonda EuTc, dependendo da concentração do mesmo na solução (Figura 32). Este fato 
demonstra não ser necessário a utilização de enzima para a determinação indireta de colesterol, o que reduz custos e torna a medição mais precisa por ser um método direto.

a)

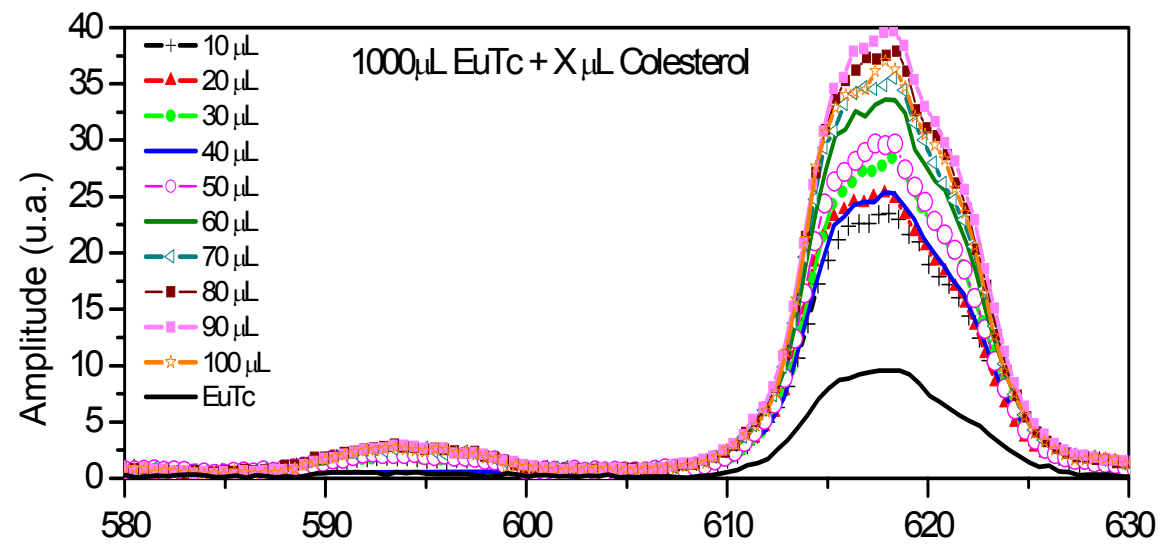

b)

Comprimento de Onda (nm)

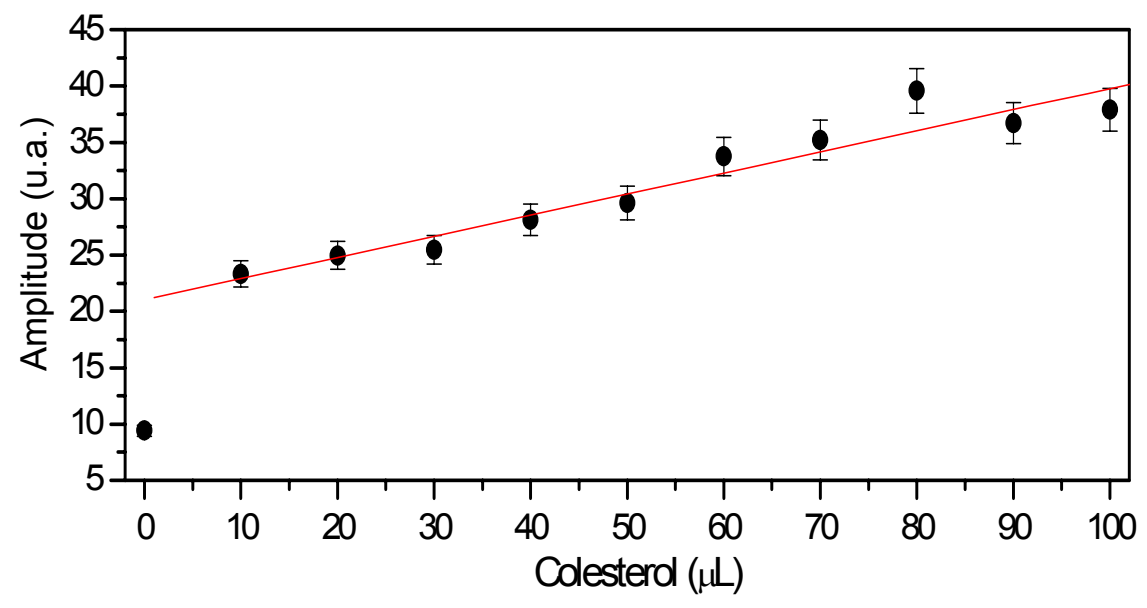

Figura 33 - Aumento da emissão do EuTc na presença do colesterol. a) Espectro de emissão em função da concentração do colesterol. b) Dependência da intensidade de emissão em $618 \mathrm{~nm}$ com a concentração de colesterol. A função linear foi plotada como curva de calibração.

$\mathrm{Na}$ Figura 33.a) o espectro de emissão para todas as concentrações de colesterol da solução VIII comprova ser possível a determinação da concentração direta do colesterol, sem a necessidade da enzima. Uma curva de calibração foi obtida ajustando a intensidade de emissão em $618 \mathrm{~nm}$ em função da concentração de colesterol, e os resultados são mostrados na Figura 33.b). Nesse gráfico observa-se que a intensidade aumenta linearmente com a concentração de 
colesterol até uma variação máxima de $90 \mu \mathrm{L}$ de colesterol (8,3\% de colesterol). É importante mencionar que o aumento da emissão não é instantâneo, levando aproximadamente 1000s para estabilizar, como pode ser visto na Figura 34.

O tempo de vida da transição ${ }^{5} \mathrm{D}_{0} \rightarrow{ }^{7} \mathrm{~F}_{2}$ do európio das soluções IV e VIII foi medido pela excitação pulsada em $420 \mathrm{~nm}$, e os resultados são expostos na Figura 35. O tempo de vida da emissão do európio (ajustados com as eq. (4) e eq. (5)) aumenta com a adição de colesterol na solução, de $\sim 21 \mu \mathrm{s}$, para a solução de EuTc pura (IV), para $83 \mu \mathrm{s}$, para a solução EuTc - Colesterol (VIII).

Para explicar o princípio do aumento da luminescência do európio no complexo EuTc, devido à presença do colesterol, é sugerido que as moléculas de água na solução EuTc-Colesterol são agrupadas ao redor do grupo polar da molécula de colesterol, isolando, dessa forma, o íon conectado à tetraciclina, diminuindo assim a perda da energia adquirida pelo $\mathrm{Eu}^{3+}$, através da transferência de energia pela tetraciclina, para a água. E ainda, as moléculas de colesterol podem se auto-arranjar ao redor do EuTc impedindo o seu contato direto com o solvente. Dessa forma há o aumento tanto da luminescência do íon quanto do tempo de vida do complexo.

Nesse estudo também fora fracionado o colesterol de amostras de sangue humano em HDL, LDL e VLDL e as medidas são mostradas a seguir (Figura 36). Como pode ser observado, todas as soluções que contêm lipoproteínas apresentam um sinal mais intenso, como seria esperado. O princípio do aumento da luminescência do európio no complexo EuTc, na presença de HDL, LDL e VLDL, é o mesmo já descrito acima, para o colesterol total.

Devido à grande importância do LDL e do OxLDL e sua relação com doenças cardiovasculares, foi realizado um estudo, mais aprofundado, dessa lipoproteína, tanto em sua forma nativa (LDL), quanto oxidada (OxLDL), e os resultados são mostrados a seguir:

Na Figura 37.a) é mostrado o espectro de absorção da solução aquosa de LDL e de OxLDL indicando que a banda de maior importância aparece em torno de $275 \mathrm{~nm}$. Na Figura 37.b) mostra-se o espectro de absorção do EuTc puro, do EuTc: LDL e do EuTc: OxLDL, as três soluções apresentam espectros similares. 


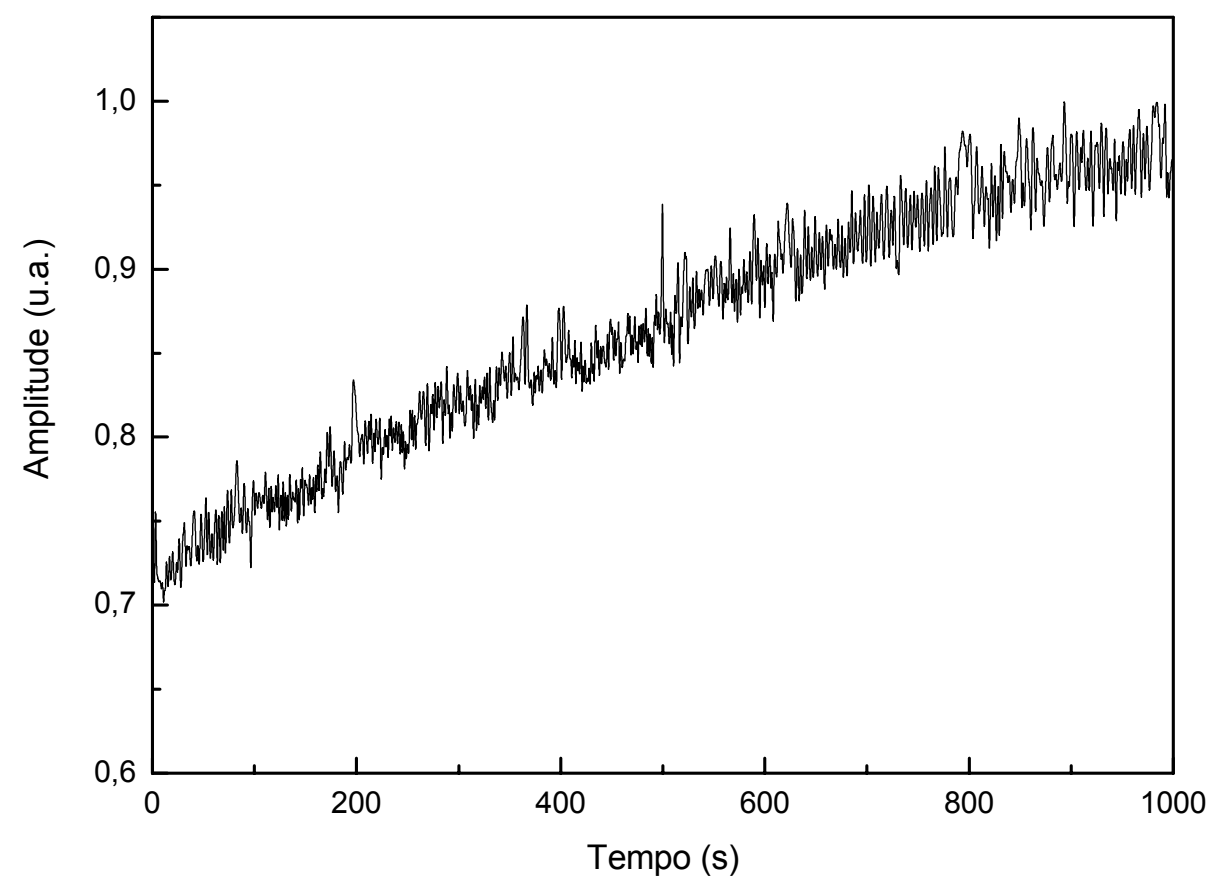

Figura 34 - Dependência da intensidade de emissão em $618 \mathrm{~nm}$ com o tempo, mostrando uma estabilização após 1000s.

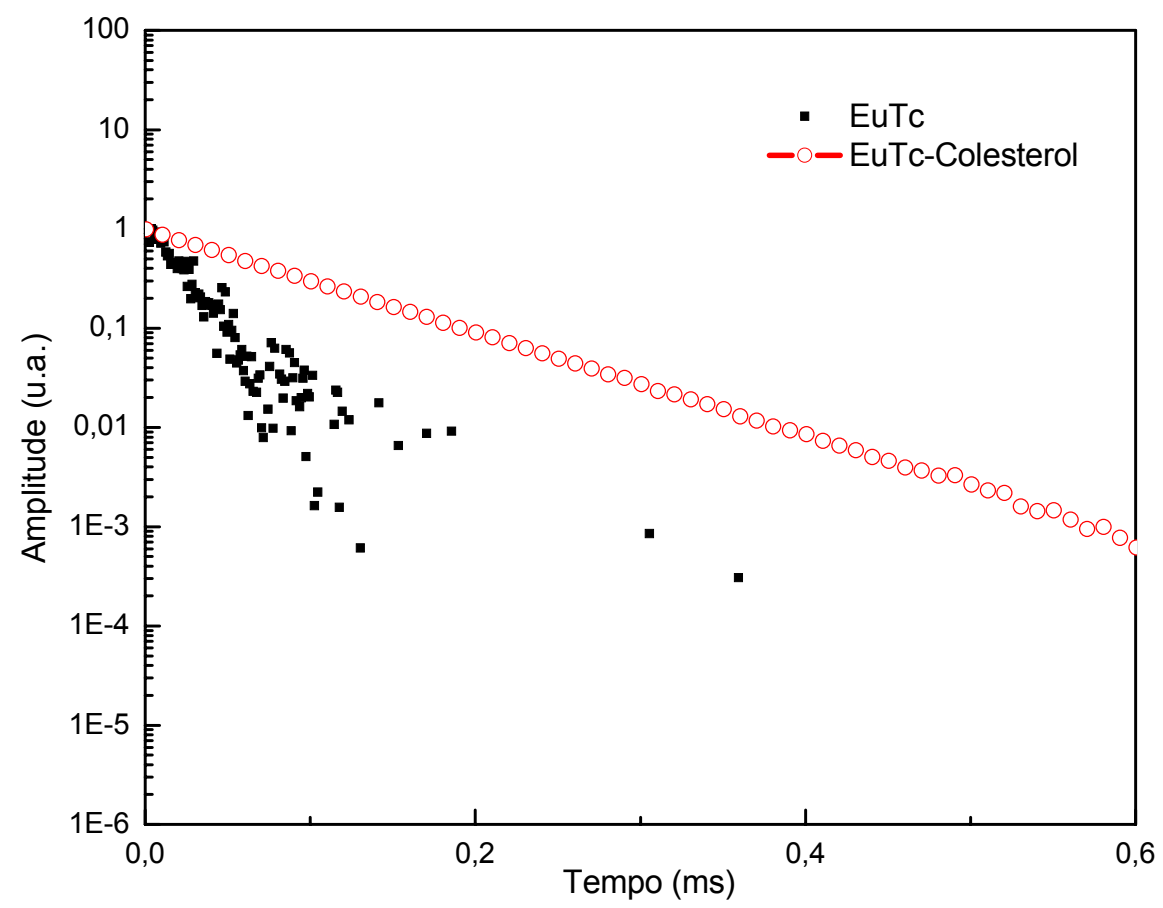

Figura 35 - Tempo de Vida das soluções EuTc e EuTc-Colesterol (IV e VIII, respectivamente) obtidos pela excitação pulsada em $420 \mathrm{~nm}$ com laser OPO. 


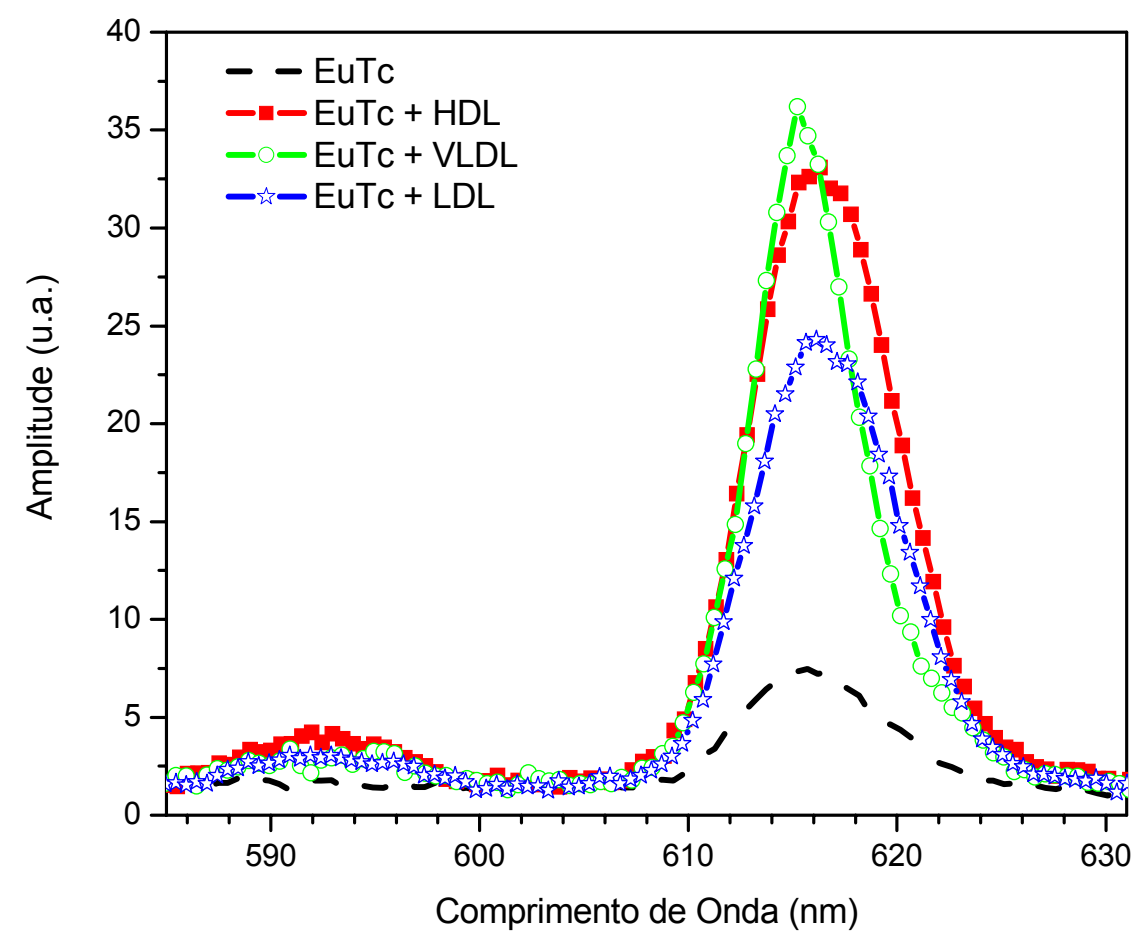

Figura 36 - Emissão da solução EuTc acrescida de $5 \mu \mathrm{L}$ de HDL, VLDL e LDL.

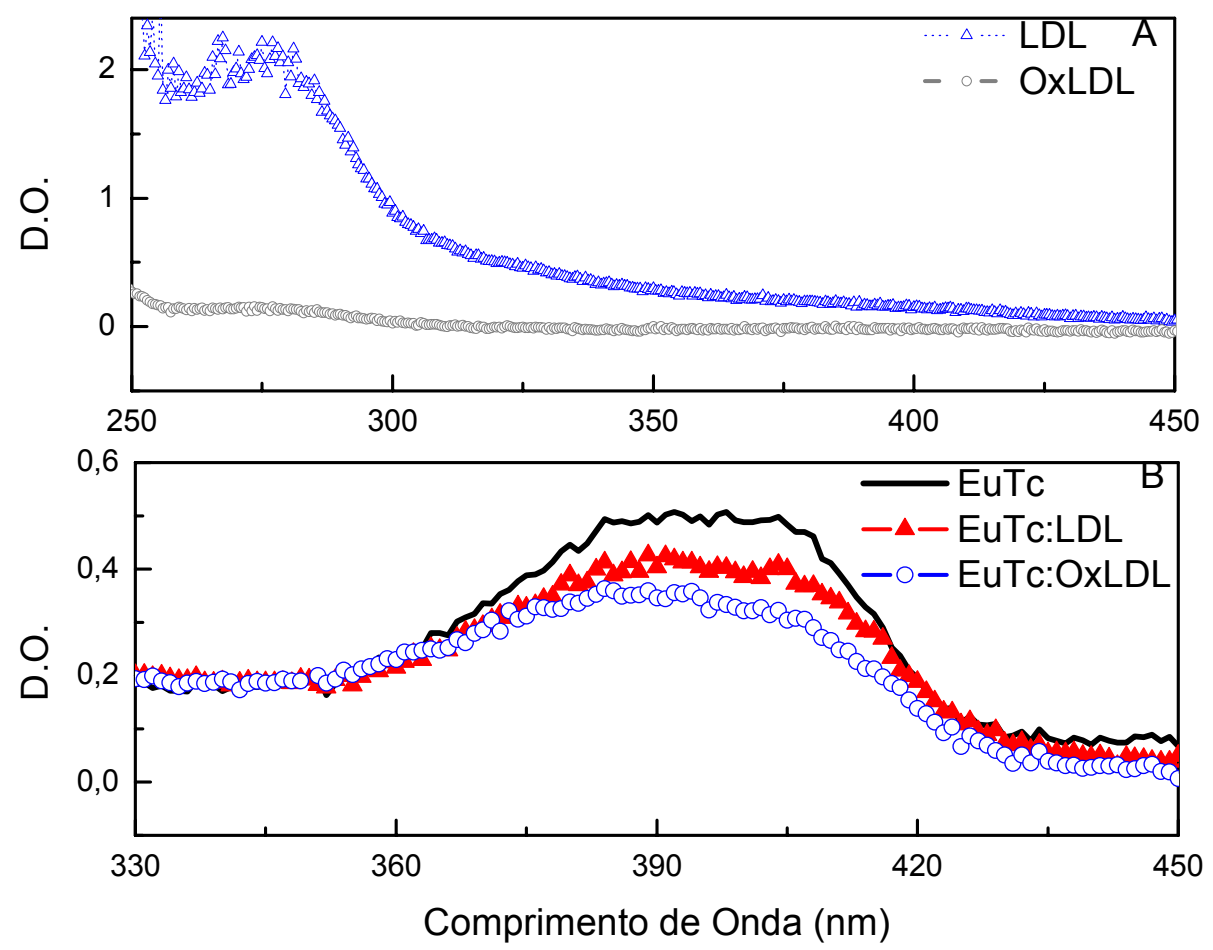

Figura 37 - Absorção óptica de a) LDL (7,7 mg/mL) e OxLDL ( $6 \mathrm{mg} / \mathrm{mL})$; b) EuTc, EuTc:LDL e EuTc:OxLDL. 
Um estudo da fluorescência das soluções de EuTc com diferentes concentrações de LDL e OxLDL, separadamente, foi realizado: um volume fixo de $10 \mu \mathrm{L}$ da solução LDL (ou OxLDL) com 0,7; 1,5; 3,0; 5,6 e 7,7 mg/mL de LDL (ou 0,$7 ; 1,5$ e $3,0 \mathrm{mg} / \mathrm{mL}$ de OxLDL), foi adicionado a $1 \mathrm{~mL}$ de EuTc. As concentrações de LDL e OxLDL foram escolhidas porque essas variações são tipicamente encontradas em plasma humano. Os resultados são mostrados na Figura 38 e Figura 39. Em ambos os casos há um aumento da fluorescência do európio com o aumento da concentração da lipoproteína.
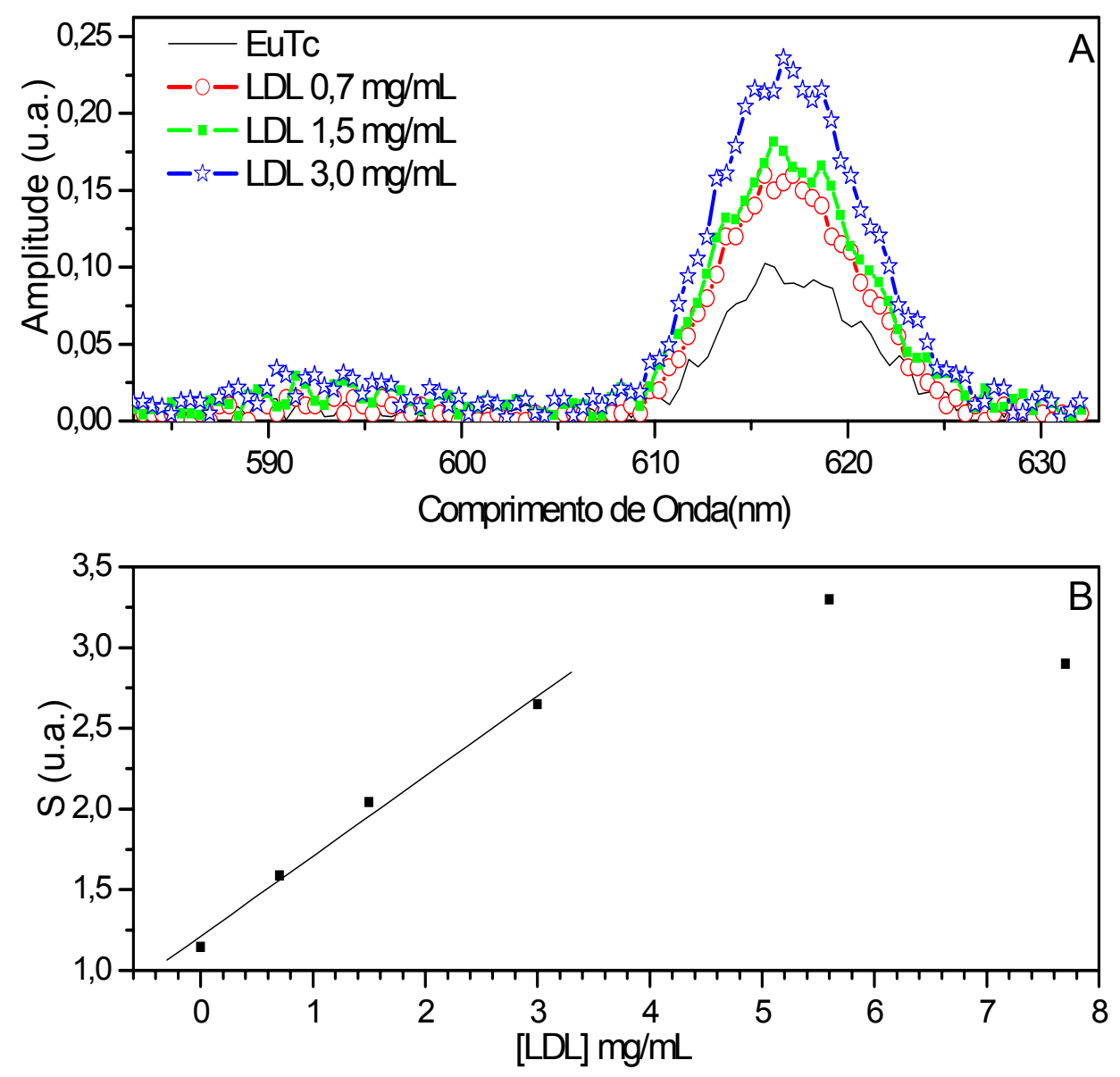

Figura 38 - a) Espectro de emissão das soluções EuTc e EuTc:LDL com diferentes concentrações da lipoproteína; b) Área integrada (S) do espectro de emissão em função da concentração de LDL. A linha sólida corresponde ao ajuste linear dos dados experimentais. 
É interessante mencionar que a taxa desse aumento para as amostras de LDL difere da das amostras que contêm OxLDL. Para uma investigação quantitativa, a integração das áreas das bandas do espectro de fluorescência foi calculada e plotada na Figura 40, em função das concentrações de LDL/OxLDL.

Os resultados plotados são razoavelmente bem descritos por uma função linear $(y=a+b x)$ entre 0 a $3 \mathrm{mg} / \mathrm{mL}$ tanto para as amostras de LDL quanto OxLDL, onde $x$ é a concentração de lipoproteína. Os valores experimentais de a e $b$ em ambas as soluções (LDL e OxLDL) são: $a_{\mathrm{LDL}}=(4,85 \pm 0,27) \times 10^{-4}$ e $b_{\mathrm{LDL}}=$ $(1,98 \pm 0,15) \times 10^{-4}(\mathrm{~mL} / \mathrm{mg}) ; a_{O x}=(4,94 \pm 0,30) \times 10^{-4}$ e $b_{O x}=(2,31 \pm 0,18) \times 10^{-4}$ $(\mathrm{mL} / \mathrm{mg})$, respectivamente. O limite de detecção é, em ambos os casos, 0,23

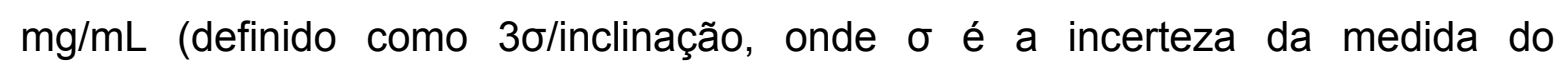
parâmetro $b$ ).
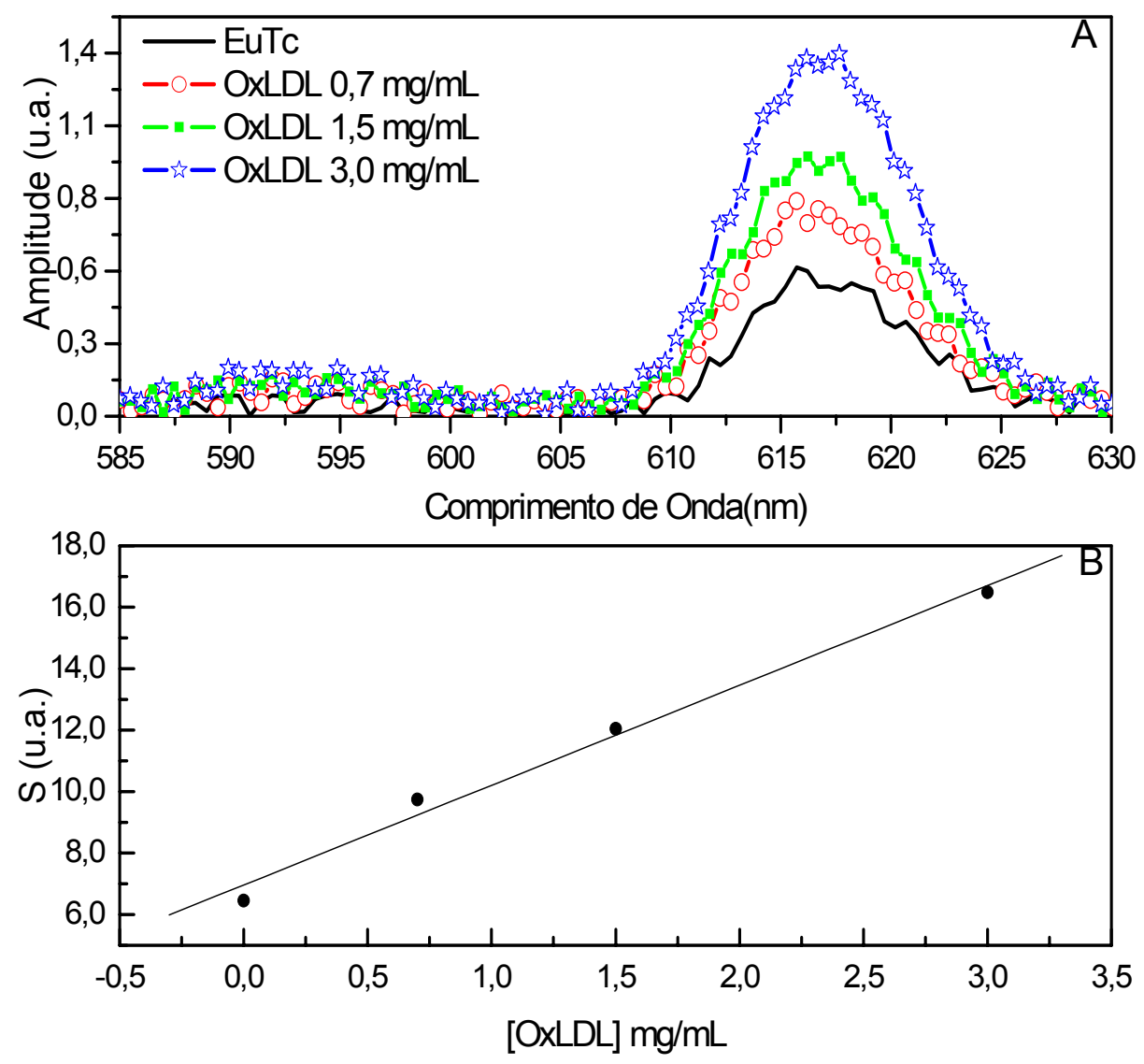

Figura 39 - a) Espectro de emissão das soluções EuTc e EuTc:OxLDL com diferentes concentrações da lipoproteína; b) Área integrada (S) do espectro de emissão em função da concentração de OxLDL. A linha sólida corresponde ao ajuste linear dos dados experimentais. 


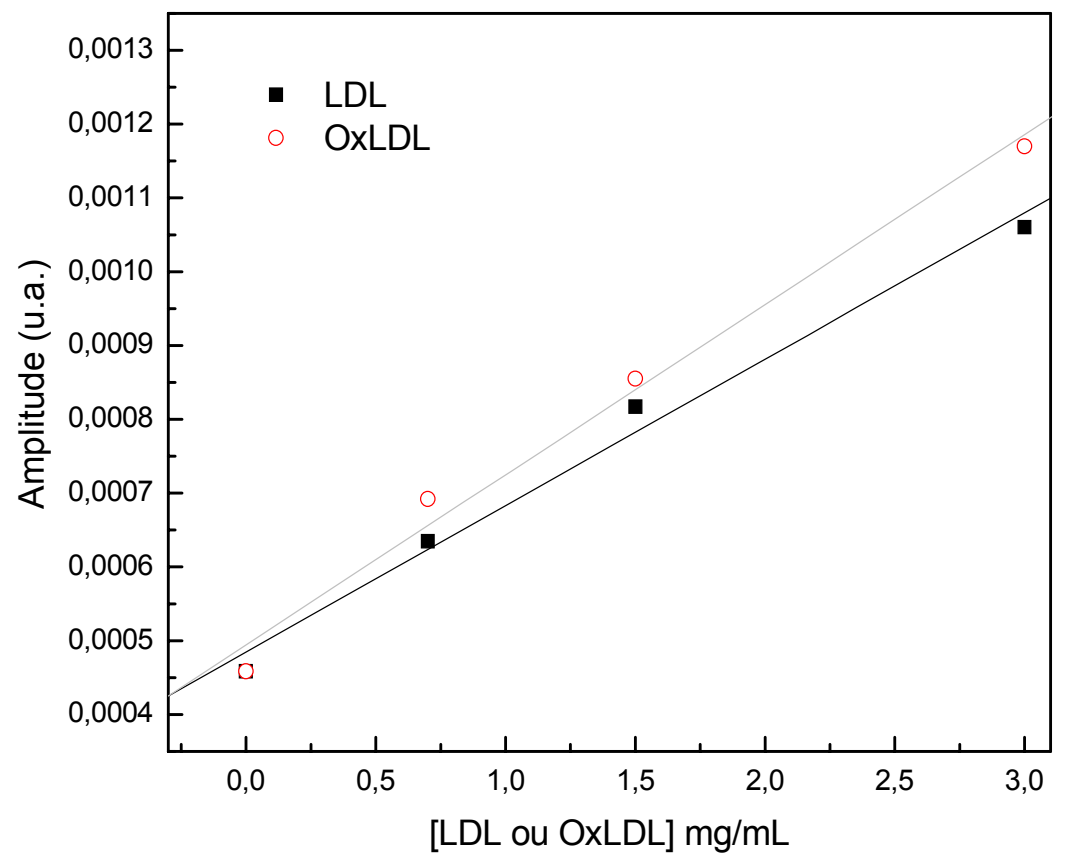

Figura 40 - Comparação entre as curvas de calibração LDL e OxLDL, intensidade de emissão X concentração da lipoproteína.
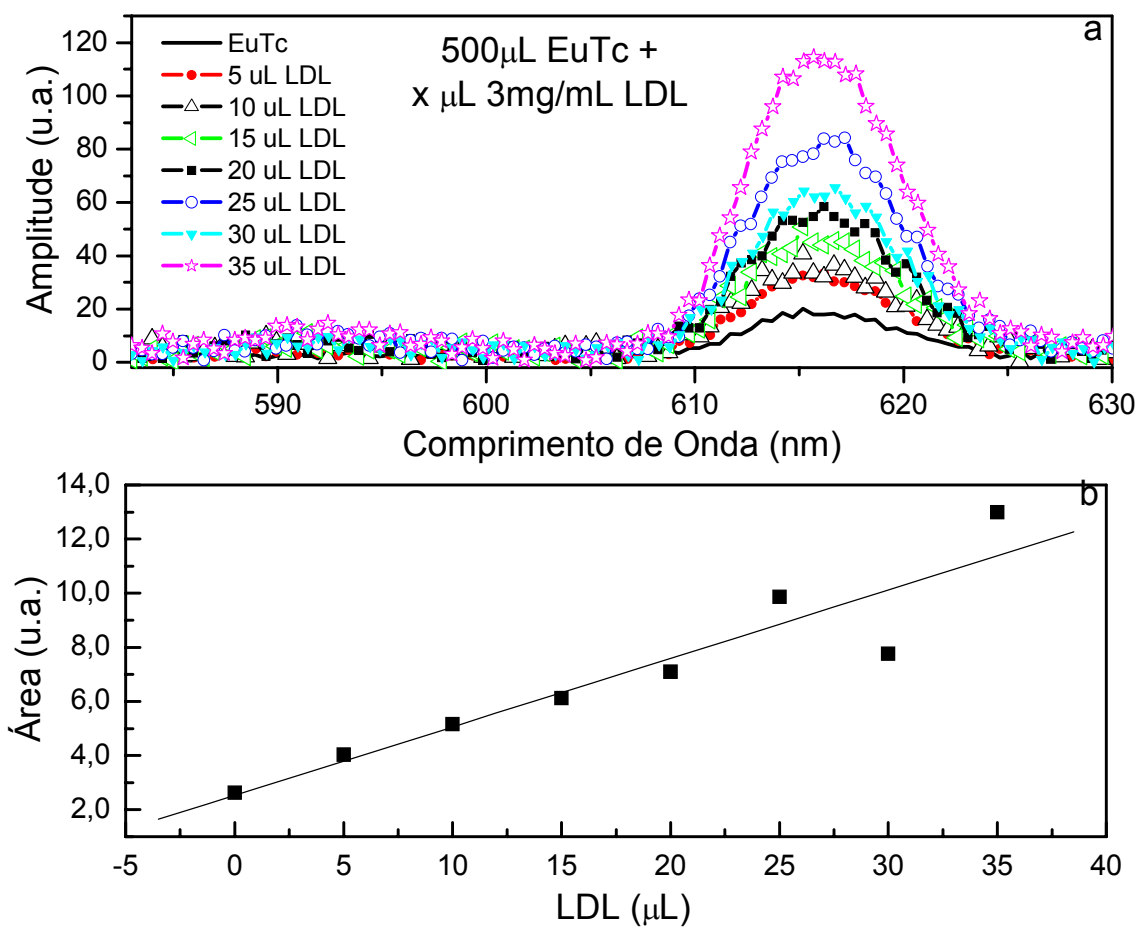

Figura 41 - a) Aumento da luminescência do európio com a variação da concentração de LDL $(3 \mathrm{mg} / \mathrm{mL})$ na solução EuTc. b) Dependência da área da banda de emissão do complexo, com a variação de LDL. 

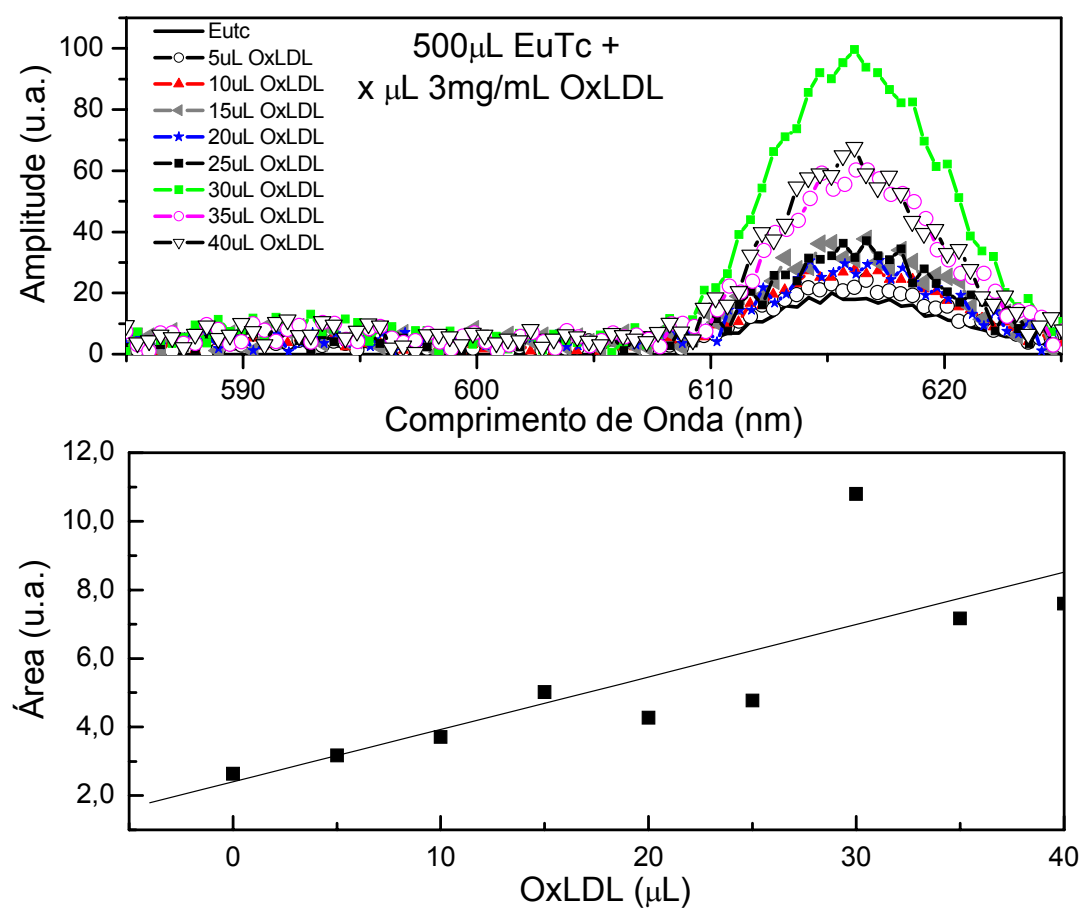

Figura 42 - a) Aumento da luminescência do európio com a variação da concentração de OxLDL $(3 \mathrm{mg} / \mathrm{mL})$ na solução EuTc. b) Dependência da área da banda de emissão do complexo, com a variação de OxLDL.

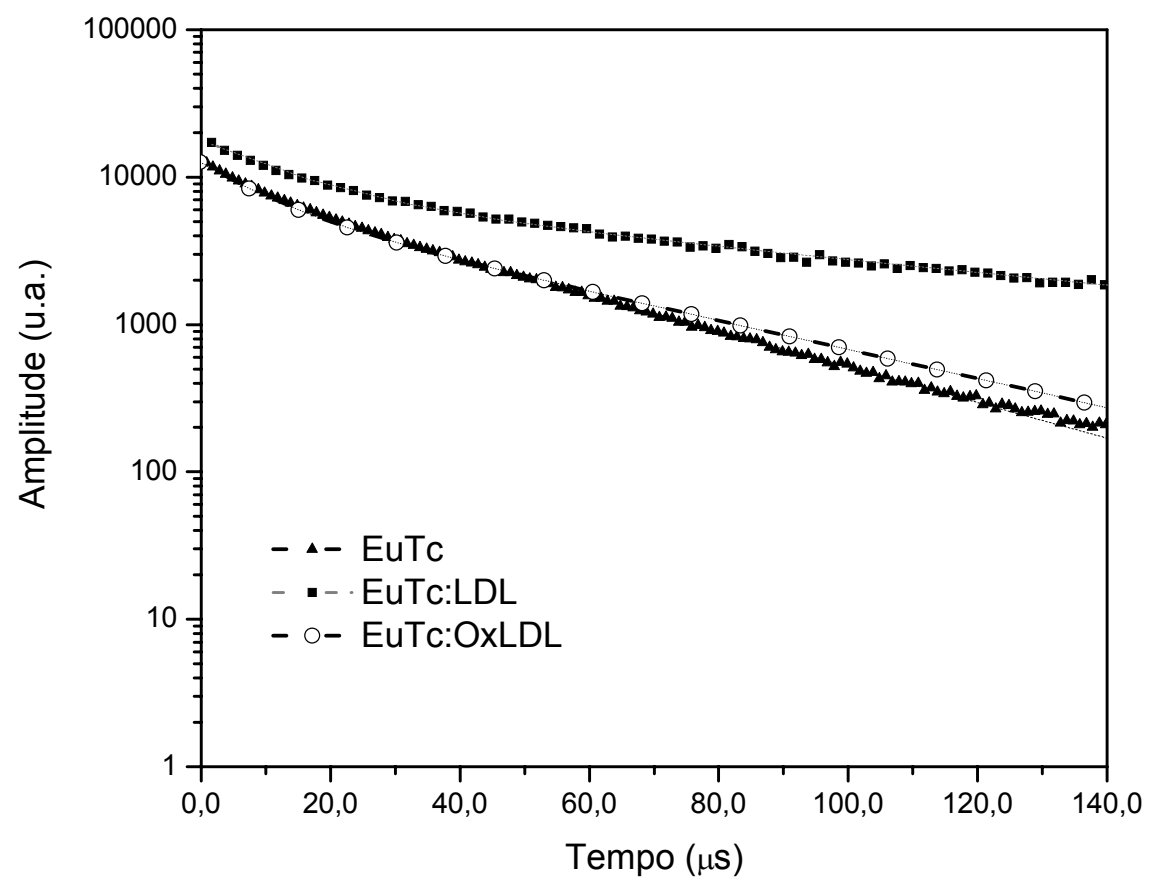

Figura 43 - Perfil do tempo de vida das soluções EuTc pura $(500 \mu \mathrm{L})$ e na presença de $5 \mu \mathrm{L}$ de LDL / OxLDL $(2,84 \mathrm{mg} / \mathrm{mL})$. 
Em relação ao tempo de vida do complexo na presença de LDL e OxLDL, como mostrado na Figura 43, há um aumento no tempo de decaimento para as amostras que contêm lipoproteínas. As médias do tempo de vida para as amostras são $21 \mu \mathrm{s}, 89 \mu \mathrm{s}$ e $34 \mu \mathrm{s}$ para o EuTc, EuTc:LDL e EuTc: OxLDL, respectivamente. Essa diferença entre o tempo de vida das amostras que contêm LDL e as que contêm OxLDL pode ser devido a algum processo de transferência de energia ocorrendo entre os íons $\mathrm{Eu}$ e $\mathrm{Cu}$, ou mesmo devido a modificação da lipoproteína durante o processo de oxidação.

Tabela 6 - Parâmetros para o ajuste das eq. (4) e eq. (5) com os dados experimentais da Figura 43.

\begin{tabular}{cccccc}
\hline Complexo & \multicolumn{2}{c}{ Parâmetros } & Erros $( \pm)$ & Amplitude $(\%)$ & $\tau_{a v}(\mu s)$ \\
\hline EuTc & $\mathrm{A}_{1}$ & 216.57996 & 15.0014 & $(17.7 \%)$ & \\
& $\tau_{1}$ & $3.48728 \mathrm{E}-6$ & $3.9547 \mathrm{E}-7$ & & \\
& $\mathrm{~A}_{2}$ & 1006.3941 & 14.5471 & $(82.3 \%)$ & 20,8 \\
& $\tau_{2}$ & $2.0855 \mathrm{E}-5$ & $2.3851 \mathrm{E}-7$ & & \\
EuTc: LDL & $\mathrm{A} 1$ & 10463 & 63 & $(58,7 \%)$ & \\
& $\tau_{1}$ & $10,0 \mathrm{E}-6$ & $2,0 \mathrm{E}-7$ & & \\
& $\mathrm{~A} 2$ & 7369 & 63 & $(41,3 \%)$ & 89 \\
& $\tau_{2}$ & $100,0 \mathrm{E}-6$ & $1,0 \mathrm{E}-7$ & & \\
EuTc: & $\mathrm{A} 1$ & 6018,1 & 0,1 & $(48,1 \%)$ & \\
OxLDL & $\tau_{1}$ & $10,0 \mathrm{E}-6$ & $1,0 \mathrm{E}-6$ & $(51,9 \%)$ & 34,4 \\
& $\mathrm{~A} 2$ & 6490,8 & 0,1 & & \\
\hline
\end{tabular}

O processo é muito simples, rápido e de baixo custo. A determinação do colesterol, seja total ou fracionado (muito importante em análises clínicas, na indústria química e alimentícia), é feita simplesmente pela adição da amostra das frações de colesterol à solução EuTc. 


\subsection{GLICOSE}

Pelas eq. (1) e eq. (2) verifica-se que é possível a determinação de glicose pela sonda EuTc. Em vista disso, realizou-se um estudo com esses reagentes, apresentados nas figuras a seguir.

Na Figura 44 é mostrado que a presença de glicose não proporciona aumento na intensidade de emissão do európio na solução, porém quando se adiciona GOx, com a quebra da molécula e a subseqüente liberação de HP na solução, possibilita, assim, uma intensidade muito maior da emissão do complexo (Figura 45), além, de dividir a banda em duas (Figura 47), como ocorreu na presença de HP e PHU. No estudo realizado foi considerado que a melhor concentração de GOx na solução é $5 \%$ da concentração de glicose utilizada (Figura 45), pois com $100 \mu \mathrm{L}$ de glicose para $5 \mu \mathrm{L}$ de GOx já há um aumento considerável e para maiores concentrações de glicose, para a mesma quantidade de GOx, o aumento é pouca coisa maior, o que não justifica a utilização de mais reagente.

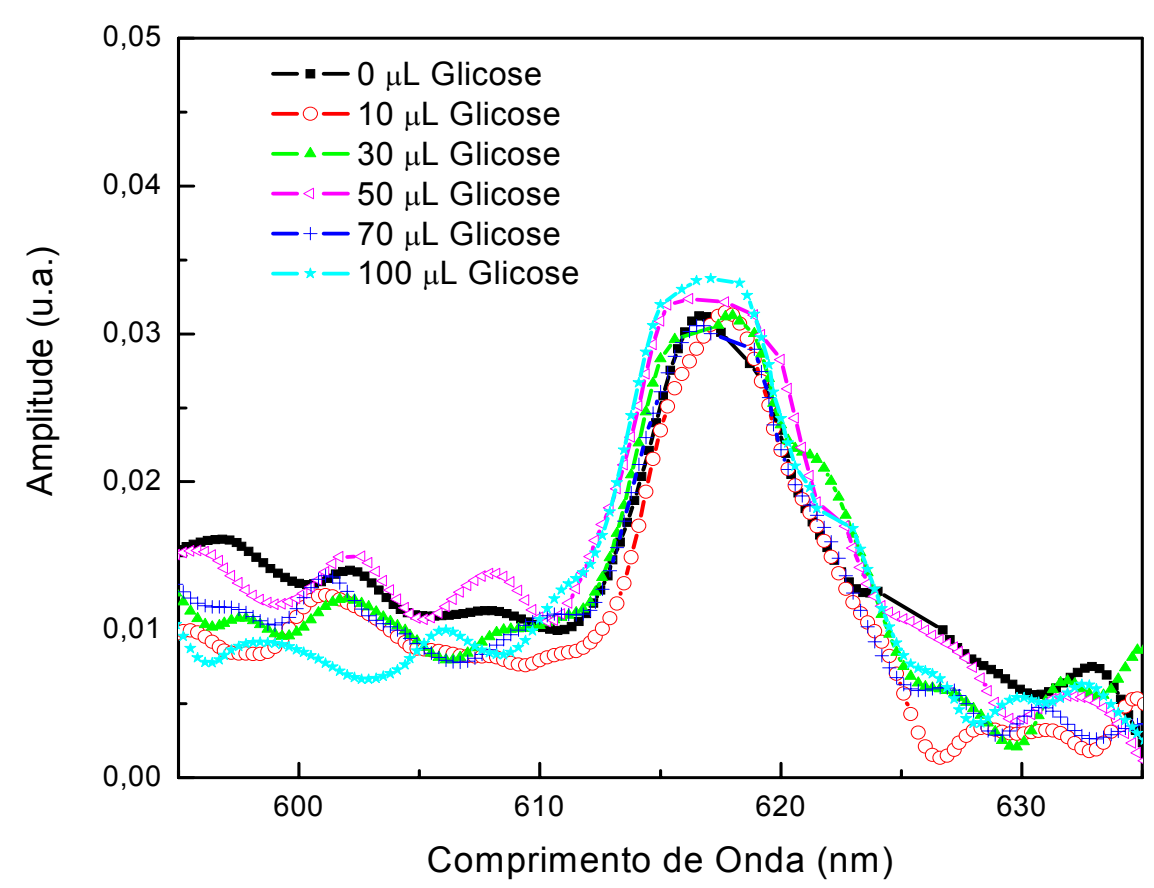

Figura 44 - Emissão do complexo EuTc com adição de Glicose. 


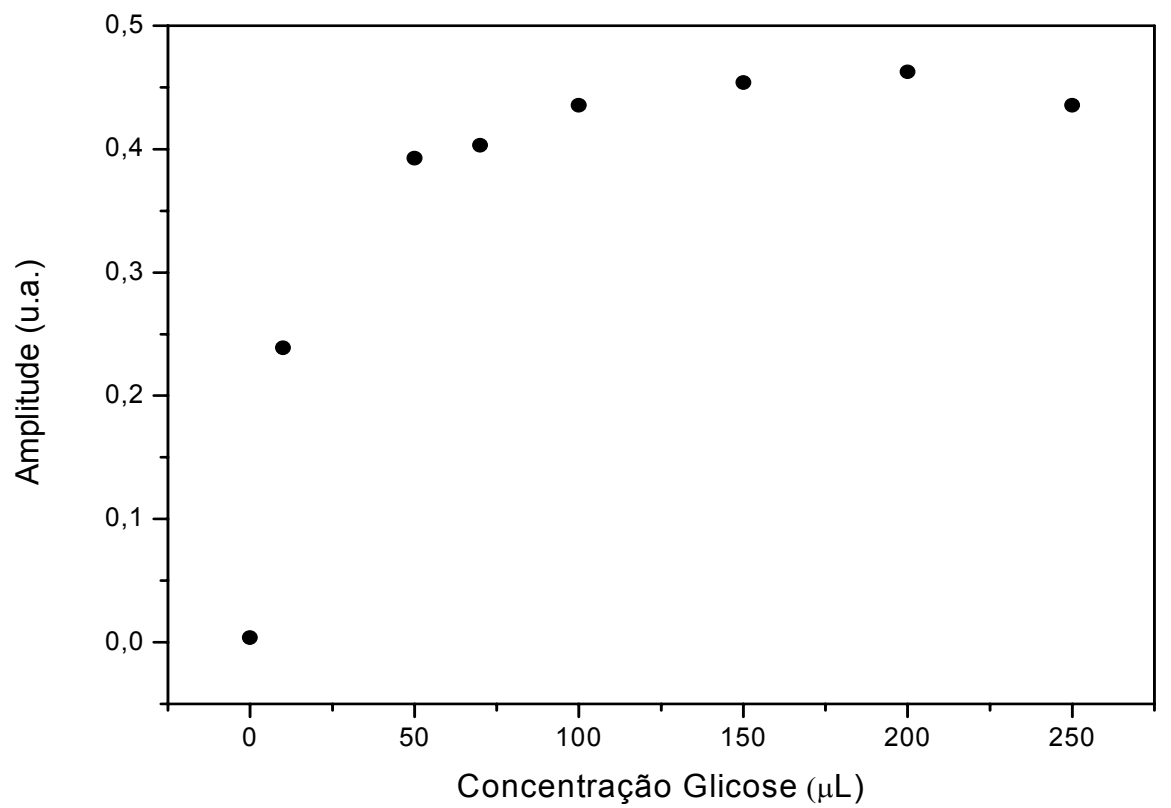

Figura 45 - Solução EuTc: Glicose + GOx. Variação da glicose de 0 a $250 \mu \mathrm{L}$ para $5 \mu \mathrm{L}$ de GOx.

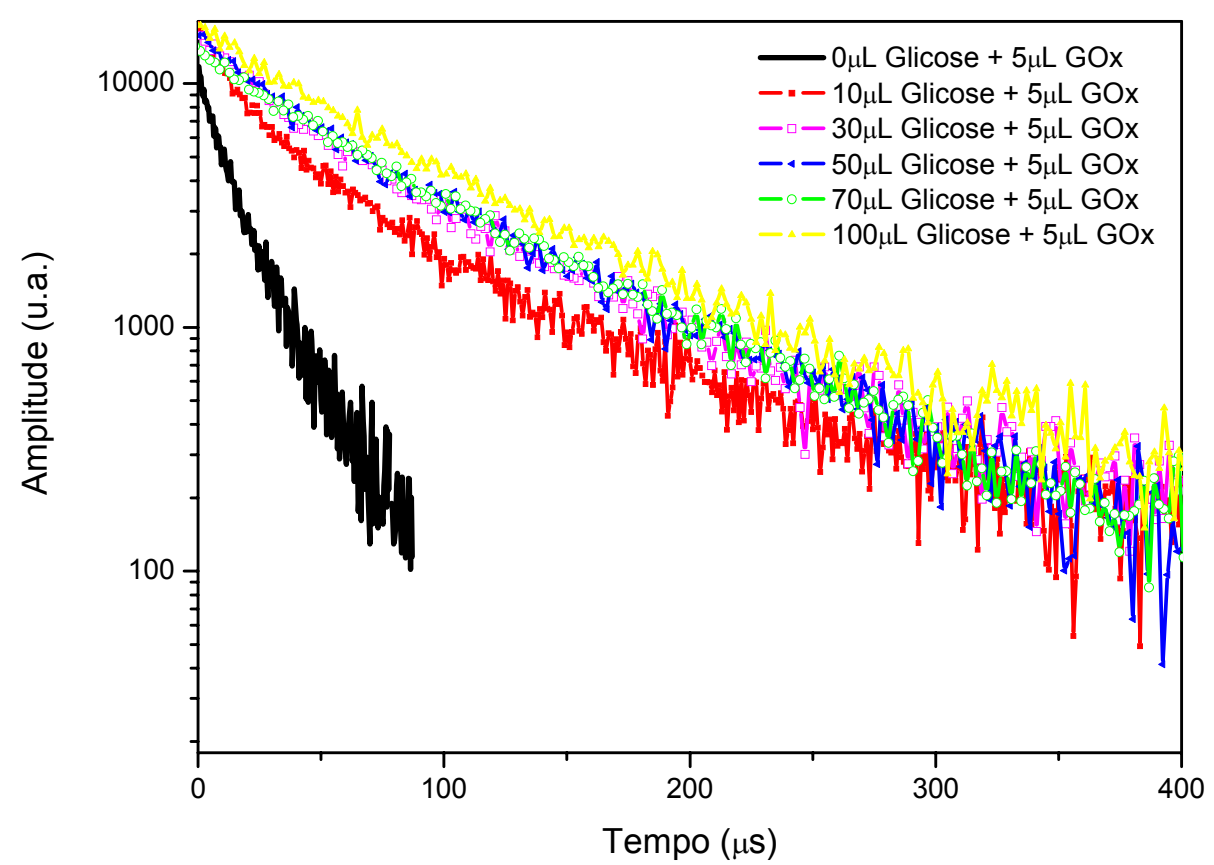

Figura 46 - Perfil de decaimento do tempo de vida das soluções de EuTc contendo variadas concentrações de glicose e $5 \mu \mathrm{L}$ de GOx. 
Os tempos de vida dessas soluções também foram medidos (Figura 46) e mostram que há um tempo de decaimento mais longo para maiores concentrações de glicose, pois há uma maior liberação de HP e dessa forma mais moléculas de água são substituídas na coordenação do európio. Na Tabela 7 é apresentado o tempo de vida total, de cada uma das soluções.

Tabela 7 - Tempo de vida total das soluções de $1 \mathrm{~mL}$ EuTc $+X \mu \mathrm{L}$ glicose $+5 \mu \mathrm{L}$ GOx.

\begin{tabular}{cc}
\hline $\begin{array}{c}\text { Complexo } \\
\text { EuTc }\end{array}$ & $\begin{array}{c}\text { Tempo de } \\
\text { Vida }\end{array}$ \\
\hline $0 \mu \mathrm{L}$ Glicose $+5 \mu \mathrm{L} \mathrm{GOx}$ & $20,8 \mu \mathrm{s}$ \\
$10 \mu \mathrm{L}$ Glicose $+5 \mu \mathrm{L}$ GOx & $61,6 \mu \mathrm{s}$ \\
$30 \mu \mathrm{L}$ Glicose $+5 \mu \mathrm{L}$ GOx & $70,5 \mu \mathrm{s}$ \\
$50 \mu \mathrm{L}$ Glicose $+5 \mu \mathrm{L}$ GOx & $76,6 \mu \mathrm{s}$ \\
$70 \mu \mathrm{L}$ Glicose $+5 \mu \mathrm{L}$ GOx & $78,8 \mu \mathrm{s}$ \\
$100 \mu \mathrm{L}$ Glicose $+5 \mu \mathrm{L}$ GOx & $82,9 \mu \mathrm{s}$ \\
\hline
\end{tabular}

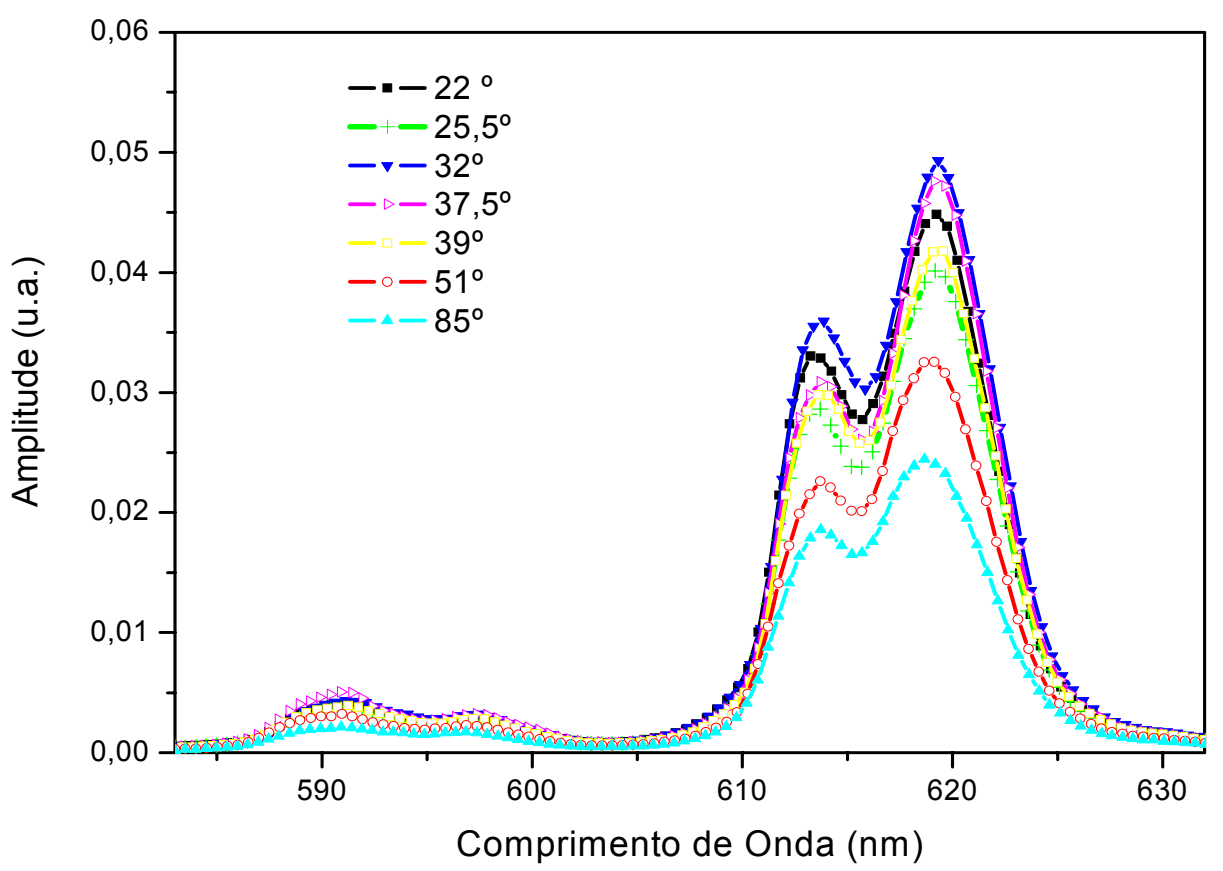

Figura 47 - Variação Temperatura 
Para verificar qual a melhor temperatura de utilização do biossensor para a determinação de glicose, foram preparadas sete soluções de $1 \mathrm{~mL}$ de EuTc adicionando-se $100 \mu \mathrm{L}$ de glicose e em seguida, misturou-se $5 \mu \mathrm{L}$ de GOx, em cada. Assim que esse último reagente foi adicionado, a solução foi levada para o equipamento de variação de temperatura e nele permaneceu por 10 minutos. Para cada solução foi escolhida uma das temperaturas: $22^{\circ} \mathrm{C} ; 25,5^{\circ} \mathrm{C} ; 32^{\circ} \mathrm{C} ; 37,5^{\circ} \mathrm{C}$; $39^{\circ} \mathrm{C} ; 51^{\circ} \mathrm{C}$ ou $85^{\circ} \mathrm{C}$. Observa-se, na Figura 47 , que a melhor temperatura para os testes de Glicose $+\mathrm{GOx}$ é $32^{\circ} \mathrm{C}$.

Sabendo-se a melhor temperatura, foi proposto o estudo da variação do tempo de reação para a solução EuTc + Glicose $+\mathrm{GOx}$ à $32^{\circ} \mathrm{C}$. Verifica-se que tanto a intensidade do sinal quanto a área da banda principal do espectro apresentam um aumento quase linear até aproximadamente $20 \mathrm{~min}$. (Figura 48).
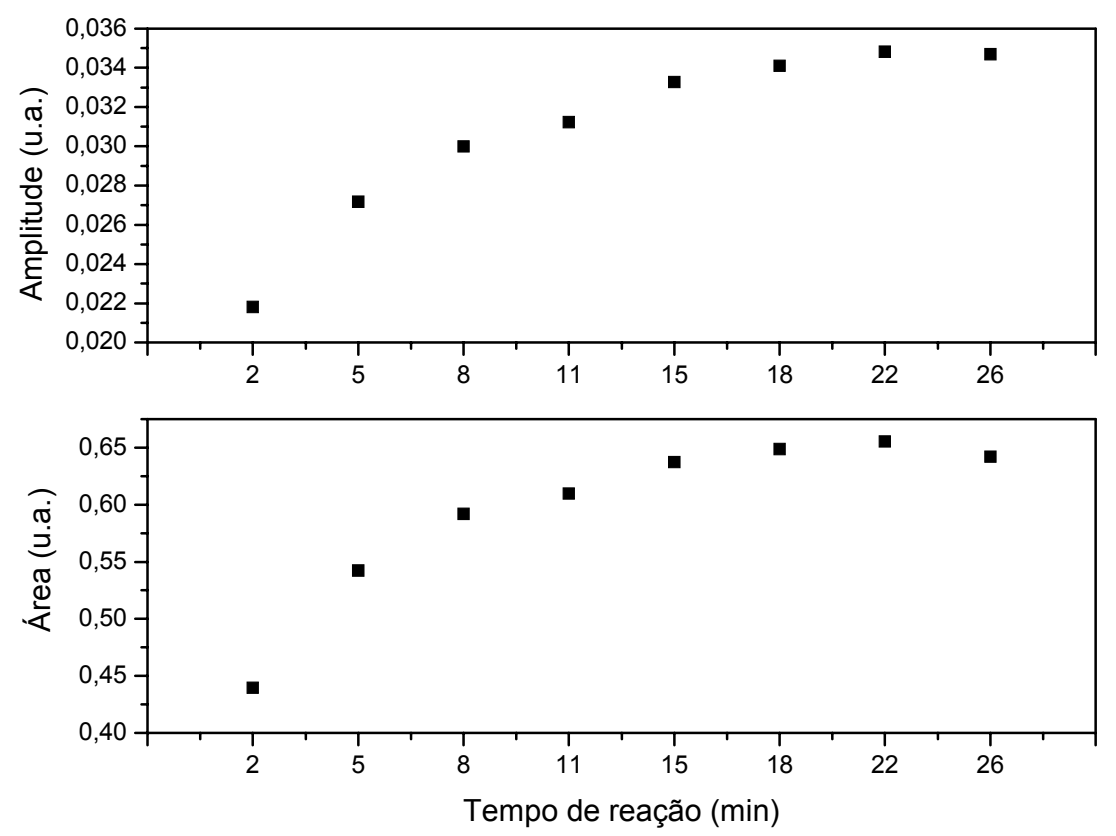

Figura 48 - Curva de calibração de intensidade e área do sinal em função da Temperatura $\left(32^{\circ} \mathrm{C}\right)$ para variados tempos de reação da solução EuTc:Glicose + GOx.

\subsection{BIOSSENSOR EUTC}

Na Tabela 8 é mostrado o resumo dos resultados das medidas de peróxido de hidrogênio, peróxido de uréia, colesterol, LDL e OxLDL, e glicose, utilizando o 
biossensor EuTc. A intensidade relativa representa a intensidade máxima medida para cada substância / intensidade de emissão do complexo EuTc puro.

Pode-se verificar que não há uma relação direta entre o aumento no tempo de vida e na intensidade de emissão da solução, embora a variação no sinal, dependendo da concentração da substância em questão presente na solução, possa ser analisada tanto pelo tempo de vida quanto pela emissão.

Tabela 8 - Resumo dos resultados obtidos para o biossensor EuTc.

\begin{tabular}{cccc}
\hline Complexo & $\begin{array}{c}\text { Intensidade } \\
\text { Relativa }\end{array}$ & $\begin{array}{c}\text { Limite de } \\
\text { Detecção }\end{array}$ & $\begin{array}{c}\text { Tempo de } \\
\text { Vida }\end{array}$ \\
\hline EuTc & 1 & - & $\sim 21 \mu \mathrm{s}$ \\
EuTc - HP & 5,75 & $0,331 \mathrm{mg} / \mathrm{mL}$ & $48,5 \mu \mathrm{s}$ \\
EuTc - PHU & 43,07 & $0,115 \mathrm{mg} / \mathrm{mL}$ & $64,8 \mu \mathrm{s}$ \\
EuTc - Colesterol & 5,56 & $0,101 \mathrm{mg} / \mathrm{mL}$ & $83 \mu \mathrm{s}$ \\
EuTc - LDL & 6,76 & $0,234 \mathrm{mg} / \mathrm{mL}$ & $89 \mu \mathrm{s}$ \\
EuTc - OxLDL & 5,56 & $0,234 \mathrm{mg} / \mathrm{mL}$ & $34 \mu \mathrm{s}$ \\
EuTc - Glicose & 116,1 & $1,07 \mathrm{mg} / \mathrm{mL}$ & $82,9 \mu \mathrm{s}$ \\
\hline
\end{tabular}

\subsection{MONTAGEM E TESTES DO PROTÓTIPO DO EQUIPAMENTO}

Foi proposto o desenvolvimento de um protótipo de um equipamento miniaturizado, e de baixo custo, para a realização das medidas de emissão. Esse equipamento é composto de uma fonte de radiação: o LED violeta, um filtro de banda passante e um detector: fotodiodo com amplificador (sensor óptico). Eventualmente podem ser adicionadas lentes para focalizar o feixe incidente ou a radiação emitida e filtro para barrar a luz em outros comprimentos de onda. 


\subsubsection{Testes do LED}

Foram testados dois LEDs montados em dois tipos de arranjos diferentes. O primeiro LED (LED ajustável) permitia o ajuste da intensidade luminosa e o segundo LED (LED fixo) tinha uma intensidade fixa.

Uma caracterização dos dois arranjos foi realizada utilizando-se o complexo EuTc:PHU e um espectrômetro de fibra da Newport. Na montagem do LED ajustável foi construído um circuito utilizando-se um potenciômetro para verificar se a intensidade do LED interferia no resultado. Verificou-se que com o aumento da intensidade do LED, maior é o sinal detectado (Figura 49.a), e o sinal da solução EuTc-PHU é proporcionalmente mais intenso também.

Na Figura 49.b é mostrado o espectro obtido do LED fixo, construído com a menor resistência permitida, para obter-se a maior intensidade de luz. Podemos observar que no LED ajustável o comprimento de onda da luz é de $407 \mathrm{~nm}$, enquanto no outro é de $403 \mathrm{~nm}$; como a absorção do complexo EuTc é em aproximadamente $396 \mathrm{~nm}$, o LED com comprimento de onda mais próximo a esse é o mais indicado para ser usado no estudo que se segue.

Na Figura 50, é mostrada a diferença entre as intensidades de emissão do európio, para a mesma solução EuTc-PHU, no caso da utilização dos dois LEDs já mencionados acima (o LED fixo e o LED ajustável (na intensidade máxima)). Aquele que apresenta excitação em 403 nm possibilita uma maior intensidade devido à maior ressonância com a banda de absorção do complexo.

E por último, pode ser observada a variação da concentração de PHU na solução EuTc (Figura 51), obtidos nos testes preliminares com o LED fixo.

Como visto na Figura 52, a fibra óptica do detector é colocada a $90^{\circ} \mathrm{em}$ relação ao LED, para que seja coletada somente a radiação emitida e não a incidente. Entre eles é posicionada a cubeta que recebe a solução em estudo. No caso em questão, a solução era EuTc-PHU. É possível verificar uma emissão no vermelho, e comprová-la pelo espectro mostrado no visor do detector. Na Figura 53 é mostrada a lateral da cubeta em detalhe. 
a)

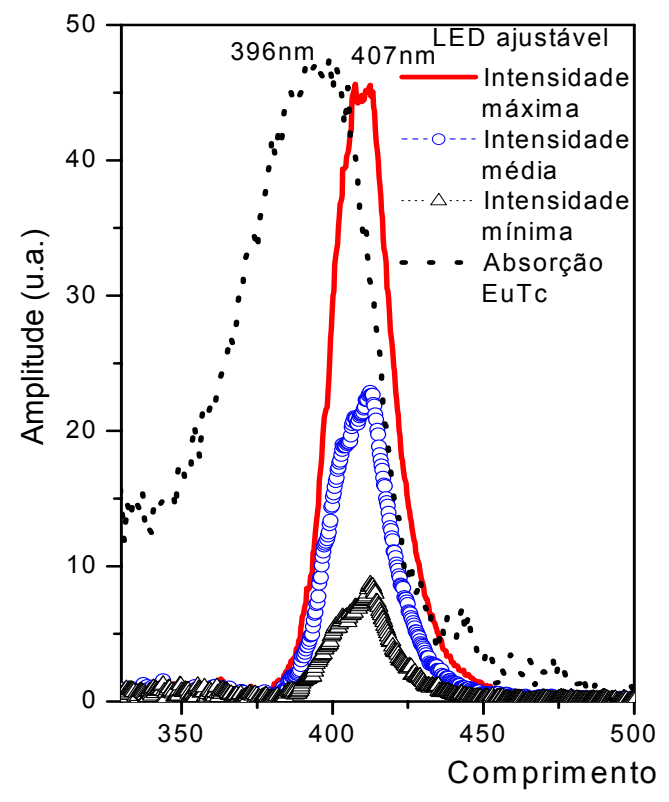

b)

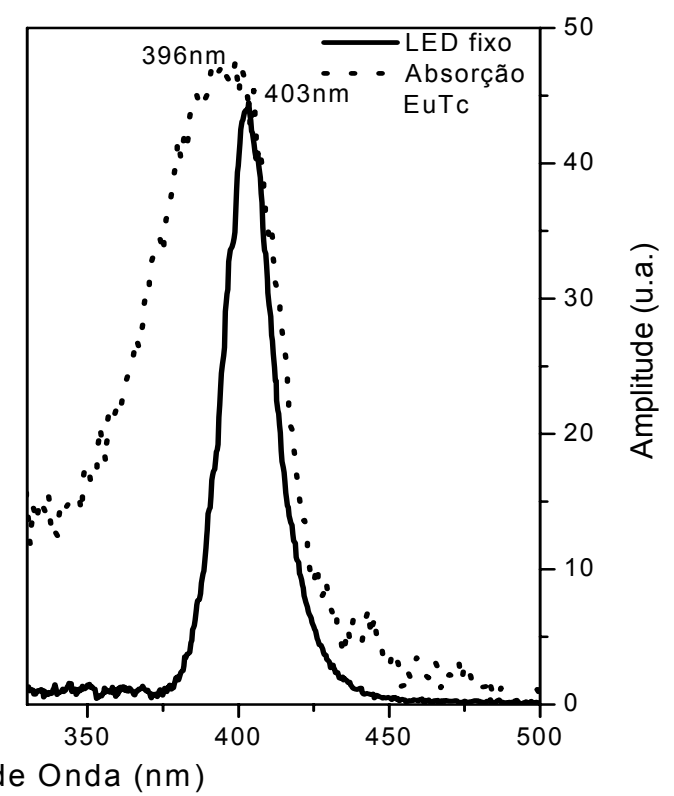

Figura 49 - LEDs com variadas intensidades e comprimentos de onda. E em pontilhado é mostrada a curva de absorção do complexo EuTc.

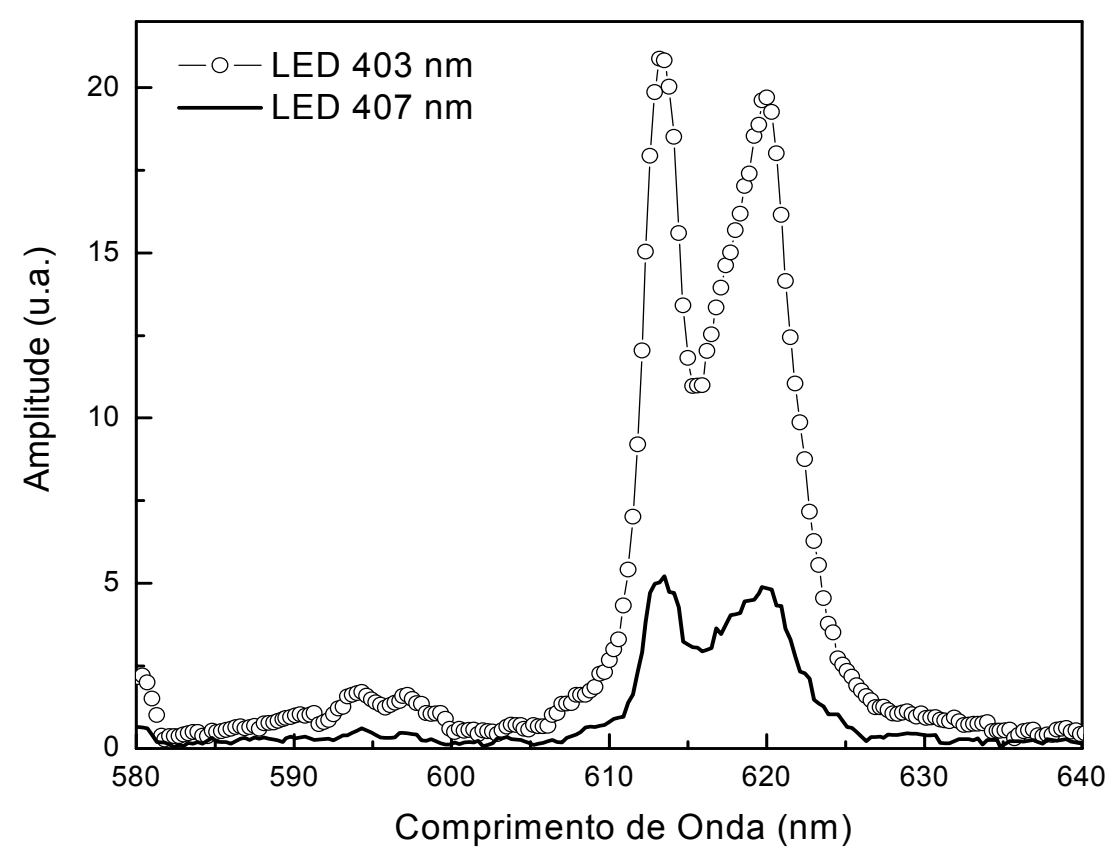

Figura 50 - Intensidade de emissão do európio na solução EuTc-PHU para comprimentos de onda distintos. 


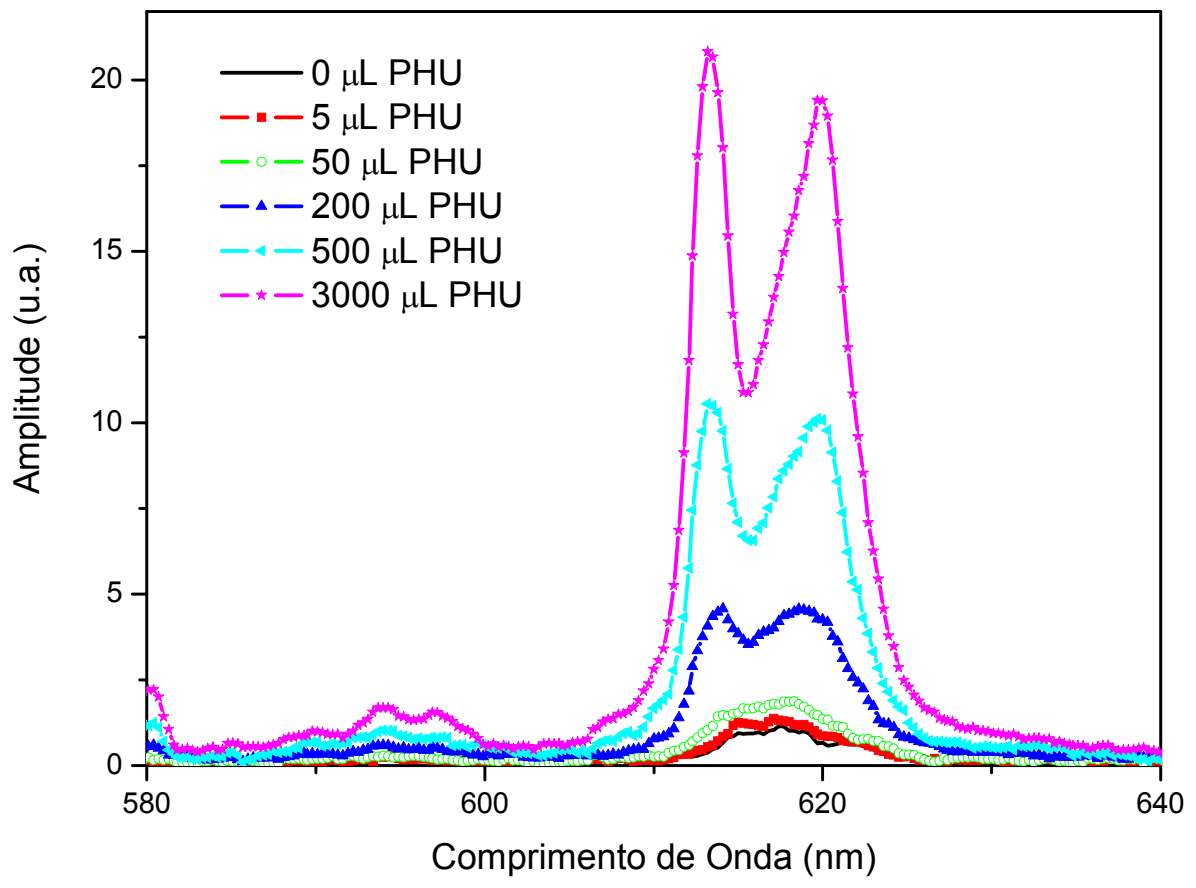

Figura 51 - Espectro obtido com o LED do protótipo do equipamento montado: variação de PHU na solução EuTc.

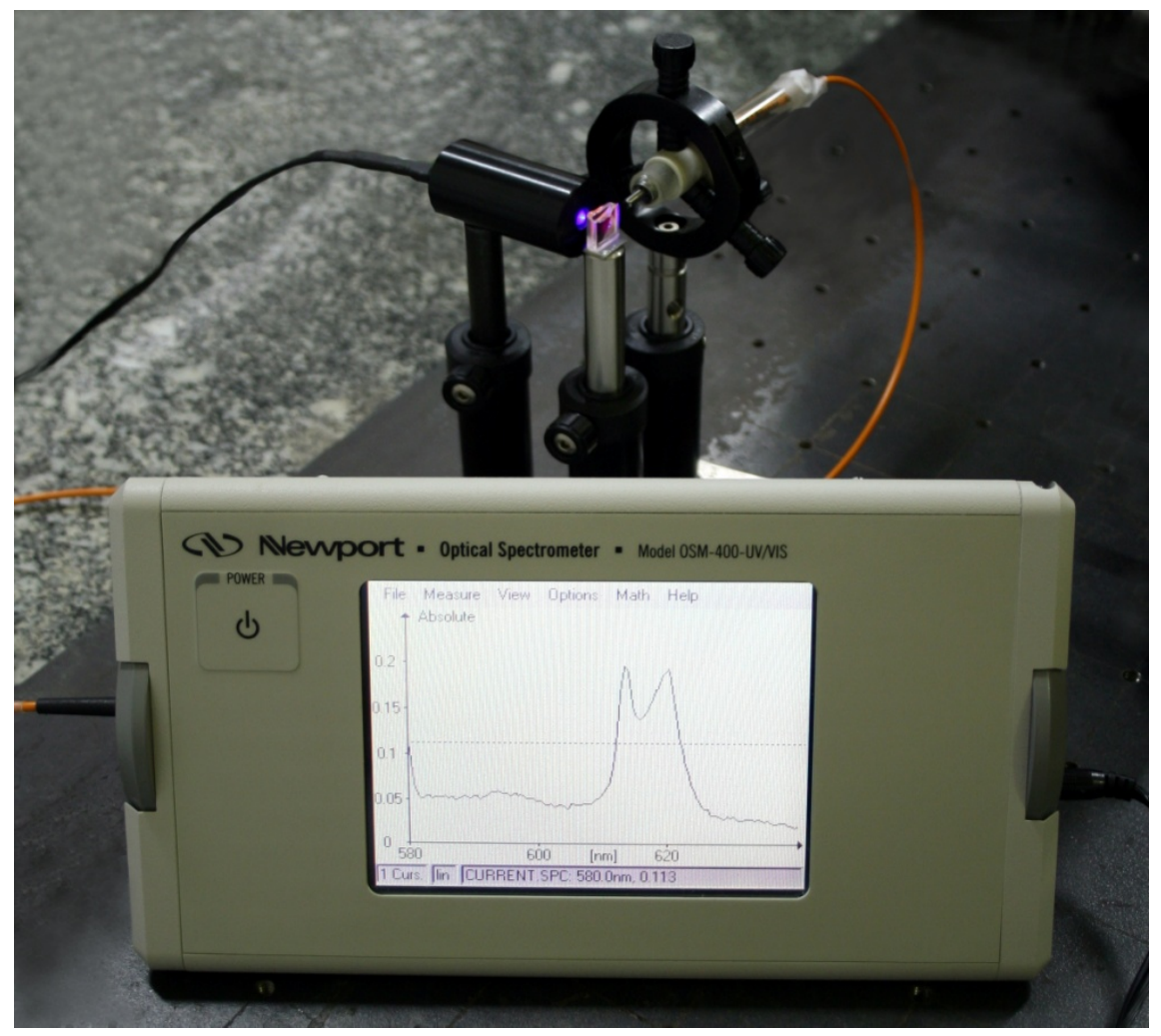

Figura 52 - Testes preliminares do LED para o protótipo do equipamento de emissão. 


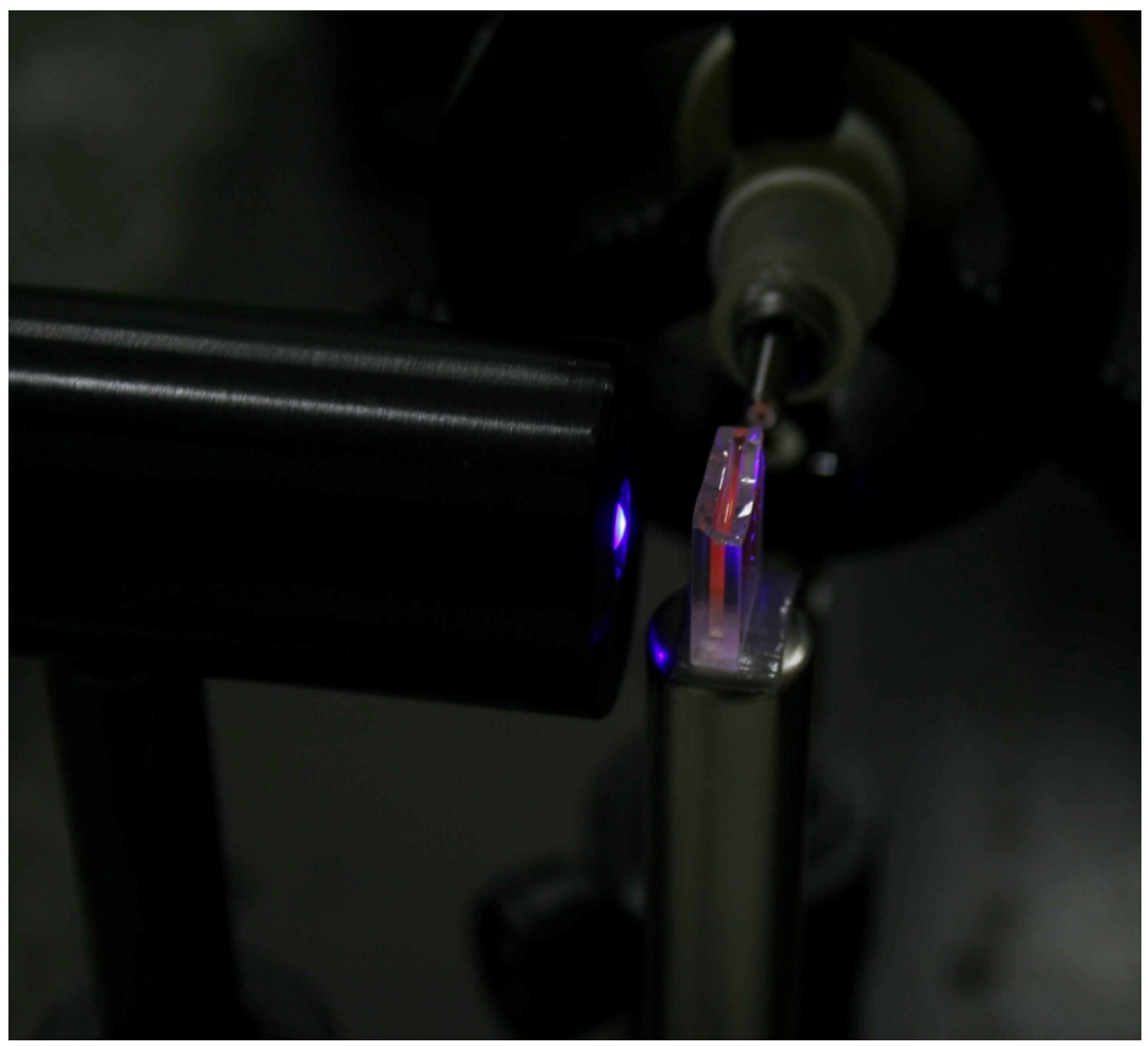

Figura 53 - Em detalhe, a lateral da cubeta com o complexo EuTc sendo excitado pelo LED violeta.

\subsubsection{TESTES FOTODIODO (SENSOR ÓPTICO)}

Para testar o sensor óptico foi utilizado o Conversor USB 6009 da National Instruments e o software LabView. Os componentes (LED, cubeta, filtro e detector (fotodiodo)) foram posicionados na mesma geometria da figura acima (a fonte de excitação a $90^{\circ}$ do detector). Os resultados mostram que o sensor óptico apresenta sensibilidade não só para detectar o sinal emitido pelo complexo EuTc na presença do PHU, mas também para distinguir as variadas concentrações do peróxido através da intensidade de luz emitida pelo európio, convertendo-a em voltagem (Figura 54). 


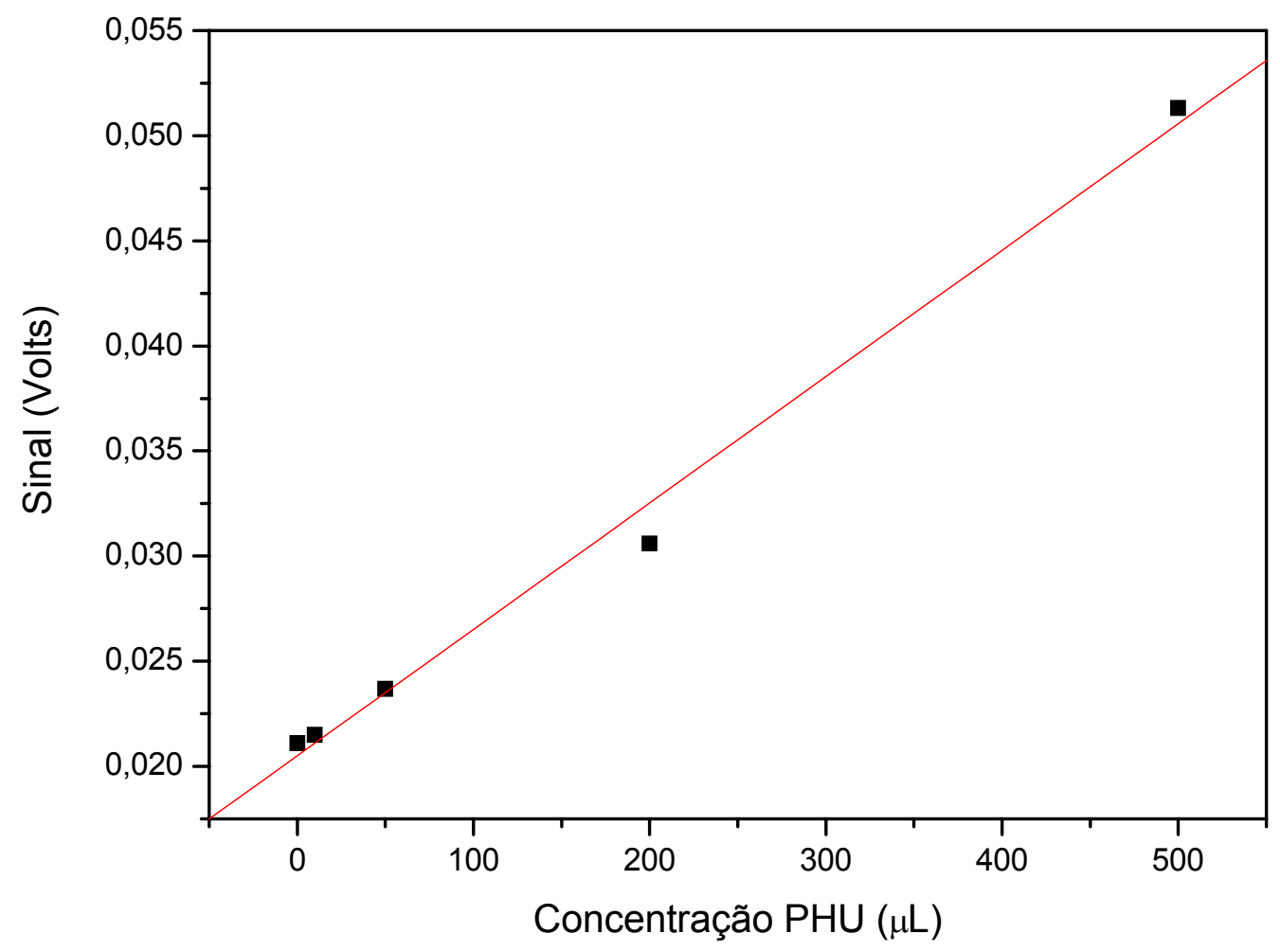

Figura 54 - Testes preliminares do sensor óptico: Concentração de PHU x Tensão.

As figuras a seguir mostram o esquema montado para os testes com o sensor óptico.

Na Figura 55 observa-se o arranjo com o LED violeta (1) excitando a solução na cubeta (2), a luz emitida juntamente com a luz de excitação chegam ao filtro (3), o qual deixa passar a luz emitida, que chega ao sensor óptico (4) sendo convertida em tensão (volts).

A Figura 56 mostra a lateral da cubeta, detalhando a emissão (vermelho) da solução EuTc na presença de $500 \mu \mathrm{L}$ de PHU.

Na Figura 57 é mostrado o arranjo completo montado para os testes do sensor óptico com o circuito montado para o fotodiodo e o conversor USB 6009 da National Instruments. 


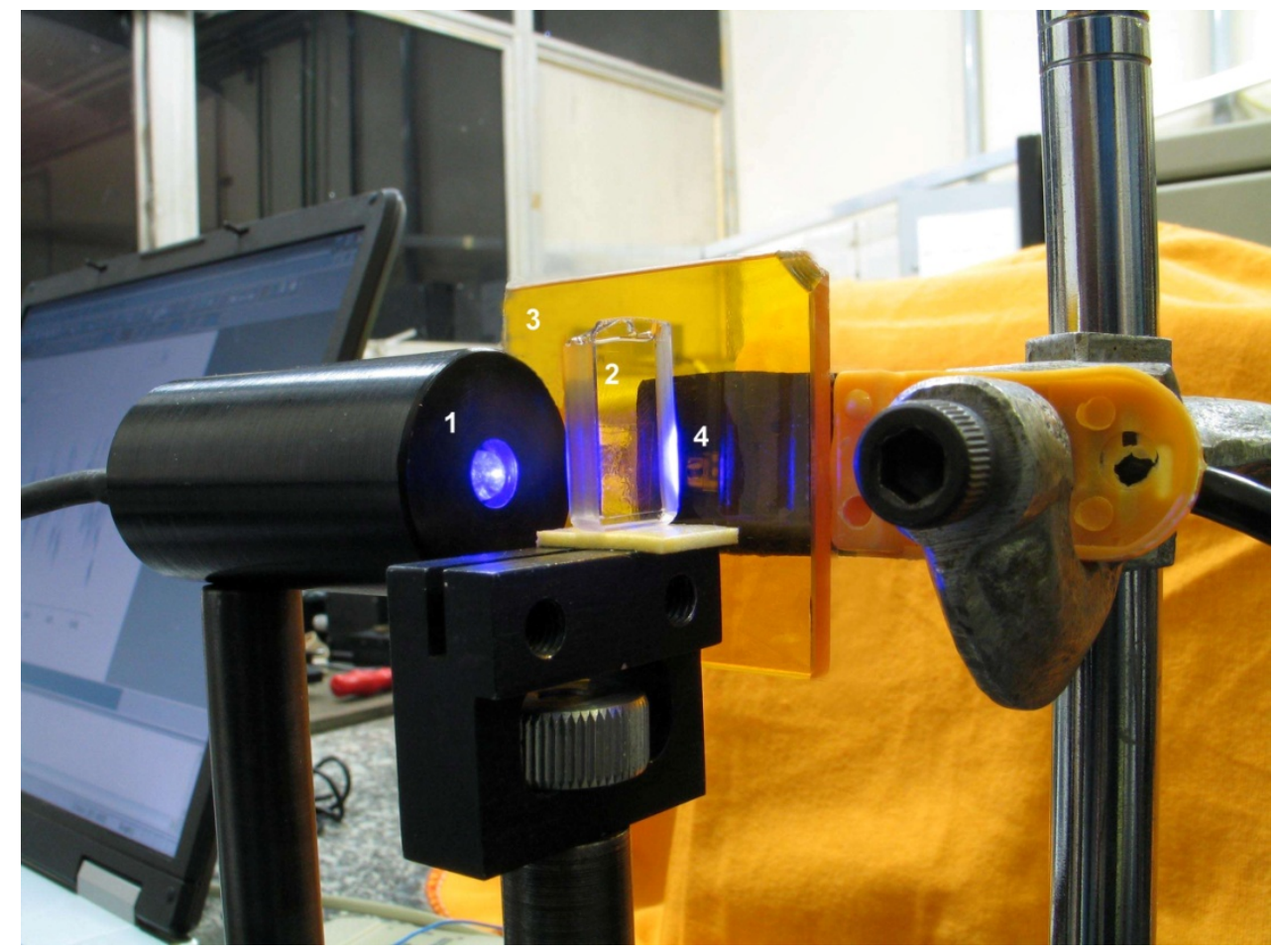

Figura 55 - Testes do sensor óptico: (1) LED, (2) Cubeta, (3) Filtro, (4) Sensor Óptico.

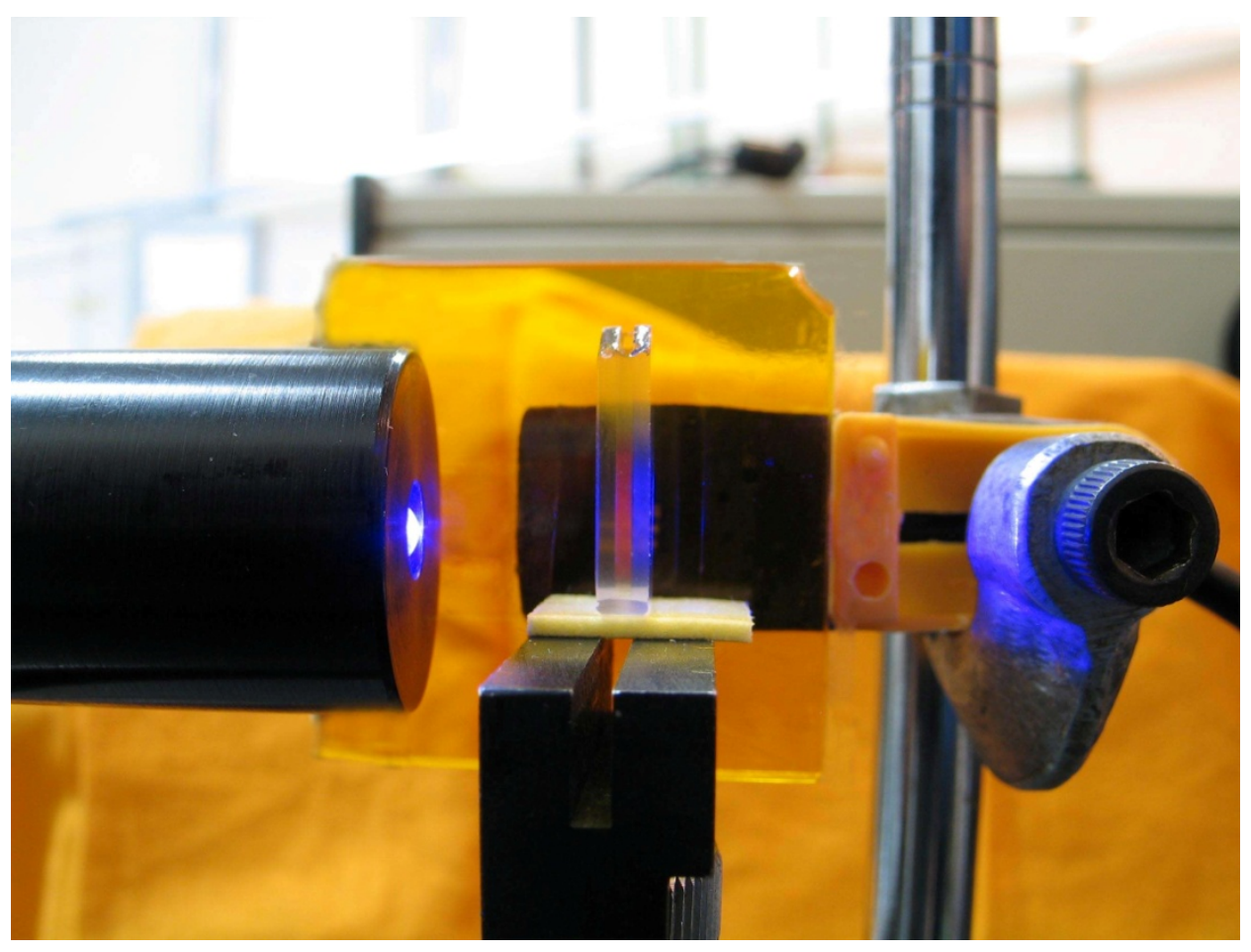

Figura 56 - Vista lateral da cubeta, mostrando em detalhe a emissão do Eu no complexo EuTc na presença do $\mathrm{PHU}$. 


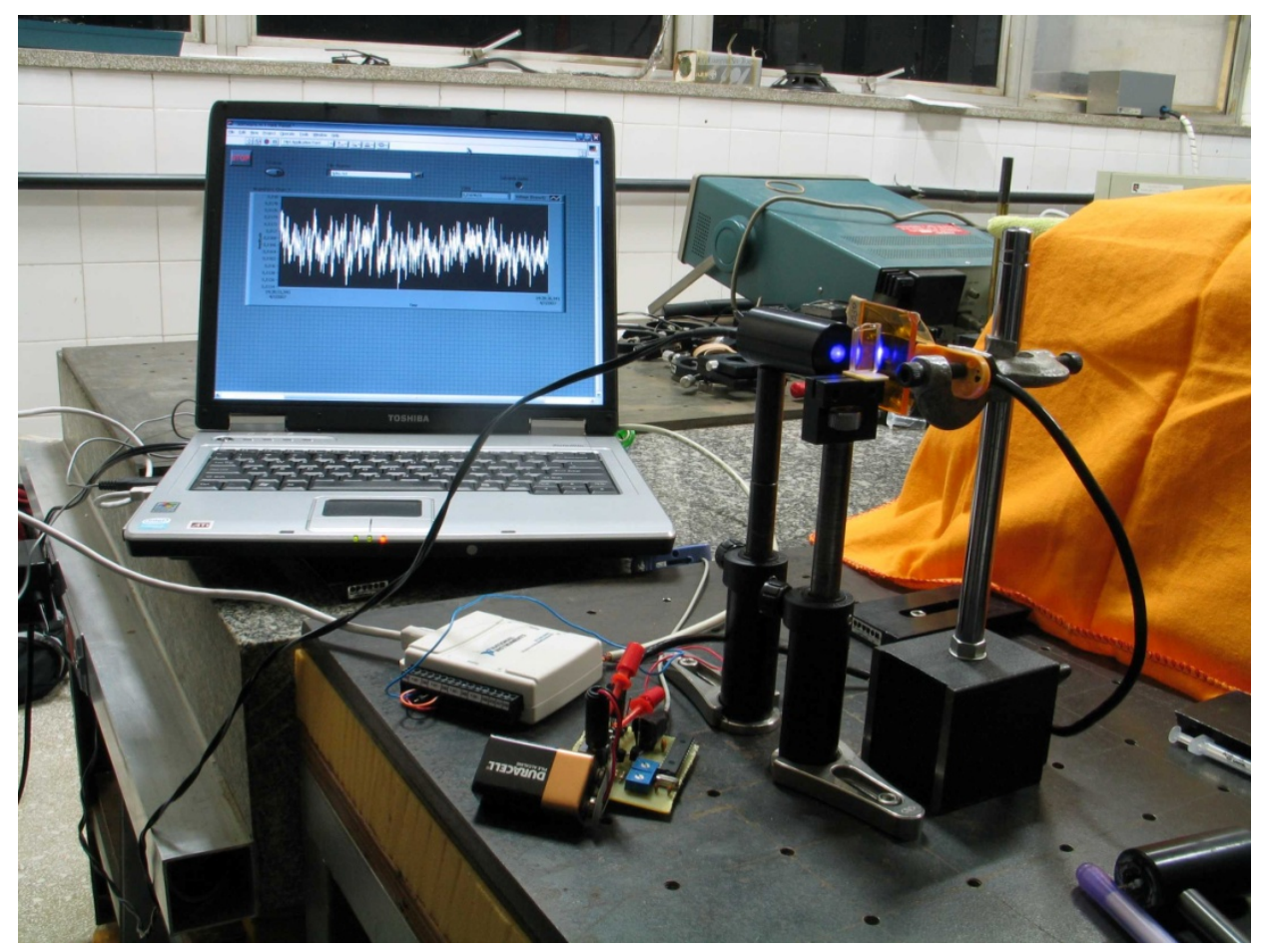

Figura 57 - Montagem completa para o teste do sensor óptico.

$\mathrm{O}$ circuito apresenta uma bateria de $9 \mathrm{~V}$, um regulador de tensão para $5 \mathrm{~V}, \mathrm{o}$ sensor óptico e o conversor digital. Quanto ao LabView, são usadas VIs expressas que reconhecem o conversor da National Instruments e fazem a leitura do sinal. Não fora usado nenhum filtro do LabView (o que poderia ser feito para suavizar o sinal), demonstrando que tanto a montagem do circuito quanto do programa é muito simples. 


\section{CONCLUSÕES}

Neste trabalho foi estudado um complexo do lantanídeo európio, o complexo Európio-Tetraciclina (EuTc), com o principal objetivo de utilizar os resultados destes estudos no desenvolvimento de um biossensor óptico de peróxido de hidrogênio. No decorrer deste estudo constatou-se a possibilidade de utilização do material para a quantificação também de peróxido de uréia, colesterol total, frações de colesterol e glicose. Desta forma o complexo EuTc é um sistema ou dispositivo analítico usado para a detecção de peróxido de hidrogênio, peróxido de uréia, glicose, colesterol e suas frações, em conjunção com um transdutor óptico, que converte o evento de reconhecimento biológico, no caso a fluorescência do íon európio, em um sinal de saída utilizável.

O complexo EuTc foi estudado e apresentou as seguintes características: grande deslocamento Stokes, picos de absorção em $\sim 400 \mathrm{~nm}$ e emissão em $\sim 615 \mathrm{~nm}$, tempo de vida longo ( $21 \mu \mathrm{s})$ e forte luminescência em $\mathrm{pH}$ neutro.

A estequiometria do complexo de európio com a tetraciclina foi investigada e o complexo 1,0Eu:1,0Tc apresenta maior sinal. Na presença de peróxido de hidrogênio o sinal de maior intensidade ocorre na proporção 3,0Eu:1,0Tc.

O aumento da emissão do európio com a adição de peróxido de hidrogênio e peróxido de uréia na solução EuTc ocorre devido à substituição de moléculas de água na coordenação do európio e a oxidação da Tc pelo peróxido, que permite a complexação de mais íons $\mathrm{Eu}^{3+}$ nos sítios da tetraciclina.

O peróxido de uréia proporciona uma intensidade até 40 vezes maior que a do európio sozinho na Tc, enquanto que o peróxido de hidrogênio aumenta em até 15 vezes. Isso significa que a sonda EuTc é ainda mais sensível para o PHU, permitindo a determinação de uma grande variedade de concentrações do peróxido na solução, sendo possível a utilização dessa sonda em análises clínicas. Isso torna a determinação mais precisa, rápida e barata por ser um método direto.

Foi observado, pela primeira vez, que o colesterol puro também aumenta a intensidade de emissão do európio, sem a necessidade da adição de enzima para a liberação de $\mathrm{H}_{2} \mathrm{O}_{2}$. A intensidade cresce linearmente com a concentração de colesterol até uma variação máxima de $90 \mu \mathrm{L}$ de colesterol total. O tempo de vida

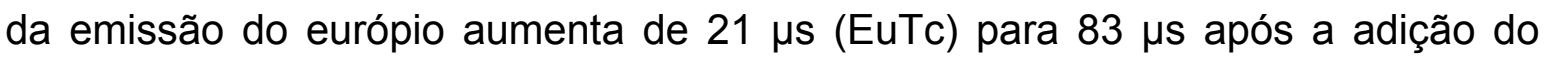


colesterol puro (solução EuTc-Colesterol). As frações de colesterol (LDL, VLDL e HDL) também podem ser determinadas por esse método, sem a necessidade de utilização de outros reagentes, sendo de rápida e barata análise. Um estudo mais aprofundado foi realizado com a Lipoproteína de Baixa Densidade tanto em sua forma nativa (LDL) quanto oxidada (OxLDL) devido à grande importância da mesma em análises clínicas, visto que ela está diretamente relacionada a doenças coronárias. Esse método, pela primeira vez proposto, simplifica a determinação de LDL e OxLDL.

O complexo EuTc se mostrou eficiente na detecção de glicose, sendo nesse caso, necessário a adição de glicose oxidase (GOx) para a liberação do peróxido de hidrogênio, pois a glicose sozinha não altera a resposta do complexo EuTc. Na presença de GOx, há um aumento na intensidade de emissão e no tempo de vida do Eu, diretamente proporcional à concentração de Glicose e GOx na solução. A temperatura de $32^{\circ} \mathrm{C}$ se mostrou a mais adequada para a ocorrência da reação enzimática.

O desenvolvimento do protótipo do equipamento, miniaturizado, de baixo custo para as medidas da emissão do Európio(III) se mostrou possível de ser realizado com um LED violeta, como fonte de excitação, um filtro de banda passante em $\sim 610 \mathrm{~nm}$ e um sensor óptico, atuando como detector. O fotodiodo apresenta sensibilidade para ser usado como sensor de colesterol total e suas frações, glicose, peróxido de hidrogênio e peróxido de uréia, convertendo a intensidade de luz emitida pelo európio, na presença desses reagentes, em tensão. O protótipo montado é de fácil portabilidade, rapidez nos resultados, ótima sensibilidade e acurácia, e baixo custo.

Como trabalhos futuros vislumbra-se a melhora do protótipo do equipamento para medida da emissão utilizando um LCD e um microcontrolador para torná-lo independente, e não mais ser necessário um notebook (com LabView ou outro software) para leitura do resultado das medidas, e diminuindo os custos para a fabricação do mesmo. Além disso, pode-se desenvolver o equipamento usando fibra óptica, guia de ondas (para medidas evanescentes), CCD e etc. Também um sistema sem fio (wireless) transferindo os dados para um palm, por exemplo, é uma outra opção.

E como trabalhos futuros com o biossensor, pretende-se analisar amostras de sangue de pacientes diabéticos. 


\section{PUBLICAÇÕES E PARTICIPAÇÃO EM EVENTOS}

\section{ARTIGOS COMPLETOS PUBLICADOS EM PERIÓDICOS}

1. SILVA, Flávia R.O.; Samad, Ricardo Elgul; GOMES, Laércio; COURROL, L. C. Enhancement of Europium Emission Band of Europium Tetracycline Complex in the Presence of Cholesterol. Journal of Fluorescence, v. 18, n. 1, p. 169-174, 2008.

2. COURROL, L. C.; MONTEIRO, A. M.; SILVA, Flávia R.O.; GOMES, Laércio ; VIEIRA JUNIOR, Nilson Dias; GIDLUND, M. A.; FIGUEIREDO NETO, A. M. Novel Fluorescent Probe for Low Density Lipoprotein. Optics Express, v. 15, p. 7066-7074, 2007.

3. COURROL, L. C.; SILVA, Flávia R.O.; GOMES, Laércio. A simple method to synthesize silver nanoparticles by photo-reduction. Colloids and Surfaces. A, Physicochemical and Engineering Aspects, v. 305, n. 1-3, p. 54-57, 2007.

4. COURROL, L. C.; SILVA, Flávia R.O.; COUTINHO, E. L.; PICCOLI, M. F.; MANSANO, Ronaldo; VIEIRA JUNIOR, Nilson Dias; SCHOR, N.; BELLINI, Maria Helena. Study of blood porphyrin spectral profile for diagnosis of tumor progression. Journal of Fluorescence, v. 17, n. 3, p. 289-292, 2007.

5. COURROL, L. C.; SILVA, Flávia R.O.; VIEIRA JUNIOR, Nilson Dias; GOMES, Laércio. Energy transfer Study of Europium-Tetracycline complexes. Journal of Luminescence, v. 122, p. 288-290, 2006.

6. COURROL, L. C.; BELLINI, Maria Helena; TARELHO, Luis Vicente Gomes; SILVA, Flávia R.O.; MANSANO, Ronaldo; GOMES, Laércio; VIEIRA JUNIOR, Nilson Dias; SCHOR, N. The Urea Hydrogen Peroxide Determination in Whole Blood Using Europium Tetracycline Probe. Analytical Biochemistry, v. 355, n. 1, p. 140-144, 2006. 
7. SILVA, Flávia R.O.; COURROL, L. C.; BELLINI, Maria Helena; TARELHO, Luis Vicente Gomes; MANSANO, Ronaldo ; VIEIRA JUNIOR, Nilson Dias; SCHOR, N. DETERMINAÇÃO DE PERÓXIDO DE URÉIA EM SANGUE TOTAL UTILIZANDO A SONDA TETRACICLINA-LANTANÍDEO. Boletim Técnico da Faculdade de Tecnologia de São Paulo, v. BT/20, p. 16-20, 2006.

8. SILVA, Flávia R.O.; COURROL, L. C.; MANSANO, Ronaldo; TARELHO, Luis Vicente Gomes; GOMES, Laércio; VIEIRA JUNIOR, Nilson Dias. ESTUDO ESPECTROSCÓPICO DE COMPLEXOS TETRACICLINA-LANTANÍDEOS PARA APLICAÇOES BIOLÓGICAS. Boletim Técnico da Faculdade de Tecnologia de São Paulo, v. BT/20, p. 21-26, 2006.

9. SILVA, Flávia R.O.; COURROL, L. C.; MANSANO, Ronaldo. Estudos de Complexos Tetraciclina-Lantanídeos na presença de peróxido de uréia e suas aplicações. Boletim Técnico da Faculdade de Tecnologia de São Paulo, v. BT/19, p. 37, 2006.

\section{CAPÍTULOS DE LIVROS PUBLICADOS}

1. COURROL, L. C.; SILVA, Flávia R.O.; BELLINI, Maria Helena; MANSANO, Ronaldo; SCHOR, N.; VIEIRA JUNIOR, Nilson Dias. Blood porphyrin luminescence and tumor growth correlation. David Kessel, Editor, 64270Y. (Org.). Proceedings of SPIE - Optical Methods for Tumor Treatment and Detection: Mechanisms and Techniques in Photodynamic Therapy XVI: 2007, v. 6427.

2. COURROL, L. C.; SILVA, Flávia R.O.; Samad, Ricardo Elgul; MANSANO, Ronaldo; VIEIRA JUNIOR, Nilson Dias. Europium tetracycline biossensor for the determination of cholesterol. SPIE. (Org.). Proceedings of SPIE: 2007, v. 6430, p. 17-24. 
3. COURROL, L. C.; SILVA, Flávia R.O.; TARELHO, Luis Vicente Gomes; BELLINI, Maria Helena; MANSANO, Ronaldo; GOMES, Laércio; VIEIRA JUNIOR, Nilson Dias. Enhancement of europium luminescence in tetracyclineeuropium complex in the presence of urea hydrogen peroxide. In: Samuel I. Achilefu, Darryl J. Bornhop, Ramesh Raghavachari; Eds. (Org.). Proceedings of SPIE of Optical Molecular Probes for Biomedical Applications. Los Angeles: 2006, v. 6097, p. 104-112.

\section{TRABALHOS COMPLETOS PUBLICADOS EM ANAIS DE CONGRESSOS}

1. COURROL, L. C.; SILVA, Flávia R.O.; BELLINI, Maria Helena; MANSANO, Ronaldo; SCHOR, N.; VIEIRA JUNIOR, Nilson Dias. Blood Porphyrin Luminescence and Tumor Growth Correlation. In: Rede de Pesquisa da Unifesp, 2007, São Paulo. Livro de resumos do evento, 2007.

2. COURROL, L. C.; SILVA, Flávia R.O.; Samad, Ricardo Elgul; GOMES, Laércio; MANSANO, Ronaldo; VIEIRA JUNIOR, Nilson Dias. Europium Tetracycline Biossensor for the Cholesterol Determination. In: Rede de pesquisas da Unifesp, 2007, São Paulo. Livro de resumos do evento, 2007.

3. COURROL, L. C.; SILVA, Flávia R.O.; MANSANO, Ronaldo; Samad, Ricardo Elgul; VIEIRA JUNIOR, Nilson Dias. Europium tetracycline biossensor for the determination of cholesterol. In: Photonics West, 2007, San Jose. Proceedings of SPIE, 2007.

4. COURROL, L. C.; SILVA, Flávia R.O.; COUTINHO, E. L.; BELLINI, Maria Helena; SCHOR, N.; VIEIRA JUNIOR, Nilson Dias. Study of the correlation between blood porphyrin luminescence and tumor growth. In: Photonics West, 2007. Proceedings da Photonics West 2007, 2007.

5. COURROL, L. C.; SILVA, Flávia R.O.; TARELHO, Luis Vicente Gomes; GOMES, Laércio; BELLINI, Maria Helena; MANSANO, Ronaldo; VIEIRA JUNIOR, Nilson Dias. Enhancement of europium luminescence in tetracycline- 
europium complexes in the presence of urea hydrogen peroxide. In: Photonics West 2006, 2006, São Jose. Proceedings Near Infrared and other Reporters and Sensors, 2006.

\section{RESUMOS EXPANDIDOS PUBLICADOS EM ANAIS DE CONGRESSOS}

1. SILVA, Flávia R.O.; GOMES, Laércio; MANSANO, Ronaldo; VIEIRA JUNIOR, Nilson Dias; COURROL, L. C. Characterization of EuTc complex in the presence of Hydrogen Peroxide and Urea Hydrogen Peroxide. In: XXX ENFMC, 2007, São Lourenço. Optics Technical Digest, 2007.

\section{RESUMOS PUBLICADOS EM ANAIS DE CONGRESSOS}

1. COURROL, L. C.; A. M. MONTEIRO; GIDLUND, M. A.; SILVA, Flávia R.O.; FIGUEIREDO NETO, A. M.; MANSANO, Ronaldo; GOMES, Laércio; VIEIRA JUNIOR, Nilson Dias. Enhancement of Europium Emission Band of Europium Tetracycline Complex in the presence of Low Density Lipoprotein. In: XXX ENFMC, 2007, São Lourenço. Programa e Resumos XXX ENFMC, 2007.

2. SILVA, Flávia R.O.; GOMES, Laércio; MANSANO, Ronaldo; VIEIRA JUNIOR, Nilson Dias; COURROL, L. C. Optical and structural changes of silver nanoparticles, prepared using autopolymerizable resin, after $514 \mathrm{~nm}$ nanosecond laser reduction. In: XXX ENFMC, 2007, São Lourenço. Programa e Resumos XXX ENFMC, 2007.

3. SILVA, Flávia R.O.; MANSANO, Ronaldo; BELLINI, Maria Helena; COUTINHO, E. L.; SCHOR, N.; COURROL, L. C. Tumor growth investigation using blood porphyrin auto-fluorescence. In: XXX ENFMC, 2007, São Lourenço. Programa e Resumos XXX ENFMC, 2007.

4. SILVA, Flávia R.O.; COUTINHO, E. L.; BELLINI, Maria Helena; MANSANO, Ronaldo; SCHOR, N.; VIEIRA JUNIOR, Nilson Dias; COURROL, L. C. 
Spectroscopy study of tissues and blood of healthy and tumor induced mice. In: XXX ENFMC, 2007, São Lourenço. Programa e Resumos XXX ENFMC, 2007.

5. PEIXOTO, Pedro Henrique; SILVA, Eduardo Fabrício; COURROL, L. C.; TATUMI, Sonia Hatsue; SILVA, Flávia R.O.; MANSANO, Ronaldo. Estudo da viabilidade de utilização do complexo Europio-tetraciclina com um biossensor de análises clínicas. In: XXIX ENFMC, 2006, São Lourenço. Livro de resumos do XXIX ENFMC, 2006.

6. SILVA, Eduardo Fabrício; PEIXOTO, Pedro Henrique; COURROL, L. C.; SILVA, Flávia R.O.; MANSANO, Ronaldo; TATUMI, Sonia Hatsue. Desenvolvimento de biossensores baseados na emissao do europio (III) em tetraciclina. In: XXIX ENFMC, 2006, São Lourenço. Livro de resumos do XXIX ENFMC, 2006.

7. COURROL, L. C.; SILVA, Flávia R.O.; GOMES, Laércio; TARELHO, Luis Vicente Gomes; VIEIRA JUNIOR, Nilson Dias. Study of tetracycline-europium complex and its applications in bioanalysis. In: XXIX ENFMC, 2006, São Lourenço. Livro de resumos do XXIX ENFMC, 2006.

8. SILVA, Flávia R.O.; COURROL, L. C.; TARELHO, Luis Vicente Gomes; MANSANO, Ronaldo; BELLINI, Maria Helena; SCHOR, N.; GOMES, Laércio; VIEIRA JUNIOR, Nilson Dias. Enhancement of europium luminescence in tetracycline-europium complex in the presence of urea hydrogen peroxide. In: XXIX ENFMC, 2006, São Lourençox. Livro de resumos do XXIX ENFMC, 2006.

9. COURROL, L. C.; SILVA, Flávia R.O.; GOMES, Laércio; MANSANO, Ronaldo; VIEIRA JUNIOR, Nilson Dias. A simple method to synthesize silver nanoparticles by photo-reduction. In: SBPMat, 2006, Florianópolis. Anais do congresso SBPMat 2006, p. 126, 2006.

10. SILVA, Flávia R.O.; COURROL, L. C.; GOMES, Laércio; MANSANO, Ronaldo; VIEIRA JUNIOR, Nilson Dias. STUDY OF MATERIALS FOR HYDROGEN 
PEROXIDE AND UREA HYDROGEN PEROXIDE BIOSSENSORS. In: SBPMat, 2006, Florianópolis. Anais do Congresso SBPMat 2006, p. 126, 2006.

PRODUTO TECNOLÓGICO

COURROL, L. C.; SILVA, Flávia R.O.; GOMES, Laércio; VIEIRA JUNIOR, Nilson Dias. Biossensor de Peróxido de Uréia Baseado no complexo Família da Tetraciclinas-Európio, 2006.

\section{PARTICIPAÇÃO EM EVENTOS}

Winter College on Micro and Nano Photonics for Life Science - Trieste/ltália - 2008 Second Nanobiotechnology School - Itajaí / SC- 2007

VI Riao/ IX Opilas - 2007

XLI SUPFAB - 2006

SBPMat - 2006

XXX ENFMC - 2007

XXIX ENFMC - 2006 


\section{REFERÊNCIAS}

\footnotetext{
${ }^{1}$ WEISSMAN, S. I. Intramolecular energy transfer: The Fluorescence of Complexes of Europium. J. of Chem. Physics, v. 10, p. 214-217, 1942.
}

${ }^{2}$ LIS, S. et al. Energy transfer in solutions of lanthanide complexes. J. of Photochemistry and Photobiology A: Chemistry, v. 150, p. 233- 247, 2002.

${ }^{3}$ LEHN, J. M. Perspectives in supramolecular chemistry from molecular recognition towards molecular information processing and selforgsanization. Angew. Chem. Int. Edit., v. 29, n. 11, p. $1304-1319,1990$.

${ }^{4}$ MATHEW, M.; BALARAM, P. A reinvestigation of chlorotetracycline fluorescence - effects of pH, metal-ions, and environment. J. Inorg. Biochem., v. 13 , n. 4 , p. 339-346, 1980.

${ }^{5}$ SELVIN, P. R. Principles and biophysical applications of lanthanides-based probes. Annual Review of Biophysics and Biomolecular Structure, v. 31, p. 275302, 2002.

${ }^{6}$ SELVIN, P. R. The renaissance of fluorescence resonance energy transfer. Nature Structural Biology, v. 7, n. 9, p.730-734, 2000.

${ }^{7}$ CHEN, J.; SELVIN, P. R. Lifetime and color-tailored fluorophores in the micro- to milli-second time regime. J. Amer. Chem. Soc., v. 122, n. 4, p. 657660, 2000.

${ }^{8}$ RAKICIOGLU, Y.; PERRIN, J. H.; SCHULMAN, S. G. Increased luminescence of the tetracycline-europium(III) system following oxidation by hydrogen peroxide. Journal of Pharmaceutical and Biomedical Analysis, v. 20, p. 397-399, 1999.

${ }^{9}$ ARNAUD N.; GEORGES J. Sensitive detection of tetracyclines using europium-sensitized fluorescence with EDTA as co-ligand and cetyltrimethylammonium chloride as surfactant. Analyst, v. 126, n. 5, p. 694697, 2001.

${ }^{10}$ SCHAFERLING, M.; WU, M.; WOLFBEIS, O. S. Time-resolved fluorescent imaging of glucose. Journal of Fluorescence, v. 14, n. 5, p. 561-568, 2004. 
${ }^{11}$ SILVA, F. R. O.; COURROL, L. C.; TARELHO, L. V. G.; GOMES. L.; VIEIRA JR, N. D. Enhancement of Europium Luminescence in Tetracycline-Europium Complexes in the Presence of Urea Hydrogen Peroxide. J. of Fluorescence, v. 15, n. 5, p. 667-671, 2005.

${ }^{12}$ SILVA, F. R.O. ; SAMAD, R. E.; GOMES, L.; COURROL, L. C. Enhancement of Europium Emission Band of Europium Tetracycline Complex in the Presence of Cholesterol. Journal of Fluorescence, v. 18, n. 1, p. 169-174, 2008.

${ }^{13}$ COURROL, L. C.; MONTEIRO, A. M.; SILVA, F. R.O.; GOMES, L.; VIEIRA JR, N. D.; GIDLUND, M. A. ; FIGUEIREDO NETO, A. M. Novel Fluorescent Probe for Low Density Lipoprotein. Optics Express, v. 15, p. 7066-7074, 2007.

${ }^{14}$ BRUNO, L. et al. Imobilização de Proteínas do Veneno do Escorpião Tytius Serrulatus em Blenda Condutora de Polianilina-Poli(Metacrilato de Hidroxietila). Polímeros: Ciência e Tecnologia, v. 14, n. 3, p. 156-161, 2004.

${ }^{15}$ MILAGRES, B. G. Desenvolvimento de biossensor para determinação de salicilato e glicose. 1996. 155 p. Tese (Doutorado em Química) - Instituto de Química, Universidade Estadual de Campinas, Campinas, 1996.

${ }^{16}$ RICCARDI, C. S.; COSTA, P. I. YAMANAKA, H. Imunossensor amperométrico. Química Nova, v. 25, n. 2, p. 316-320, 2002.

17 WONG, S-M. S. Piezoelectric biosensor for the detection of Vibrio Parahaemolyticus. 1997. 213 f. Tese (Doutorado em Ciências Biológicas) University of Rhode Island. 1997.

${ }^{18}$ LOWINSOHN D.; BERTOTTI, M. Sensores eletroquímicos: considerações sobre mecanismos de funcionamento e aplicações no monitoramento de espécies químicas em ambientes microscópicos. Química Nova, v. 29, n. 6, p. 1318-1325, 2006.

${ }^{19} \mathrm{KUTSCHENKO}$, F. et al. Análise potenciométrica - Um levantamento histórico, princípios e aplicações. Iniciação Científica CESUMAR, v. 7, n. 01, p. 48-56, 2005.

${ }^{20}$ PINHEIRO, S. C. L.; RAIMUNDO Jr., I. M. Uso de menbranas de Nafion para a construção de sensores ópticos para medidas de pH. Química Nova, v. 28, n. 5, p. 932-936, 2005. 
${ }^{21}$ DAMOS, F. S.; MENDES, R. K.; KUBOTA, L. T. Aplicação de QCM, EIS e SPR na investigação de superfícies e interfaces para o desenvolvimento de (bio) sensores. Química Nova, v.27, n. 6, p. 970-979, 2004.

${ }^{22}$ FERNANDES, J. C. B.; KUBOTA, L. T.; Neto, G. O. Eletrodos íons-seletivos: histórico, mecanismo de resposta, seletividade e revisão de conceitos. Química Nova, v. 24, n. 1, p. 120-130, 2001.

${ }^{23}$ CLARK, L. C. ; LYONS, C. Eletrode systems for continuous monitoring in cardiovascular surgery. Annals of the New York Academy of Science, v. 102, p. 29-45, 1962.

${ }^{24}$ FARRAGUT High School. Biosensor. Disponível em < http://www.farraguttn.com/fhs/math/istf/sensors.htm>. Acesso em: 21 Jan. 2008.

${ }^{25}$ SÁ, G. F. et al. Spectroscopic properties and design of highly luminescent lanthanide coordination complexes. Coord. Chem.Rev., v. 196, p. 165-195, 2000.

${ }^{26}$ SABBATINI, N. et al. Lanthanide complexes of encapsulating ligands luminescent devices at the molecular-level. Purê \& Appl. Chen., v. 67, n. 1, p. 135-140, 1995.

${ }^{27}$ SIGOLI, F. A.; DAVOLOS, M. R.; JUNIOR, M. J. Compostos luminescentes em matrizes macroporosas de sílica obtidos por tratamento hidrotérmico a partir de vidro pyrex. 2001. $182 \mathrm{f}$. Tese (Doutorado em Química) - Instituto de Química, Universidade Estadual Paulista, Araraquara, 2001.

${ }^{28}$ MAAS, H.; CURRAO, A.; FERRI, G. C. Encapsulated lanthanide as Luminescent Materials. Angew. Chem. Int. En., v. 41, n. 14, p. 2495-2497, 2002.

${ }^{29}$ SERRA, O. A. et al. Luminescence of a new $\mathrm{Tm}^{3+}$ beta-diketonate compound. J. Alloys Comp., v. 277, p. 838-840, 1998.

${ }^{30}$ SASTRI, V. S.; BÜNZLI, J. -C.; RAMACHANDRA RAO, V.; RAYUDU, G. V. S.; PERUMAREDDI, J. R. Modern Aspects of Rare Earths and their Complexes. USA: Elsevier. 2003. 1006 p. 
${ }^{31}$ TURRO, C.; FU, P. K.-L.; BRADLEY, P. M. Lanthanide íons as luminescent probes of proteins and nucleic acid. Departamento de Química. Universidade do Estado de Ohio. USA.

${ }^{32}$ HORROCKS W.; SUDNICK JR., D. R. Artificial Photosynthesis: Water cleavage into Hydrogen and Oxygen by visible light. Acc. Chem. Res., v. 14, p. 376-384, 1981.

${ }^{33}$ HOLZ, R. C.; CHAND, C. A.; HORROCKS, W. Spectroscopic Characterization of the Europium(III) Complexes of a Series of N,N'-Bis(carboxymethy1) Macrocyclic Ether Bis(1actones). J. Inorg. Chem., v. 30, p. 3270-3275, 1991.

${ }^{34}$ FRANVILLE, A.C.; ZAMBON, D.; MAHIOU, R. Influence of OH groups on the spectral characteristics of $\mathrm{Eu}^{3+}$ ions in hybrid organic-inorganic materials sinthesized by sol-gel. Laboratoire des Matériaux Inorganiques - UPRES A6002, Université Blaise Pascal - Aubière.

${ }^{35}$ SELVIN, P. R. In Applied Fluorescence in Chemistry. Biology and Medicine, edited by W. Rettig, B. Strehmenl, S. Schrader, Springer Verlag, p. 457-487, 1999.

${ }^{36}$ HUBER, W.G. In: N.H. Booth, L.E. McDonald (Eds), Veterinary Pharmacology and Therapeutics, lowa State University Press, 1988.

${ }^{37}$ MITSCHER, L. A. The Chemistry of the Tetracycline Antibiotics, New York: Marcel Dekker, 1978.

${ }^{38}$ ALBERT, A. Avidity of terramycin and aureomycin for metallic cations. Nature, v. 172, n. 4370, p. 201-201, 1953.

${ }^{39}$ COIBION, C.; LASZLO, P. Binding of the alkali-metal cations to tetracycline. Biochem. Pharmac., v. 28, n. 8, p. 1367-1372, 1979.

${ }^{40}$ CELOTTI, M.; FAZAKERLEY, G. V. Conformation of various tetracycline species determined with aid of a nuclear magnetic-resonance relaxation probe. J. Chem. Soc. Perkin Trans., v. 2, n. 10, p. 1319-1322, 1977.

${ }^{41} \mathrm{HIRSCHY}$, L. M. et al. Characteristics of the binding of Europium(III) to Tetracycline. Analytica Chimica Acta, v. 166, p. 207-219, 1984. 
${ }^{42}$ CHOPRA, I.; ROBERTS, M. Tetracycline Antibiotics: Mode of Action, Applications, Molecular Biology, and Epidemiology of Bacterial Resistence. Microbio. And Mol. Bio. Rev., v. 65, n. 2, p. 232-260, 2001.

${ }^{43}$ CHOPRA, I.; HAWKEY, P. M.; HINTON, M. Tetracycline, molecular and clinical aspects. J. Antimicrob. Chemother., v. 29, n. 3, p. 245-277, 1992.

${ }^{44}$ RICHARDSON, F.S. Terbium(III) and Europium(III) ions as luminescent probes and stains for biomolecular systems. Chemical Reviews, v. 82, n. 5, p. 541-552, 1982.

${ }^{45}$ HIRSCHY, L. M.; DOSE E. V; WINEFORDNER J.D. Lanthanide-sensitized luminescence for the detection of tetracyclines. Anal. Chim. Acta, v. 147, p. 311-316, 1993.

${ }^{46}$ ATVARS, T.D.Z.; MARTINELLI, C. Espectroscopia de Luminescência. Disponível em <http://www.chemkeys.com/bra/md/ede_5/edl_14/edl_14.htm> Acesso em: 10 Jan. 2007.

${ }^{47}$ GLOGAUER, A.; AKCELRUD, L. Síntese e caracterização fotofísica de dois copolímeros eletroluminescentes: um completamente conjugado e outro multibloco tendo como unidade cromofórica o fluoreno-vinileno-fenileno. 2004. 133 p. Dissertação (Mestrado) - Setor de Ciências Exatas, Universidade Federal do Paraná, Curitiba, 2004.

${ }^{48}$ SILVA, R.; MOREIRA, S. G. C. Estudo das propriedades ópticas de absorção e fotoluminescência do ácido oléico diluído com beta-caroteno. 2004. 59 f. Dissertação (Mestrado) - Centro de Ciências Exatas e Naturais, Universidade Federal do Pará, Belém. 2004.

${ }^{49}$ LIN, Z.; WOLFBEIS O. Time-resolved Fluorescence-Based Europium derived probes for peroxidase bioassays, citrate cycle imaging and chirality sensing, 2004. 140 p. Tese (Doutorado),- Faculdade de Química e Farmácia, Universidade de Regensburg, Alemanha, 2004..

${ }^{50}$ REISFELD, R. Structure and Bonding 22. Springer-Verlag, New York, 1975.

${ }^{51}$ GEORGES, J. Lanthanide-sensitized luminescence and applications to the determination of organic analytes. A review. Analyst., v. 118, n. 12, p. 14811486, 1993. 
52 YATSIMIRSKII, K. B.; DAVIDENKO, N. K. Absorption spectra and structure of lanthanide coordination compounds in solution. Coordination Chemistry Reviews, v. 27, n. 3, p. 223-273, 1979.

${ }^{53}$ WANG T.; JIANG C. Q. Spectrofluorimetric determination of lecithin using a tetracycline-europium probe. Analytica Chimica Acta, v. 561, n. 1-2, p. 204-209, 2006.

${ }^{54}$ ZHU X. J.; WANG X. L.; JIANG C. Q. Spectrofluorimetric determination of heparin using a tetracycline-europium probe. Analytical Biochemistry, v. 341, n. 2, p. 299-307, 2005.

${ }^{55}$ DÜRKOP A. et al. Microtiter plate assay for phosphate using a europiumtetracycline complex as a sensitive luminescent probe. Analytica Chimica Acta, v. 555, n. 2, p. 292-298, 2006.

${ }^{56}$ Jiang C. Q.; Luo L. Spectrofluorimetric determination of human serum albumin using a tetracycline-europium complex. Analytical Letters, v. 37, n. 6 , p. 1129-1137, 2004.

${ }^{57}$ LIN Z.H. et al. Fluorescent imaging of citrate and other intermediates in the citric acid cycle. ANGEWANDTE CHEMIE-INTERNATIONAL EDITION, v. 43, n. 13, p. 1735-1738, 2004.

${ }^{58}$ MATTOS, I. V. et al. Peróxido de Hidrogênio : importância e determinação. Química Nova, v. 26, n, 3, p. 373-380, 2003.

59 THOMPSON, A. M. The oxidizing capacity of the earths atmosphere probable past and future changes. Science, v. 256, p. 1157-1165, 1992.

${ }^{60}$ ANGLADA J. M., APLINCOURT P. H., BOFILL J. M., CREMER D. Atmospheric formation of $\mathrm{OH}$ radicals and $\mathrm{H}_{2} \mathrm{O}_{2}$ from alkene ozonolysis under humid conditions. Chem. Phys. Chem., v. 3, n. 2, p. 215-221, 2002.

${ }^{61}$ CHEN, J.; RULKENS, W. H.; BRUNING, H. Photochemical elimination of phenols and cod in industrial wastewaters. Water Sci. Technol., v. 35, n. 4, p. 231-238, 1997. 
62 LIU, Y. et al. Regenerated silk fibroin membrane as immobilization matrix for peroxidase and fabrication of a sensor for hydrogen peroxide utilizing methylene blue as electron shuttle. Anal. Chim. Acta, v. 316, p. 65-72, 1995.

${ }^{63}$ YOKOYAMA, H. et al. In Vivo Analysis of Hydrogen Peroxide and Lipid Radicals in the Striatum of Rats Under Long-Term Administration of a Neuroleptic. Free Radical Biol. Med., v. 24, n. 6, p. 1056-1060, 1998.

${ }^{64}$ OHURA, $\mathrm{H}$. et al. Potentiometric flow-injection determination of trace hydrogen peroxide based on its induced reaction in iron(III)-iron(II) potential buffer containing bromide and molybdenum(VI). Talanta, n. 43, p. 943-950, 1996.

${ }^{65}$ SERGEYEVA, T. A.; LAVRIK, N. V.; RACHKOV, A. E.; Hydrogen peroxide sensitive enzyme sensor based on phthalocyanine thin film. Anal. Chim. Acta, v. 391, n. 3, p. 289-297, 1999.

${ }^{66}$ DÍAZ, A. N.; PEINADO, M. C. R.; MINGUEZ, M. C. T. Sol-gel horseradish peroxidase biosensor for hydrogen peroxide detection by chemiluminescence. Anal. Chim. Acta, v. 363, p. 221-227, 1998.

${ }^{67} \mathrm{CHEN}, \mathrm{Q}$. et al. Application of iron-tetrasulfonatophthalocyanine as a new mimetic peroxidase in the determination of hydrogen peroxide with $\mathbf{p}$ hydroxyphenylpropionic acid as a substrate. Anal. Chim. Acta, v. 381, p. 175182, 1999.

${ }^{68} \mathrm{ZHOU}, \mathrm{X}$; ARNOLD, M. A. Internal enzyme fiber-optic biosensors for hydrogen peroxide and glucose. Anal. Chim. Acta, v. 304, p. 147, 1995.

${ }^{69}$ OSZWALDOWSKI, S.; LIPKA, R.; JAROSZ, M. Sensitive reversed-phase liquid chromatographic determination of hydrogen peroxide and glucose based on ternary vanadium(V)-hydrogen peroxide-2-(5-bromo-2-pyridylazo)5-diethylaminophenol system. Anal. Chim. Acta, v. 421, p. $35-43,2000$.

${ }^{70}$ DÜRKOP, A.; WOLFBEIS O. S. Nonenzymatic Direct Assay of Hydrogen Peroxide at Neutral pH Using the $\mathrm{Eu}_{3} \mathrm{Tc}$ Fluorescent Probe. Journal of Fluorescence, v. 15, n. 5, p. 755-761, 2005.

${ }^{71}$ WU, M.; LIN, Z.; DÜRKOP, A.; WOLBEIS, O. S. Time-resolved enzymatic determination of glucose using a fluorescent europium probe for hydrogen peroxide. Anal. Bioanal. Chem., v. 380, p. 619-626, 2004. 
${ }^{72} \mathrm{WU}, \mathrm{M}$. et al. Fluorescence imaging of the activity of glucose oxidase using a hydrogen-peroxide-sensitive europium probe. Anal. Biochem., v. 340, p. 6673, 2004.

${ }^{73}$ FELDMAN, J. Saiba mais sobre a Diabetes. Disponível em <http://www.saudevidaonline.com.br/artigo47.htm>. Acesso em: 16 Out. 2007.

${ }^{74}$ MINISTÉRIO DA SAÚDE. Disponível em <www.saude.gov.br>. Acesso em: 17 Out. 2007.

${ }^{75}$ MIN, R. W. et al. Simultaneous monitoring of glucose and L-lactic acid during a fermentation process in an aqueous two-phase system by on-line FIA with microdialysis sampling and dual biossensor detection. Analytica Chimica Acta, v. 366, p. 127-135, 1998.

76 TKAC, J.; STURDIK, E.; GEMEINER, P. Novel glucose non-interference biossensor for lactose detection based on galactose oxidase-peroxidase with and without co-immobilised beta-galactosidase. Cutis, v. 85, n. 4 (Suppl), p. 16-111, 2005.

${ }^{77}$ HEMMILÄ, I. Luminescent lanthanide chelates - a way to more sensitive diagnostic method. J. of Alloys Comp., v. 225, p. 480, 1995.

${ }^{78}$ PATIL, S. D.; PAPADIMITRAKOPOULOS, F.; BURGESS, D. J. Dexamethasone-loaded poly(lactic-co-glycolic) acid microspheres/poly(vinyl alcohol) hydrogel composite coatings for inflammation control. Diabetes Technol Ther., v. 6, n. 6, p. 887-897, 2004.

${ }^{79}$ PRATA, M. I. M.; SANTOS, A. C.; GERALDES, C. F. G.; LIMA, J. J. P. Structural and in vivo studies of metal chelates of $\mathbf{G a ( I I I )}$ relevant to biomedical imaging. J. of Inorg. Biochemistry, v. 79, p. 359, 2000.

${ }^{80}$ WU, M.; LIN, Z.; WOLFBEIS, O. S. Determination of the activity of catalase using a europium(III)-tetracycline-derived fluorescent substrate. Anal Biochem., v. 320, n. 1, p. 129-135, 2003.

${ }^{81}$ MAESTRO, P. Materials: 'Today and Tomorrow', Paris: Rhône -Poulenc Ed., 1991. 
82 GORENEK, G.; AKYILMAZ, E.; DINCKAYA, E. Immobilization of catalase by entrapping in alginate beads and catalase biossensor preparation for the determination of hydrogen peroxide decomposition. Artif. Cells Blood Substit. Immobil. Biotechnol., v. 32, n. 3, p. 453-619, 2004.

${ }^{83}$ RAJENDRAN, V. et al. Amperometric peroxide sensor based on horseradish peroxidase and toluidine blue 0 -acrylamide polymer in carbon paste. Analytica Chimica Acta, v. 373, p. 241-251, 1998.

${ }^{84}$ VIJAYAKUMAR, A. R. et al. Alcohol biossensors based on coupled oxidaseperoxidase systems. Analytica Chimica Acta, v. 327, p. 223-234, 1996.

${ }^{85}$ ARNAUD, N.; GEORGES, J. Comprehensive study of the luminescent properties and lifetimes of $\mathrm{Eu}^{3+}$ and $\mathrm{Tb}^{3+}$ chelated with various ligands in aqueous solutions: influence of the synergic agent, the surfactant and the energy level of the ligand triplet. Spectrochimica Acta, Part A: Molecular and Biomolecular Spectroscopy, v. 59A, n. 8, p. 1829-1840, 2003.

${ }^{86}$ HARVEY, R.; FERRIER, D. R.; CHAMPE, P. C. Biochemistry. $3^{\text {rd }}$ ed. Baltimore: Lippincott, 2005, p. 235-238.

${ }^{87}$ LUDKE, M. C. M. M.; LÓPEZ, J. Colesterol e composição dos ácidos graxos nas dietas para humanos e na carcaça suína. Ciência Rural, Santa Maria, v. 29, n. 1, p.181-187, 1999.

${ }^{88}$ NATIONAL CHOLESTEROL EDUCATION PROGRAM. Second report of the expert panel on detection,evaluation, and treatment of high blood cholesterol in adults. NIH Pub. No. 93-3095. Bethesda, MD: National Heart, Lung, and Blood Institute, 1993.

${ }^{89}$ Colesterol. Disponível em

<http://www.corpohumano.hpg.ig.com.br/abr2003/colesterol.html>. Acesso em: 05 Set. 2007.

${ }^{90}$ Diagnósticos das Américas, índice de exames. Disponível em $<$ http://www.diagnosticosdaamerica.com.br/exames/lipoproteinas.shtml>. Acesso em: 27 Ago. 2007.

${ }^{91}$ CASTELLI, W. Lipoproteins and Cardiovascular Disease: Biological Basis and Epidemiological Studies. Value Health, v. 1, p. 105-109, 1998. 
92 DANESE, C. et al. Do hypertension and diabetes mellitus influence the site of Atherosclerotic plaques?. Clin. Ter., v. 157, p. 9-13, 2006.

${ }^{93}$ STEMME, S. et al. T lymphocytes from human atherosclerotic plaques recognize oxidized Low density lipoprotein. Proc. Nat. Acad. Sci. USA, v. 92, p. 3893-3897, 1995.

94 HARA, H. et al. Induction of acetylated low density lipoprotein receptors and suppression of low density liprotein receptors on the cells of human monocytic leukemia cell line (THP-I cell). Biochem. Biophys. Res. Commun., v. 146, p. 802-808, 1987.

${ }^{95}$ HASSALL, D. G. Three probe flow cytometry of a human foam-cell forming macrophage. Cytometry, v. 13, p. 381-388, 1992.

${ }^{96}$ Detection and Evaluation, American Heart Association (Circulation), v. 106, n. 25, p. 3227-3234, 2002. Disponível em <http://circ.ahajournals.org/cgi/content/full/106/25/3227?ck=nck>. Acesso em: 25 Jul. 2007.

97 JABBAR, J.; SIDDIQUI, I.; RAZA, Q. Comparison of two methods (precipitation manual and fully automated enzymatic) for the analysis of HDL and LDL cholesterol. J. Pak. Med. Assoc., v. 56, n. 2, p. 59-61, 2006.

${ }^{98}$ VEGA, G. L.; GRUNDY. S. M. Does measurement of apolipoprotein B have a place in cholesterol management. Arteriosclerosis, v. 10, p. $668-671,1990$.

99 TRETTNAK, W.; WOLFBEIS, O. S. Fiber optic cholesterol biossensor with an oxygen optrode as the transducer. Analytical Biochemistry, v. 184, n. 1, p. 124-127, 1990.

${ }^{100}$ BASU, A. K.; CHATTOPADHYAY, P.; ROYCHOUDHURI, U.; CHAKRABORTY, $R$. Development of cholesterol biossensor based on immobilized cholesterol esterase and cholesterol oxidase on oxygen electrode for the determination of total cholesterol in food samples. Bioelectrochemistry, v. 70, n. 2, p. 375-379, 2007. 
${ }^{101}$ HOŞAFÇI, G.; KLEIN, O.; OREMEK, G.; MÄNTELE, W. Clinical chemistry without reagents? An infrared spectroscopic technique for determination of clinically relevant constituents of body fluids. Anal. Bioanal. Chem., v. 387, n. 5, p. 1815-1822, 2007.

${ }^{102}$ HANKS, C. T. et al. Cytotoxicity and dentin permeability of carbamide peroxide and hydrogen-peroxide vital bleaching materials in vitro. J. Dent. Res., v. 72, n. 5, p. 931-938, 1993.

${ }^{103}$ LOWENTHAL, A. Urea Cycle Diseases (Advances in Experimental Medicine and Biology), Plenum Pub. Corp., v. 153, 1982.

${ }^{104} \mathrm{MOH}$, A. et al. Increased production of urea hydrogen peroxide from Maillard reaction and a UHP-Fenton pathway related to glycoxidation damage in chronic renal failure. J. Am. Soc. Nephrol., v. 15, n. 4, p. 1077-1085, 2004.

${ }^{105}$ MONNIER, V. M. et al. Maillard reaction-mediated molecular damage to extracellular matrix and other tissue proteins in diabetes aging, and uremia. Diabetes, v. 41, n. 2 (Suppl), p. 36-41, 1992.

${ }^{106}$ WINKELMANN, K.H. On the applicability of imaging spectrometry for the detection and investigation of contaminated sites with particular consideration given to the detection of fuel hydrocarbon contaminants in soil. 2005. 243 p. Tese (Doutorado) - Berlim, 2005.

${ }^{107}$ BUONO-CORE, G. E.; LI, H.; MARCINIAK, B. Quenching of excited-states by lanthanide ions and chelates in solution. Coord. Chem. Rev., v. 99, p. 55-87, 1990.

${ }^{108}$ DÜRKOP, A.; WOLFBEIS, O. S. Luminescent Metal-Ligand Complexes as Labels for Polarization Immunoassays and for Determination of Hydrogen Peroxide, 2001. 113 p. Tese (Doutorado),- Faculdade de Química e Farmácia, Universidade de Regensburg, Alemanha, 2001.

${ }^{109}$ MICHALSKA, T. et al. The extra-weak chemiluminescence generated during oxidation of some tetracycline antibiotics. 2. Peroxidation. J. Photochem. Photobiol. B: Biol., v. 16, n. 3-4, p. 305-318, 1992. 